FUNDCHRONIK

AUSGRABUNGEN UND

FUNDE IM JAHR 2019

Martin Allemann

Sven Billo

Ingmar M. Braun

Simon Graber

Johann Savary

Roman Schmidig

Norbert Spichtig

Susan Steiner 
Frankreich
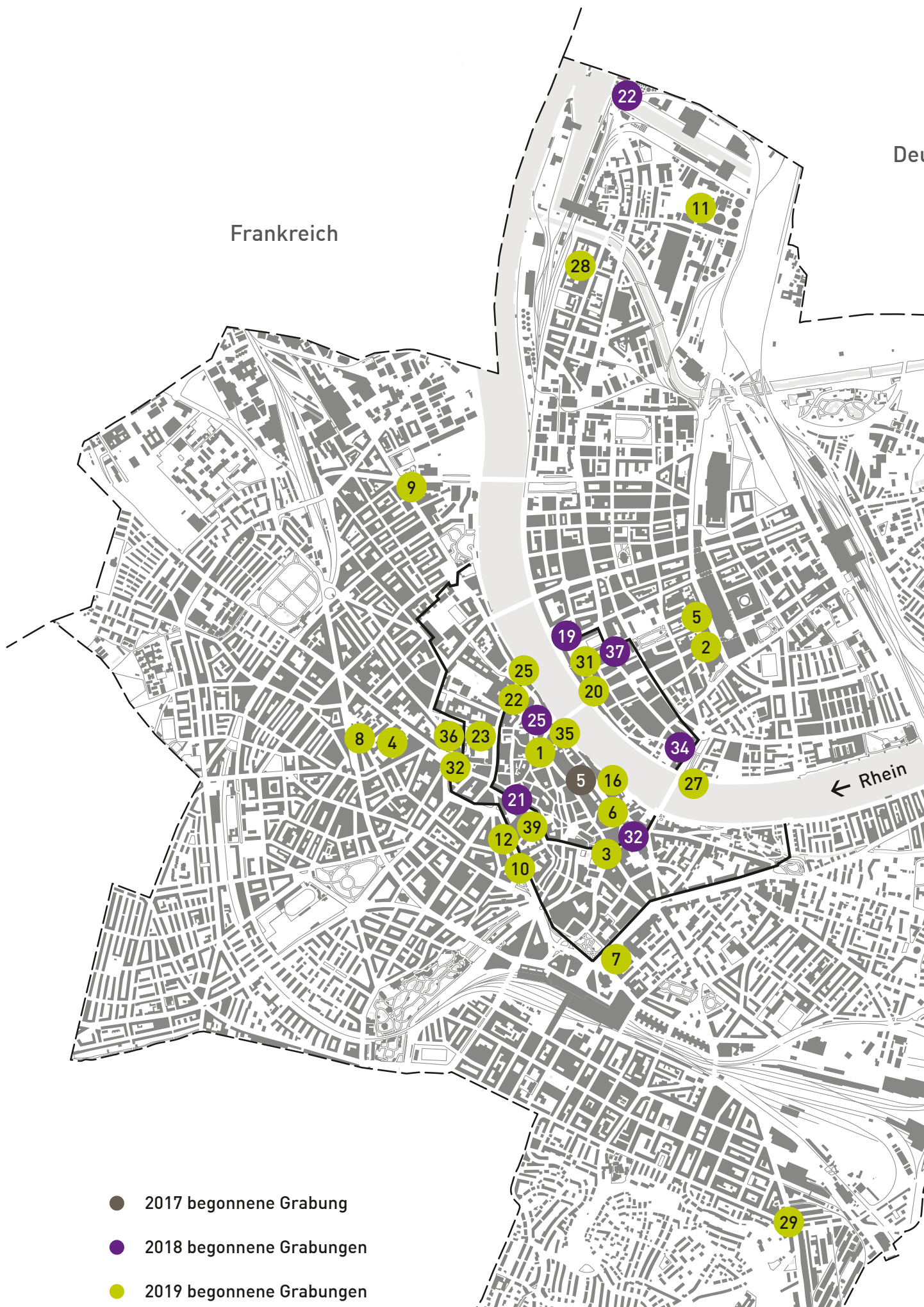

$39=-1$
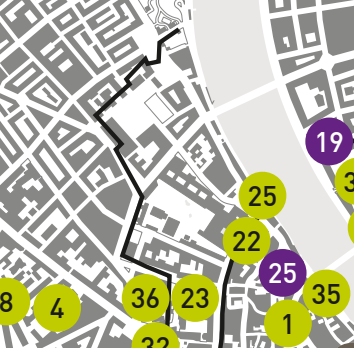

.

N

27

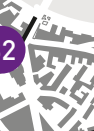

1) $\div$

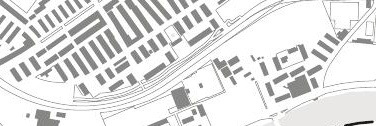

24

1

2 


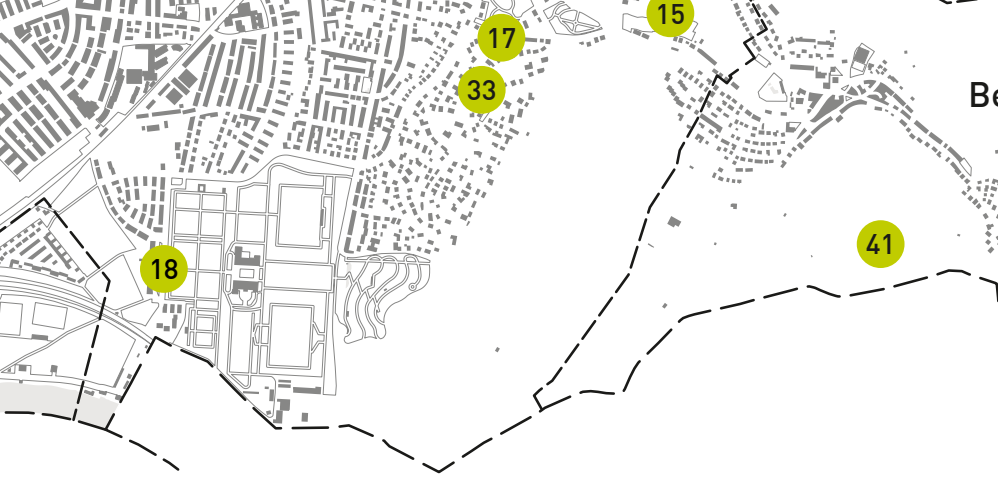

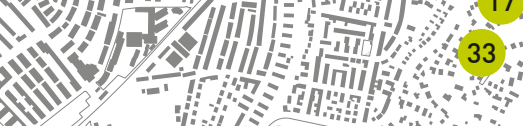

$37, ;=\cdots$

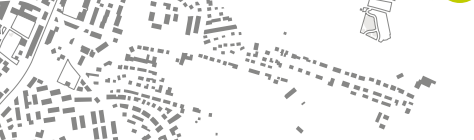

1

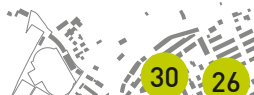

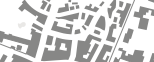

4

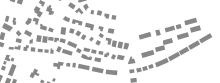

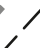

1

Riehen<smiles>CCI</smiles>

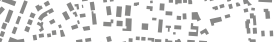

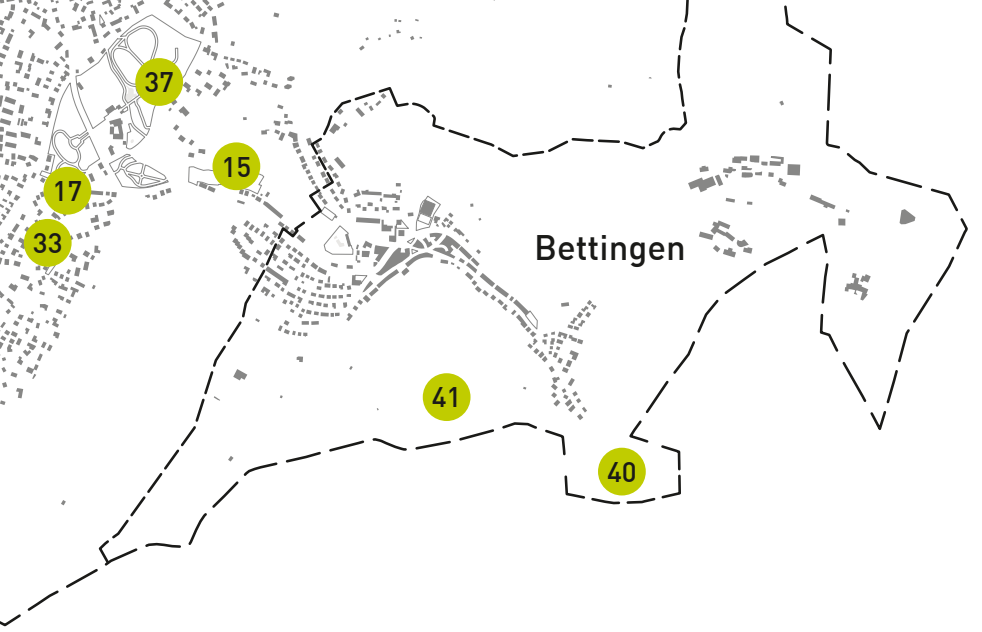

\section{AUSGRABUNGEN UND FUNDE \\ IM JAHR 2019}

Übersichtsplan des Kantons Basel-Stadt mit den Einsatzstellen der ABBS im Jahr 2019.

Zu den einzelnen Einsatzstellen vgl. die Tabellen auf den folgenden Doppelseiten «Übersicht nach Laufnummern» und «Übersicht nach Bereichen».

Plangrundlage: Grundbuch- und Vermessungsamt des Kantons Basel-Stadt. Ergänzungen und Kartierung: Peter von Holzen.

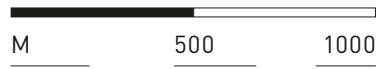




\section{ÜBERSICHT}

\section{NACH LAUFNUMMERN}

Im Berichtsjahr 2019 laufende Untersuchungen der Archäologischen Bodenforschung Basel-Stadt im Kantonsgebiet nach Laufnummern. Fundstellen ohne aussagekräftige Befunde oder Funde sowie noch nicht abgeschlossene

Projekte sind im Text nicht berücksichtigt. Dies gilt desgleichen für weitere an einem Fundplatz belegte Zeitstellungen, wenn diese eher marginaler Art sind. Zusammenstellung: Andreas Niederhäuser

\section{LEGENDE}

PAL Paläolithikum

NL Neolithikum

BZ Bronzezeit

HZ Hallstattzeit

LZ Latènezeit

RZ Römische Zeit

FMA Frühmittelalter

MA Mittelalter

NZ Neuzeit

ZU Zeit unbestimmt

ㅁ Befund ohne Funde

- Befund mit Funden

- Streu- und Einzelfunde/

Funde bei Prospektionsgängen

- Geologischer Befund

- Ohne Befund/Funde

> Untersuchung noch nicht abgeschlossen

\section{BEGONNENE UNTERSUCHUNGEN}

\begin{tabular}{|c|c|c|c|}
\hline Nr. & Lauf-Nr. & Adresse $(\mathrm{A}=$ Allmend $)$ & Ergebnis \\
\hline 5 & $2017 / 5$ & Schlüsselberg (A) & $\square \mathrm{RZ} / \boldsymbol{\square} \mathrm{MA} / \boldsymbol{\mathrm { N } Z}$ \\
\hline
\end{tabular}

\section{BEGONNENE UNTERSUCHUNGEN}

\begin{tabular}{|c|c|c|c|}
\hline Nr. & Lauf-Nr. & Adresse ( $A=$ Allmend $)$ & Ergebnis \\
\hline 19 & $2018 / 19$ & Unterer Rheinweg 28 & $\square \mathrm{MA} / \mathbf{n Z}$ \\
\hline 21 & $2018 / 21$ & Leonhardsgraben 46 & $>$ \\
\hline 22 & $2018 / 22$ & Hiltalingerstrasse 68,76 & NZ \\
\hline 25 & $2018 / 25$ & Spiegelgasse 11 & $\boldsymbol{\nabla} \mathrm{RZ} / \boldsymbol{m A} / \boldsymbol{m} \mathrm{NZ}$ \\
\hline 32 & $2018 / 32$ & St. Alban-Graben (A) 5 / Luftgässlein (A) & $\square \mathrm{RZ} / \boldsymbol{m A} / \boldsymbol{m} \mathrm{NZ}$ \\
\hline 34 & $2018 / 34$ & Theodorskirchplatz 7 & $\square M A / \square N Z$ \\
\hline 37 & $2018 / 37$ & Kasernenstrasse 23 (Kirchenchor) & $\square \mathrm{MA} / \boldsymbol{\nabla} \mathrm{NZ}$ \\
\hline
\end{tabular}

\section{BEGONNENE UNTERSUCHUNGEN}

\begin{tabular}{|c|c|c|c|}
\hline Nr. & Lauf-Nr. & Adresse $(\mathrm{A}=\mathrm{Allmend})$ & Ergebnis \\
\hline 1 & $2019 / 1$ & Marktplatz (A) 2-11 & $\boldsymbol{\square} \mathrm{MA} / \boldsymbol{\nabla} \mathrm{NZ}$ \\
\hline 2 & $2019 / 2$ & Clarastrasse 52,54 & $>$ \\
\hline 3 & $2019 / 3$ & Steinenberg $(A) /$ Elisabethenstrasse $(A)$ & $\square \mathrm{MA} / \mathbf{n Z}$ \\
\hline 4 & $2019 / 4$ & Missionsstrasse $21 \mathrm{~b}$ & - $\mathbf{m Z}$ \\
\hline 5 & $2019 / 5$ & Riehenring 63-75 (Claraturm) & $\square \mathrm{MA} / \mathbf{\mathrm { NZ }}$ \\
\hline 6 & $2019 / 6$ & Rittergasse 4 & 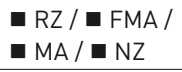 \\
\hline 7 & $2019 / 7$ & Parkweg (A), Nauenstrasse - Aeschengraben & $\square N Z$ \\
\hline 8 & $2019 / 8$ & Nonnenweg 56 & $\square N Z$ \\
\hline 9 & $2019 / 9$ & Voltastrasse 43, 41, 39 / Elsässerstrasse 54, 56 & $>$ \\
\hline 10 & $2019 / 10$ & Steinengraben 30-36 & - MA \\
\hline 11 & 2019/11 & Grenzstrasse 15 / Neuhausstrasse 85 & $>$ \\
\hline 12 & $2019 / 12$ & Steinengraben (A) IWB & 口MA \\
\hline 13 & $2019 / 13$ & Riehen - Inzlingerstrasse 270 & - / NZ \\
\hline 14 & $2019 / 14$ & $\begin{array}{l}\text { Riehen - Inzlingerstrasse 51, } 53 \text { / Haselrain / Ket- } \\
\text { tenackerweg } 5\end{array}$ & $>$ \\
\hline 15 & $2019 / 15$ & Riehen - Am Bettingerbach & $\diamond \mathrm{MA}$ \\
\hline 16 & $2019 / 16$ & Kleiner Münsterplatz (A) & $\boldsymbol{\nabla} \mathrm{RZ} / \mathbf{a} \mathrm{NZ}$ \\
\hline 17 & $2019 / 17$ & Rudolf-Wackernagel-Strasse 116 & $\bullet \mathrm{MA} / \mathrm{NZ}$ \\
\hline
\end{tabular}




\section{LEGENDE}

PAL Paläolithikum

NL Neolithikum

BZ Bronzezeit

$\mathrm{HZ}$ Hallstattzeit

LZ Latènezeit

RZ Römische Zeit

FMA Frühmittelalter

MA Mittelalter

NZ Neuzeit

ZU Zeit unbestimmt

ㅁ Befund ohne Funde

- Befund mit Funden

- Streu- und Einzelfunde / Funde bei Prospektionsgängen

- Geologischer Befund

- Ohne Befund/Funde

$>$ Untersuchung noch nicht abgeschlossen

\section{BEGONNENE UNTERSUCHUNGEN}

\begin{tabular}{|c|c|c|c|}
\hline Nr. & Lauf-Nr. & Adresse $(\mathrm{A}=\mathrm{Allmend})$ & Ergebnis \\
\hline 18 & 2019/18 & Riehen - Hörnliallee (A) & 0 \\
\hline 19 & $2019 / 19$ & Riehen - Äussere Baselstrasse 220 & $>$ \\
\hline 20 & $2019 / 20$ & Sägergässlein 2, 4 / Untere Rheingasse 12 & $\square \mathrm{MA} / \boldsymbol{\mathrm { N } Z}$ \\
\hline 21 & $2019 / 21$ & Riehen - Inzlingerstrasse 319 & $\bullet \mathrm{RZ} / \mathbf{\mathrm { NZ }}$ \\
\hline 22 & $2019 / 22$ & Petersgraben (A) 1 / Blumenrain $(A) 25$ & $\square N Z$ \\
\hline 23 & $2019 / 23$ & Petersplatz (A) 1 & $\mathbf{n} \mathrm{NZ}$ \\
\hline 24 & $2019 / 24$ & Eisenbahnweg 6, 22, 24 & $>$ \\
\hline 25 & $2019 / 25$ & Rhein (A), Höhe Blumenrain 34 (Seidenhof) & $\diamond \mathrm{NZ}$ \\
\hline 26 & $2019 / 26$ & Riehen - Burgstrasse 46 / Rebenstrasse 39 & $>$ \\
\hline 27 & $2019 / 27$ & Rhein (A), Nähe Wettsteinbrücke & $\bullet N Z$ \\
\hline 28 & $2019 / 28$ & Giessliweg (A) 64 & $\square N Z$ \\
\hline 29 & $2019 / 29$ & Gundeldingerstrasse / Reinacherstrasse (A) & $>$ \\
\hline 30 & $2019 / 30$ & Bettingen - Auf dem Buechholz & $\bullet$ \\
\hline 31 & $2019 / 31$ & Klingentalweglein $(\mathrm{A})$ & $\square \mathrm{MA} / \mathbf{N Z}$ \\
\hline 32 & $2019 / 32$ & Spalenvorstadt (A) 37 & $\square M A / \square N Z$ \\
\hline 33 & $2019 / 33$ & Riehen - Rütiring 84 & $>$ \\
\hline 34 & $2019 / 34$ & Riehen - Sonnenbühlstrasse 19 & $>$ \\
\hline 35 & $2019 / 35$ & Martinskirchplatz 1 & $>$ \\
\hline 36 & $2019 / 36$ & Spalengraben 8c (Botanischer Garten) & 口MA \\
\hline 37 & $2019 / 37$ & Riehen - Hellring 41 & $>$ \\
\hline 38 & $2019 / 38$ & Riehen - Oberdorfstrasse 43 & $>$ \\
\hline 39 & $2019 / 39$ & Leonhardsstrasse 6 & $\square N Z$ \\
\hline 40 & $2019 / 40$ & Bettingen - Im Junkholz & $\bullet \mathrm{PAL} / \mathrm{NL}$ \\
\hline 41 & $2019 / 41$ & Bettingen - Auf dem Buechholz & $\bullet \mathrm{PAL} / \mathrm{NL}$ \\
\hline
\end{tabular}




\section{ÜBERSICHT}

\section{NACH BEREICHEN}

Im Berichtsjahr 2019 laufende Untersuchungen der Archäologischen Bodenforschung Basel-Stadt im Kantonsgebiet nach Bereichen. Fundstellen ohne aussagekräftige Befunde oder Funde sowie noch nicht abgeschlossene Projekte sind im Text nicht berücksichtigt. Dies gilt desgleichen für weitere an einem Fundplatz belegte Zeitstellungen, wenn diese eher marginaler Art sind. Zusammenstellung: Andreas Niederhäuser

\section{LEGENDE}

PAL Paläolithikum

NL Neolithikum

BZ Bronzezeit

HZ Hallstattzeit

LZ Latènezeit

RZ Römische Zeit

FMA Frühmittelalter

MA Mittelalter

NZ Neuzeit

ZU Zeit unbestimmt

ㅁ Befund ohne Funde

- Befund mit Funden

- Streu- und Einzelfunde/

Funde bei Prospektionsgängen

- Geologischer Befund

- Ohne Befund/Funde

> Untersuchung noch nicht abgeschlossen
MÜNSTERHÜGEL

\begin{tabular}{|c|c|c|c|c|}
\hline Adresse ( $\mathrm{A}=\mathrm{Allmend})$ & Nr. & Lauf-Nr. & Ergebnis & Seitenzahl \\
\hline Schlüsselberg (A) & 5 & $2017 / 5$ & $\begin{array}{l}\square \mathrm{RZ} / \boldsymbol{\mathrm { mA }} / \\
\mathbf{\mathrm { NZ }}\end{array}$ & 44 \\
\hline Rittergasse 4 & 6 & $2019 / 6$ & 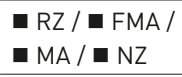 & 45 \\
\hline Kleiner Münsterplatz (A) & 16 & $2019 / 16$ & $\boldsymbol{\nabla} \mathrm{RZ} / \boldsymbol{\square} \mathrm{NZ}$ & 47 \\
\hline Martinskirchplatz 1 & 35 & $2019 / 35$ & $>$ & - \\
\hline
\end{tabular}

INNERSTADT

\begin{tabular}{|c|c|c|c|c|}
\hline Adresse ( $\mathrm{A}=\mathrm{Allmend})$ & Nr. & Lauf-Nr. & Ergebnis & Seitenzahl \\
\hline Unterer Rheinweg 28 & 19 & $2018 / 19$ & $\square \mathrm{MA} / \mathbf{\square Z}$ & 47 \\
\hline Leonhardsgraben 46 & 21 & $2018 / 21$ & $>$ & - \\
\hline Spiegelgasse 11 & 25 & $2018 / 25$ & 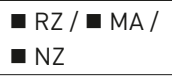 & 49 \\
\hline St. Alban-Graben (A) 5 / Luftgässlein (A) & 32 & $2018 / 32$ & $\begin{array}{l}\text { - } \mathrm{RZ} / \mathbf{m A} / \\
\square \mathrm{NZ}\end{array}$ & 49 \\
\hline Theodorskirchplatz 7 & 34 & $2018 / 34$ & $\square M A / \square N Z$ & 52 \\
\hline Kasernenstrasse 23 (Kirchenchor) & 37 & $2018 / 37$ & $\square \mathrm{MA} / \mathbf{n Z}$ & 52 \\
\hline Marktplatz (A) 2-11 & 1 & $2019 / 1$ & $\square \mathrm{MA} / \boldsymbol{\mathrm { NZ }}$ & 54 \\
\hline Steinenberg $(A) /$ Elisabethenstrasse $(A)$ & 3 & $2019 / 3$ & $\mathrm{MA} / \mathbf{N Z}$ & 55 \\
\hline Steinengraben 30-36 & 10 & $2019 / 10$ & mA & 55 \\
\hline Steinengraben (A) IWB & 12 & $2019 / 12$ & 口MA & 57 \\
\hline Sägergässlein 2, 4 / Untere Rheingasse 12 & 20 & $2019 / 20$ & - MA / $\mathrm{NZ}$ & 58 \\
\hline Petersgraben (A) 1 / Blumenrain (A) 25 & 22 & $2019 / 22$ & $\square \mathrm{NZ}$ & 59 \\
\hline Petersplatz (A) 1 & 23 & $2019 / 23$ & - NZ & 59 \\
\hline Rhein (A), Höhe Blumenrain (Seidenhof) & 25 & $2019 / 25$ & $\bullet N Z$ & 60 \\
\hline Klingentalweglein $(\mathrm{A})$ & 31 & $2019 / 31$ & $\mathbf{m A} / \mathbf{n Z}$ & 61 \\
\hline Spalenvorstadt (A) 37 & 32 & $2019 / 32$ & $\square \mathrm{MA} / \square \mathrm{NZ}$ & 61 \\
\hline Spalengraben 8c (Botanischer Garten) & 36 & $2019 / 36$ & 口MA & 62 \\
\hline Leonhardsstrasse 6 & 39 & $2019 / 39$ & 口NZ & 62 \\
\hline
\end{tabular}




\section{LEGENDE}

PAL Paläolithikum

NL Neolithikum

BZ Bronzezeit

$\mathrm{HZ}$ Hallstattzeit

LZ Latènezeit

RZ Römische Zeit

FMA Frühmittelalter

MA Mittelalter

NZ Neuzeit

ZU Zeit unbestimmt

ㅁ Befund ohne Funde

- Befund mit Funden

- Streu- und Einzelfunde/ Funde bei Prospektionsgängen

- Geologischer Befund

- Ohne Befund/Funde

> Untersuchung noch nicht abgeschlossen

\section{AUSSENBEZIRKE/BETTINGEN/RIEHEN}

\begin{tabular}{|c|c|c|c|c|}
\hline Adresse $(A=$ Allmend $)$ & $\mathrm{Nr}$. & Lauf-Nr. & Ergebnis & Seitenzahl \\
\hline Hiltalingerstrasse 68,76 & 22 & $2018 / 22$ & - NZ & 63 \\
\hline Clarastrasse 52,54 & 2 & $2019 / 2$ & $>$ & - \\
\hline Missionsstrasse 21b & 4 & $2019 / 4$ & / $\mathbf{n} \mathrm{NZ}$ & 66 \\
\hline Riehenring 63-75 (Claraturm) & 5 & $2019 / 5$ & $\square M A / \square N Z$ & 67 \\
\hline Parkweg (A) / Nauenstrasse - Aeschengraben & 7 & $2019 / 7$ & $\square N Z$ & 68 \\
\hline Nonnenweg 56 & 8 & $2019 / 8$ & $\square N Z$ & 68 \\
\hline Voltastrasse 43, 41, 39 / Elsässerstrasse 54, 56 & 9 & $2019 / 9$ & $>$ & - \\
\hline Grenzstrasse 15 / Neuhausstrasse 85 & 11 & $2019 / 11$ & $>$ & - \\
\hline Riehen - Inzlingerstrasse 270 & 13 & $2019 / 13$ & - / nZ & 69 \\
\hline $\begin{array}{l}\text { Riehen - Inzlingerstrasse 51, } 53 \text { / Haselrain / } \\
\text { Kettenackerweg } 5\end{array}$ & 14 & $2019 / 14$ & $>$ & - \\
\hline Riehen - Am Bettingerbach & 15 & $2019 / 15$ & $\bullet \mathrm{MA}$ & 70 \\
\hline Riehen - Rudolf-Wackernagel-Strasse 116 & 17 & $2019 / 17$ & $\bullet \mathrm{MA} / \mathrm{NZ}$ & 70 \\
\hline Riehen - Hörnliallee (A) & 18 & $2019 / 18$ & 0 & - \\
\hline Riehen - Äussere Baselstrasse 220 & 19 & $2019 / 19$ & $>$ & - \\
\hline Riehen - Inzlingerstrasse 319 & 21 & $2019 / 21$ & $\bullet \mathrm{RZ} / \boldsymbol{\nabla N Z}$ & 71 \\
\hline Eisenbahnweg 6, 22, 24 & 24 & $2019 / 24$ & $>$ & - \\
\hline Riehen - Burgstrasse 46 / Rebenstrasse 39 & 26 & $2019 / 26$ & $>$ & - \\
\hline Rhein (A), Nähe Wettsteinbrücke & 27 & $2019 / 27$ & $\bullet \mathrm{NZ}$ & 71 \\
\hline Giessliweg (A) 64 & 28 & $2019 / 28$ & $\square N Z$ & 72 \\
\hline Gundeldingerstrasse / Reinacherstrasse (A) & 29 & $2019 / 29$ & $>$ & - \\
\hline Bettingen - Auf dem Buechholz & 30 & $2019 / 30$ & $\bullet$ & 72 \\
\hline Riehen - Rütiring 84 & 33 & $2019 / 33$ & $>$ & - \\
\hline Riehen - Sonnenbühlstrasse 19 & 34 & $2019 / 34$ & $>$ & - \\
\hline Riehen - Hellring 41 & 37 & $2019 / 37$ & $>$ & - \\
\hline Riehen - Oberdorfstrasse 43 & 38 & $2019 / 38$ & $>$ & - \\
\hline Bettingen - Im Junkholz & 40 & $2019 / 40$ & $\diamond \mathrm{PAL} / \mathrm{NL}$ & 72 \\
\hline Bettingen - Auf dem Buechholz & 41 & $2019 / 41$ & $\diamond \mathrm{PAL} / \mathrm{NL}$ & 73 \\
\hline
\end{tabular}




\section{MÜNSTERHÜGEL}

\section{$2017 / 5$}

\section{SCHLÜSSELBERG (A)}

Anlass: Werkleitungsbau, Oberflächenerneuerung

Zeitstellung: Römische Zeit, Mittelalter, Neuzeit

Untersuchungsdauer: Februar 2017 bis April 2019

Verantwortlich: Martin Allemann, Johann Savary, Birgit Lißner

Text: Martin Allemann

Die ab 2017 teils intensiv, teils sporadisch archäologisch begleiteten Leitungsbauten am Schlüsselberg konnten im Berichtsjahr abgeschlossen werden. Bei den Arbeiten 2019 handelte es sich mehrheitlich um kleinere Leitungsgräben für Hausanschlüsse und geringe Absenkungen für die Pflästerung. ${ }^{1}$

Ein entsprechend seichter Eingriff legte die Oberkante einer abgebrochenen Mauer frei, die auf der Höhe der Liegenschaft Schlüsselberg 9 quer zur Strasse verlief. Reste derselben Mauer waren schon bei einer Ausgrabung $1975^{2}$ und vorgängig im aktuellen Projekt ${ }^{3}$ angeschnitten worden. Seit 1975 geht man davon aus, dass es sich dabei um die untersten Fundamentreste der spätantiken Befestigungsmauer des Münsterhügels handelt, denn die Flucht dieser schlecht erhaltenen Mauerreste passt zu derjenigen der Befestigungsmauer an der archäologischen Informationsstelle im Keller des Schulhauses zur Mücke: Dort verläuft eine spätrömische und im Mittelalter erneuerte Mauer ungefähr längs der Hangkante. Sie besteht allerdings aus grossen, wiederverwendeten Quadern, während die im Berichtsjahr angeschnittenen Fundamentreste eher kleinteiligeres Steinmaterial enthalten. Das kann aber daran liegen, dass die Mauer im Schulhauskeller viel besser und höher erhalten ist: Der neue Aufschluss lag zu tief und war zu seicht, um das Mauerwerk genauer vergleichen und datieren zu können.

Bei der Erneuerung einer Entwässerung im Hof des Schulhauses zur Mücke kamen drei rhombische Steinplatten in den Massen von rund $25 \times 45 \mathrm{~cm}$ zum Vorschein (ABв. 1). Die auf einer Seite glattgeschliffenen und wohl einst polierten Steinplatten lagen im Innern des bekannten spätantiken Grossbaus am Schlüsselberg. Ihre Form legt nahe, dass es sich um ehemalige Bodenplatten handelt. Solche rhombischen Platten aus vermutlich importiertem Gestein waren nicht alltäglich und dürften wohl ein repräsentatives Gebäude ausgezeichnet haben. Auf dem Münsterhügel sind praktisch identische Platten schon mehrfach zum Vorschein gekommen, wobei sich diese immer in der Umgebung des Münsterplatzes befanden (АВв. 2): so etwa bei Ausgrabungen im Bereich des ehemaligen Antistitiums in der Rittergasse, aber auch in den Innenhöfen der Häuser am Westrand des Münsterplatzes. ${ }^{4}$ Ihre Verteilung deutet an, dass sie einst zur Ausstattung von Bauten gehörten, so etwa des erwähnten
Grossbaus oben am Schlüsselberg. Ähnliche Bodenplatten, ebenfalls rhombisch und auf der einen Seite geschliffen, sind unter anderem auch aus Trier $^{5}$ und Ravenna ${ }^{6}$ bekannt. Die Trierer Stücke sehen den Basler Exemplaren recht ähnlich. Es ist jedoch unklar, ob sie auch aus dem gleichen Rohmaterial bestehen. ${ }^{7}$ Sicher ist vorerst, dass der blaugraue, ehemals wohl dunklere Kalk der Basler Stücke weder alpin ist noch aus dem Jura stammt. ${ }^{8}$

Der Schlüsselberg ist im Rahmen dieser Baubegleitung seinem Ruf als «Schlüsselstelle» der Archäologie des Münsterhügels gerecht geworden: Er erlaubte viele kleine Einblicke in die keltische, die mittelalterliche und besonders die spätantike Siedlungsgeschichte.
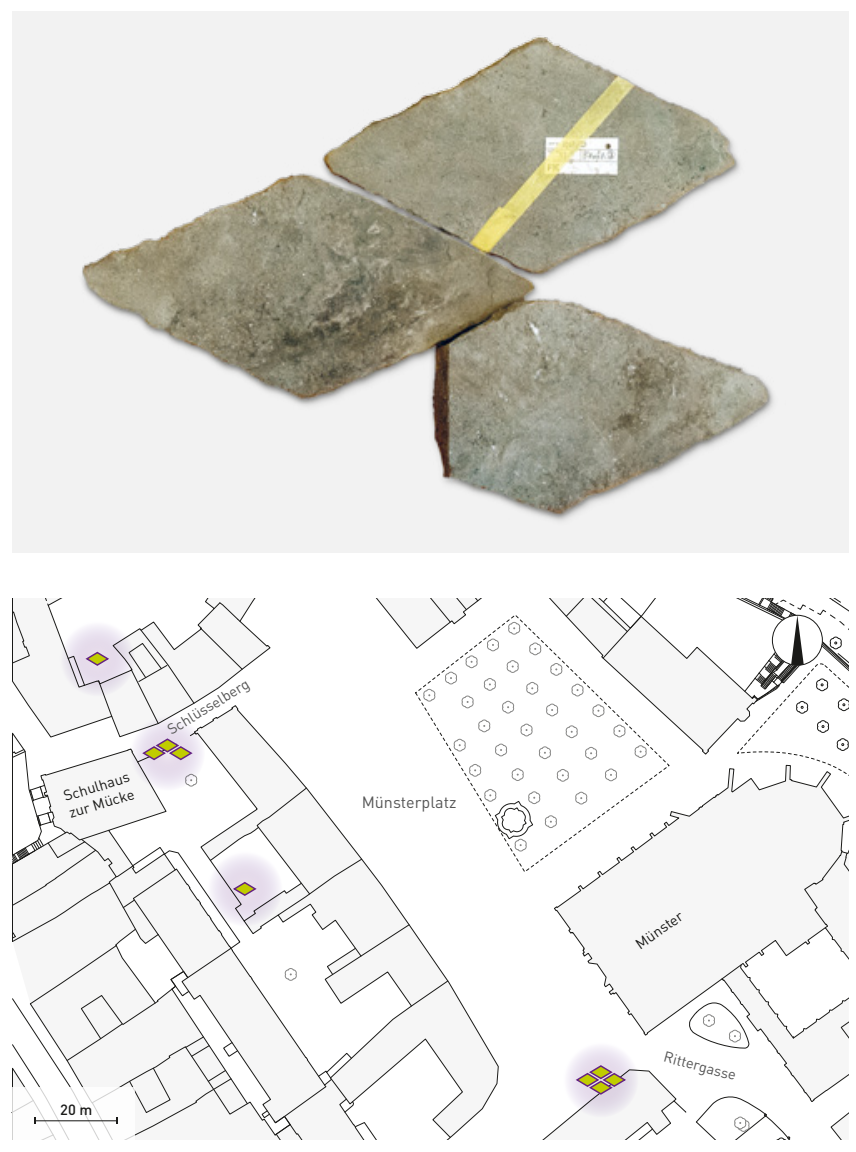

ABB. 1 Die drei im Bereich des Schlüsselberges gefundenen rhombischen Steinplatten, hier in einem möglichen Rapportmuster ausgelegt, gehörten vielleicht zur Bauausstattung des römischen Grossbaus auf dem Münsterhügel. Foto: Martin Allemann.

ABB. 2 Kartierung der bislang bekannten rhombischen dunklen Steinplatten in der Umgebung des Basler Münsterplatzes. Zeichnung: Peter von Holzen. 


\section{$2019 / 6$}

\section{RITTERGASSE 4}

Anlass: Umbau eines Verwaltungsbaus zu einem Schulhaus

Zeitstellung: Römische Zeit, Frühmittelalter, Mittelalter, Neuzeit

Untersuchungsdauer: Februar 2019 bis April 2020

Verantwortlich: Simon Graber, Martin Allemann, Benedikt Wyss

Text: Martin Allemann

Da auf dem Münsterhügel, der Keimzelle der mittelalterlichen Bischofsstadt, jeder Bodeneingriff neue Erkenntnisse zur Stadtgeschichte erbringen kann, betreuten wir auch den Umbau des Verwaltungsgebäudes an der Rittergasse 4 zu einem Schulhaus sehr intensiv: Die Bauarbeiten tangierten nicht nur die unmittelbare Umgebung der keltischen Befestigung, das heisst des Murus Gallicus, ${ }^{9}$ sondern auch einen Bereich im Innenhof des Baudepartements, dessen gut erhaltene Siedlungsschichten seit den 1980er-Jahren bekannt sind. ${ }^{10}$

Das betreffende Gebäude war 1885 bereits als Schulhaus errichtet worden. Um für diesen Neubau Platz zu schaffen, brach man damals mehrere mittelalterliche Bauten ab. Andere Gebäude waren schon früher im 19. Jahrhundert abgerissen worden. Vieles wurde dabei unbeobachtet zerstört, die wenigen Mauerreste, die Pioniere der Basler Archäologie dokumentieren konnten, zeigen aber, dass knapp südlich des neuen Schulhauses die spätrömische Befestigungsmauer verlief. ${ }^{11} 1971$ wurden zudem Reste des Murus Gallicus entdeckt und identifiziert, der fast die gleiche Bauflucht hat. ${ }^{12}$ Ein Teil dieses Keltenwalls, der seit seiner Entdeckung Gegenstand zahlreicher Forschungsgrabungen war, ist heute im Rahmen einer archäologischen Informationsstelle einsehbar. Im Jahr 1982 brachte der Umbau des Schulhauses zu einem Verwaltungsgebäude nordwestlich der beiden Befestigungen gut erhaltene Siedlungsschichten aus der keltischen sowie der früh- und spätrömischen Zeit zum Vorschein. ${ }^{13}$ Desgleichen eine frühmittelalterliche Besiedlung des Areals liess sich - wenn auch ohne deutliche Baubefunde - in Grundzügen fassen. 2017 erbrachte die Baubegleitung bei einem weiteren Umbau wertvolle Siedlungsbefunde aus der Spätantike und mutmassliche dark-earth-Schichten aus dem Frühmittelalter. ${ }^{14}$

Das aktuelle Bauprojekt zog zwar meist nur kleinflächige und seichte Bodeneingriffe nach sich, allerdings fanden diese auch an unterschiedlichen, teils bislang unberührten Stellen statt (АВв. 3). ${ }^{15}$ Insgesamt wurden drei Bauabschnitte von uns enger betreut: der Einbau eines Liftschachts im Keller des Schulhauses, die Neugestaltung des Pausenbereichs im Innenhof und die partielle Umgestaltung des Hofs beim Murus Gallicus zum Spielplatz.
Der Aushub für den Liftschacht erfolgte in einem Bereich, der 1885 noch nicht unterkellert worden war, und erreichte mehrere gelbliche Lehmböden. Bereits 1982 hatte man die nun ergrabenen Schichten im Profil dokumentiert, aber nicht flächig abgetragen. Die geringe Ausdehnung sowie Tiefe unseres Aufschlusses verhindern vorerst eine weiterführende Interpretation. Ein hier gefundenes, sehr gut erhaltenes und ins 1. Jahrhundert n. Chr. datierendes Gefäss aus Terra Sigillata stützt aber die Zugehörigkeit zu den schon 1982 festgestellten frührömischen Schichten. Aus den recht hohen Profilen nahmen wir mehrere Mikromorphologie-Proben für allfällige geoarchäologische Untersuchungen. $\rightarrow$

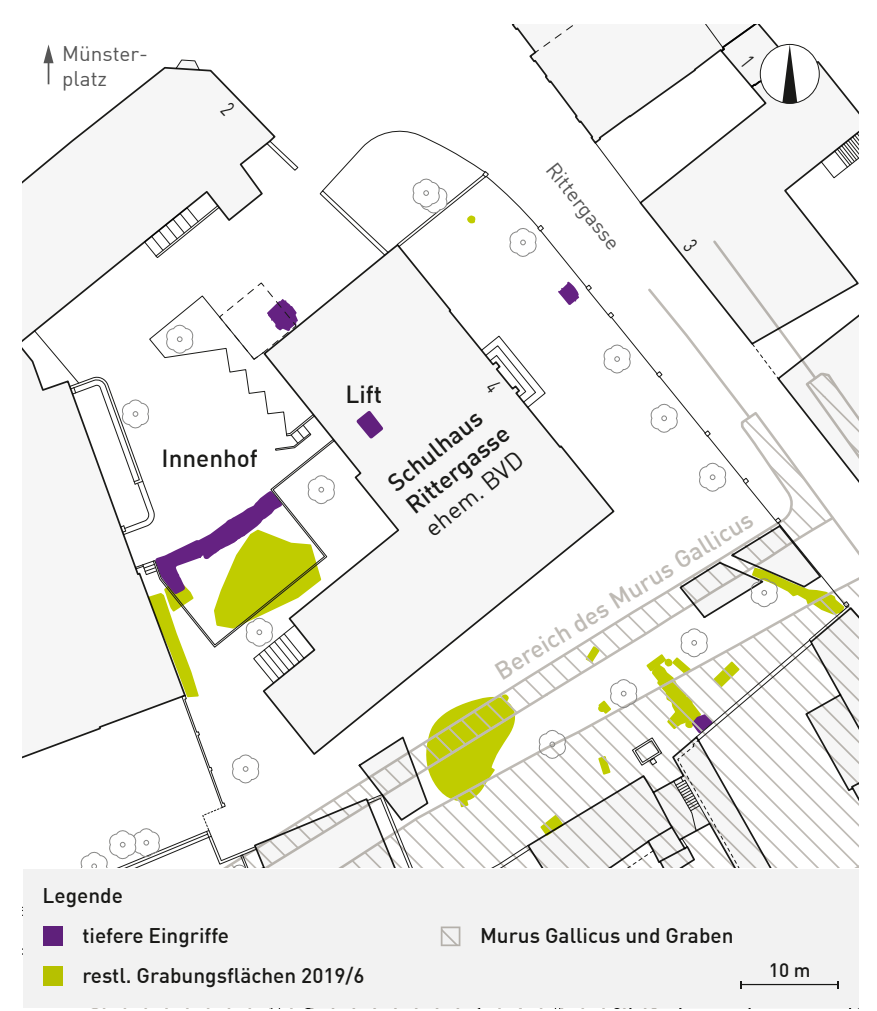

ABB. 3 Übersicht zu den archäologischen Ausgrabungen im Hof des Verwaltungsgebäudes an der Rittergasse 4 und im Bereich des Murus Gallicus. Plan: Peter von Holzen. 

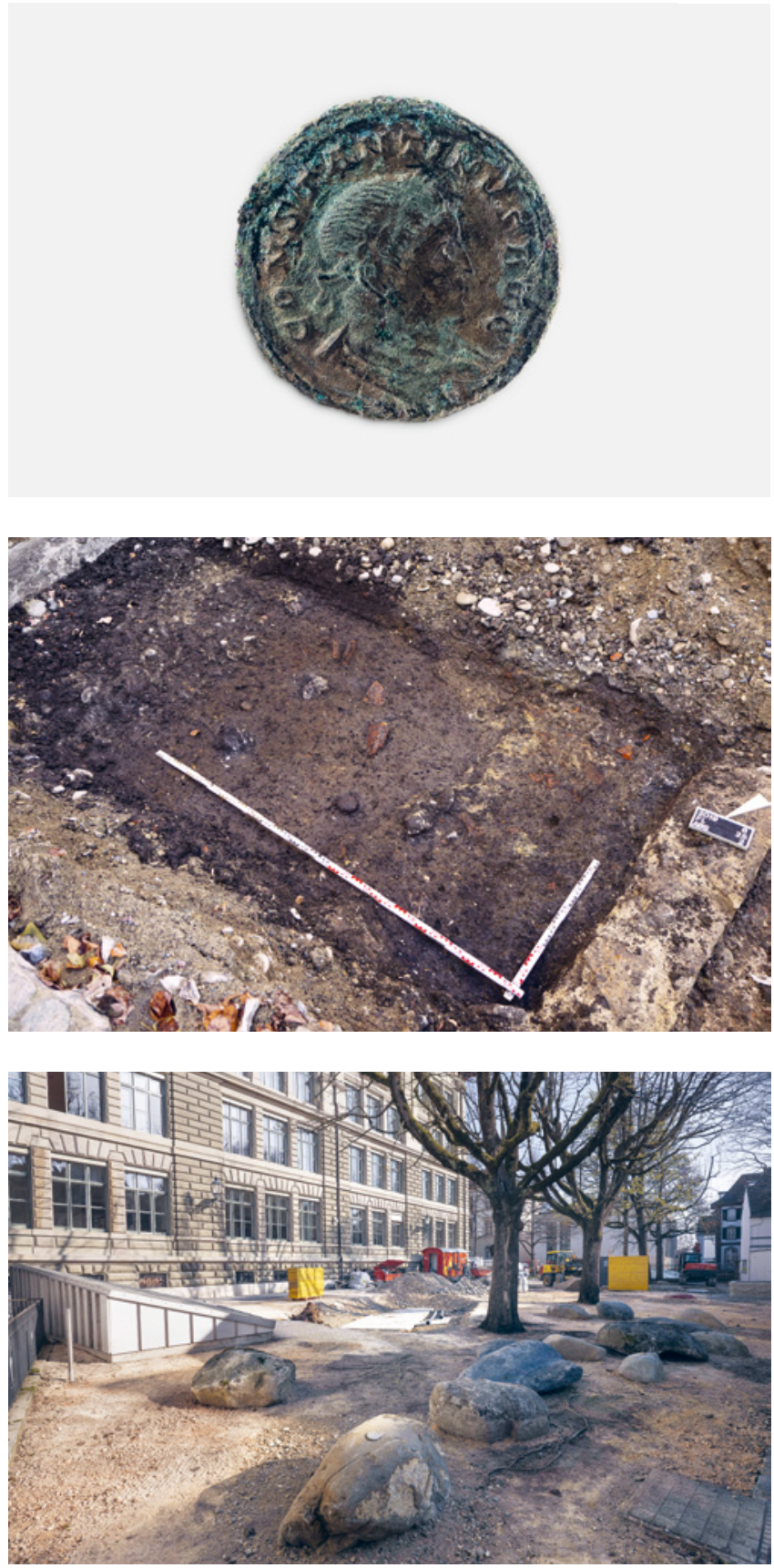

ABB. 4 Bei der Ausgrabung im Innenhofbereich konnten hervorragend erhaltene Münzen geborgen werden: Hier zum Beispiel ein Halbnummus des Kaisers Constantin I aus Treveri (Trier, Deutschland), geprägt in den Jahren 310/311 n. Chr. Foto: Philippe Saurbeck.

ABB. 5 Die abgerundete Ecke des Grubenhauses ist links im Bild am dunkleren, weicheren Material der Verfüllung und den darin eingebetteten Funden zu erkennen. Foto: Benedikt Wyss.

ABB. 6 Im von modernen Störungen durchzogenen Bereich in der Umgebung der Erdfenster beim Murus Gallicus waren die Eingriffe mehrheitlich seicht. Foto: Philippe Saurbeck.
Die meisten Überraschungen gab es im Innenhof: Zwar wurde rasch klar, dass nach der Grabung von 1982 alle frühmittelalterlichen dark-earth-Schichten flächig abplaniert und durch Kies ersetzt worden waren, so dass darunter nur noch wenig von den spätantiken und älteren Befunden erhalten geblieben ist. Die aktuellen Bodeneingriffe erfassten deshalb, obwohl die Gräben bis zu 1 m tief ausgehoben worden waren, lediglich noch ca. $20 \mathrm{~cm}$ der alten Substanz. Direkt unter der modernen Kiesauffüllung lagen noch minime Reste der frühmittelalterlichen dark-earth-Schicht, deren Fundreichtum ungefähr erahnen lässt, was nach der Grabung von 1982 zerstört worden ist. Darunter waren flächig spätantike Schichten aus sandigem, hellbraunem Lehm erhalten, in denen sich einige Steinsetzungen und Pfostenlöcher abzeichneten. Das reichhaltige Fundmaterial umfasst vor allem Keramik des späten 3. und des 4. Jahrhunderts, gut erhaltene Münzen (ABB.4) und einen Lavezbecher. Ebenfalls interessant ist ein abgerundet rechteckiger Eingriff, der die spätrömischen Schichten durchschlägt (ABB. 5): Nicht nur dessen Ähnlichkeit mit den Befunden von 1982, sondern auch eine darin angetroffene frühmittelalterliche Scherbe lassen erkennen, dass es sich um einen Teil eines frühmittelalterlichen Grubenhauses handelt.

Im dritten, mit modernen Störungen durchzogenen Bereich in der Umgebung der Erdfenster beim Murus Gallicus erreichten die mehrheitlich seichten Eingriffe an keiner Stelle keltische oder auch nur spätantike Nutzungsniveaus (ABB. 6). Es kamen nur bescheidene Mauerreste von Gebäuden zum Vorschein, die man im 19. Jahrhundert abgebrochen hatte. Beim Aushub eines Abwasserschachtes entlang der Mauer zum Nachbarhaus stiessen wir zudem auf ein reichhaltiges Ensemble aus Siedlungsabfall des Spätmittelalters und der Frühen Neuzeit, unter anderem Scherben von Glasbechern, einen fast vollständigen Becher aus Siegburger Steinzeug sowie reliefierte grünglasierte Ofenkacheln.

Weitere Massnahmen, wie der Bau von Akustikelementen entlang des zukünftigen Pausenhofs oder die Erneuerung weiterer alter Kanalisationsschächte mit teils erheblichen Bodeneingriffen, werden uns auch im Jahr 2020 beschäftigen. 
INNERSTADT

\section{$2019 / 16$}

\section{KLEINER MÜNSTERPLATZ (A)}

Anlass: Sondagen zum Erhalt der Bäume

\begin{tabular}{l} 
Zeitstellung: Römische Zeit, Neuzeit \\
\hline Untersuchungsdauer: Mai 2019 \\
Verantwortlich: Martin Allemann \\
Text: Martin Allemann
\end{tabular}

Die Rosskastanien auf dem Kleinen Münsterplatz haben das archäologische Erbe weitgehend vor einer Zerstörung durch Überbauung und Leitungsgräben bewahrt. Seit den Sondagen der 1940er-Jahre, die einen römischen Strassenkoffer und Spuren einer bescheidenden Überbauung zu Tage brachten, ${ }^{16}$ waren hauptsächlich im Rahmen der Baumpflege nur kleine Eingriffe nötig. Auch die im Berichtsjahr geöffneten vier Flächensondagen standen mit Baumsanierungsmassnahmen im Zusammenhang (Авв. 7). ${ }^{17}$ In allen Flächen führte man Sickerversuche durch und vertiefte danach zwei davon auf rund $1 \mathrm{~m}$, um auch die tiefer liegenden Wurzeln zu begutachten. Klar abgrenzbare Befunde kamen dabei nicht zum Vorschein, und das Fundmaterial war bis auf den Grund durchmischt: Unter der dominierenden neuzeitlichen Keramik zeigten sich auch spätantike Scherben, die darauf hinweisen, dass sich in grösserer Tiefe wohl noch intakte antike Schichten erhalten haben.

In allen vier Sondagen lagen zuoberst stark kompaktierte neuzeitliche Bauhorizonte und Platzoberflächen, teils so hart, dass kaum Wasser durchsickerte. Darunter trennten mächtige, schwarze, humose Schichten diese neuzeitlichen Beläge von tiefer liegenden Steinkonzentrationen, die wohl die erhaltene Oberkante archäologischer Befunde markieren. Das dunkle Humuspaket ist wohl nicht als frühmittelalterliche dark earth anzusprechen, da es im Profil nicht geschichtet war und neuzeitliche Funde enthielt. Da die allfälligen Sanierungsmassnahmen nur die stark verdichtete Oberfläche betreffen, wird der dazu notwendige Austausch des Bodenmaterials die tiefer liegenden archäologischen Befunde hoffentlich kaum tangieren.

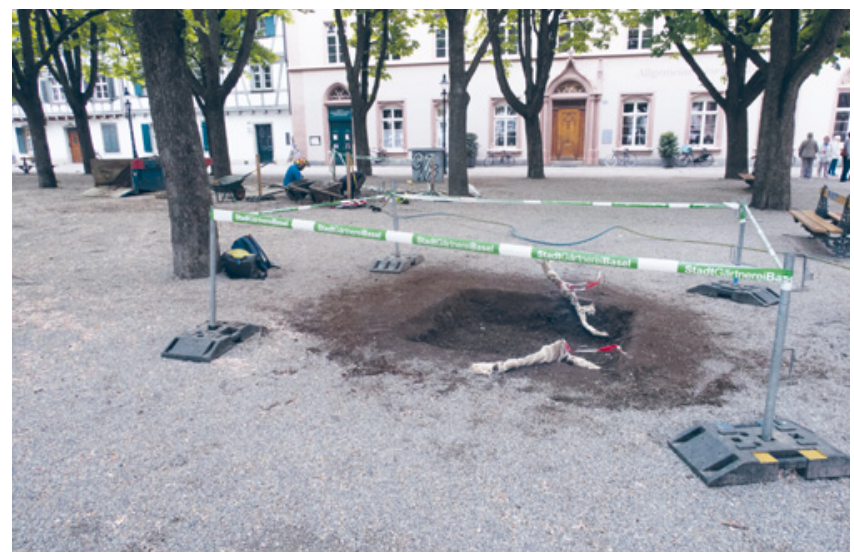

ABB. 7 In den unterschiedlich tiefen Sondagen im Bereich der Bäume auf dem Kleinen Münsterplatz kamen zwar keine klar abgrenzbaren Befunde, unter anderem aber spätantike Scherben zum Vorschein. Foto: Martin Allemann.

\section{$2018 / 19$}

\section{UNTERER RHEINWEG 28}

Anlass: Innensanierung Kaserne, Werkleitungsbauten

\section{Zeitstellung: Mittelalter, Neuzeit}

Untersuchungsdauer: September 2018 bis Dezember 2019

Verantwortlich: Roman Schmidig

Text: Roman Schmidig

Seit September 2018 werden von der Archäologischen Bodenforschung umfangreiche Bauarbeiten auf dem Kasernenareal begleitet. Anlass ist die Neugestaltung des Areals, welche auch die Innensanierung sämtlicher Gebäude beinhaltet. Im Berichtsjahr wurden insbesondere alle Böden um ca. $70 \mathrm{~cm}$ abgesenkt und grosse Teile des Hauptgebäudes neu unterkellert. Dadurch konnte dieses Gelände erstmals grossflächig archäologisch untersucht werden. ${ }^{18}$

Auf dem heutigen Kasernenareal wurde um 1274 ein Teil des Dominikanerinnenklosters Klingental errichtet. Der Gebäudekomplex, auch «Grosses Klingental» genannt, bestand aus Klosterkirche, Konvent, Ökonomiegebäuden und Äbtissinnenhaus - im Gegensatz zum «Kleinen Klingental», das heisst den Gebäuden südlich der Klosterkirche mit Brüderhaus, Pfründnerhaus und Schaffnei. Bis zu 52 Nonnen bewohnten das Kloster und machten es durch ihre vornehme Herkunft sowie ihren ausgeprägten Geschäftssinn zu einem der wohlhabendsten Klöster in Basel. Nach der Reformation kam das Kloster in den Besitz der Stadt. Die Kirche und $\rightarrow$

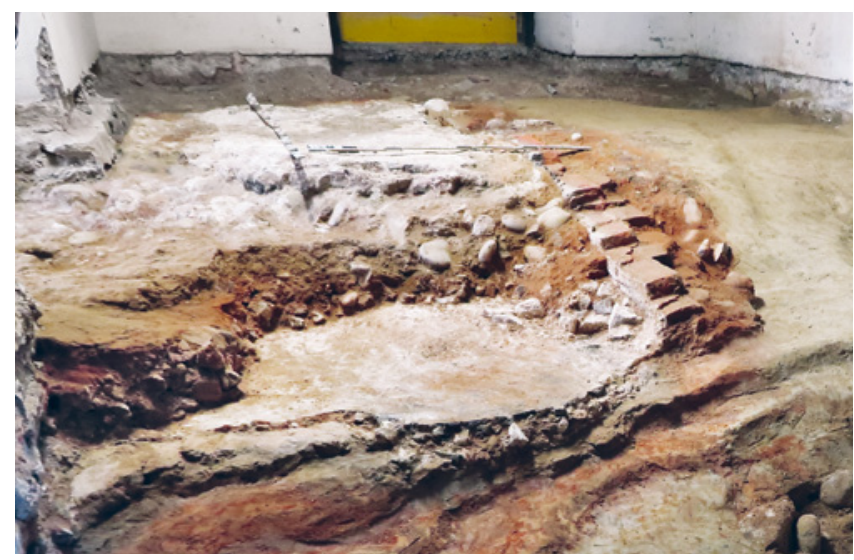

ABB. 8 Der Feuerungsraum des Ofens mit mehreren weisslichen Schlackeschichten. Foto: Fabian Bubendorf 

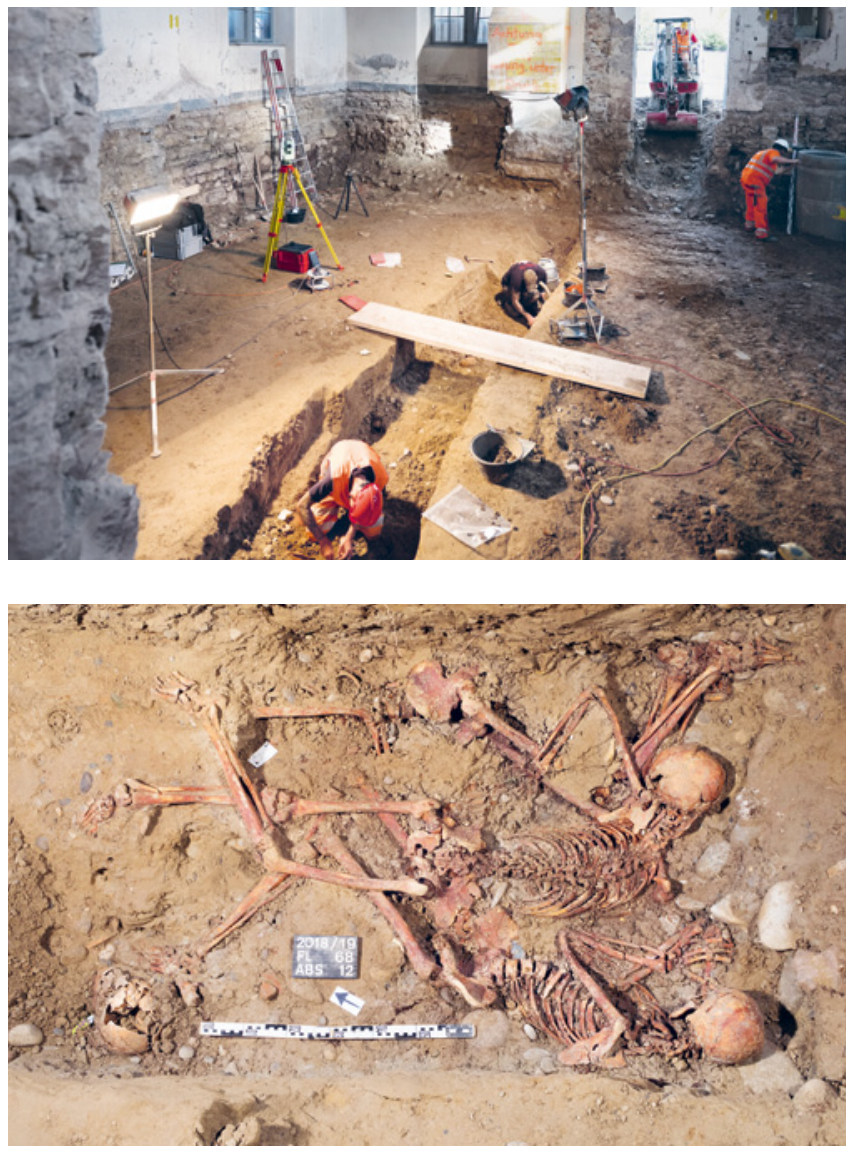

ABB. 9 Die Skelette im Massengrab werden freigelegt. Foto: Philippe Saurbeck.

АВв. 10 Die Lage der Skelette zeigt deutlich, dass die am Flecktyphus verstorbenen Männer nicht ordentlich bestattet worden sind. Foto: Samuel Thiessen. der Konvent dienten nun unter anderem als Lagerhaus und Salzmagazin sowie als Kaserne für die Stadtgarnison. Mit Ausnahme der Klosterkirche wurden die Gebäude des Grossen Klingentals bis 1863 nach und nach abgerissen und der heutige Gebäudekomplex errichtet. ${ }^{19}$

Da sich das Hauptgebäude der Kaserne ausserhalb der ehemaligen Klostergebäude befindet, waren in diesem Bereich nur wenige Befunde der klosterzeitlichen Bebauung zu erwarten. Überhaupt war zu Beginn nicht klar, wie viel der archäologischen Substanz bei der Errichtung der Kaserne bereits zerstört worden war. Nach dem Entfernen des modernen Betonbodens kam an mehreren Stellen der Bauhorizont der Kaserne mit Pfostengruben des Baugerüsts zum Vorschein. Diverse weitere Befunde sind älter als die Kaserne, können jedoch mangels Fundmaterial nicht genauer datiert werden. Einige Fundamente in der Nähe der rheinseitigen Stadtbefestigung könnten Reste des ehemaligen Äbtissinnenhauses sein, das an die Stadtmauer angebaut gewesen war. Diese Fundamente werden von einer jüngeren, ca. $2 \mathrm{~m}$ hohen Dole durchschlagen, welche in Richtung Rhein verläuft. Eine Grube mit einem rechteckig ausgeprägten Mauerwerk aus Backsteinen kann aufgrund starker Brandrötung und mehrerer Schlackeschichten als Feuerungsraum eines handwerklich genutzten Ofens gedeutet werden (ABB. 8). Die genaue Funktion bleibt jedoch unklar. Ansammlungen von Kalkpulver lassen auf einen Kalkbrennofen schliessen, allerdings wurden ähnliche rechteckige Öfen oft zur Herstellung von Keramik - etwa Ofenkacheln - genutzt. ${ }^{20}$

Erwartungsgemäss kamen im Norden des Areals am Klingentalgraben Abschnitte der Stadt- und Kontermauer zum Vorschein (ABB. 11). 1278 wurde das Kloster, das noch ausserhalb der Stadtmauer errichtet worden war, in die Stadtbefestigung einbezogen. ${ }^{21}$ Die aufgedeckten Abschnitte liegen treffend in der aus früheren Grabungen bekannten Flucht. ${ }^{22}$ Dazwischen zeichneten sich auf der Sohle des Stadtgrabens völlig überraschend zwei parallele Gräben ab, in deren oberem Verfüllungsbereich sich Menschenknochen befanden. Da nur einer der Gräben durch das Bauprojekt gefährdet war, beschlossen wir, lediglich diesen auszugraben (Авв. 9). Er enthielt 27 Skelette, die nicht ordentlich bestattet in unterschiedlicher Körperhaltung neben- und übereinander lagen (ABB. 10). Eine erste anthropologische Begutachtung ergab, dass es sich wohl ausschliesslich um Männer handelt. Das Massengrab gehört vermutlich zu einem aus Schriftquellen bekannten Notfriedhof, der 1814 «etwa zweihundert Schritte unterhalb der Kaserne» ${ }^{23}$ - womit wohl die Klingentalkirche gemeint ist - offenbar im Stadtgraben angelegt worden war. Die gegen Ende der Napoleonischen Kriege in Basel einquartierten alliierten Truppen hatten den Flecktyphus in die Stadt eingeschleppt und eine - im ganzen Oberrheingebiet wütende - Epidemie ausgelöst. Die wenigen Funde (Keramikscherben, Wallfahrts- 
medaillen, Knöpfe) bestätigen diese Datierung. Ein weiteres, nun aber einzeln in einem Sarg bestattetes Skelett lag in derselben Tiefe direkt neben dem ersten Graben. Es stammt von einem 50 bis 60 Jahre alten Mann, der unter einer starken Verkrümmung der Wirbelsäule gelitten hatte. Warum dieser Mann separat bestattet wurde und ob es sich ebenfalls um einen Soldaten handelt, muss offenbleiben.

Südlich des Gebäudes fanden zwischen dem Hauptgebäude und dem Kleinen Klingental Leitungsarbeiten statt. An dieser Stelle waren diverse, aus alten Plänen bekannte Bauten zwischen dem Kleinen und Grossen Klingental zu erwarten. ${ }^{24}$ Tatsächlich konnte ein langrechteckiger Querbau zum ehemaligen Brüderhaus des Kleinen Klingentals freigelegt werden. Er bestand aus zwei relativ hoch erhaltenen Fundamenten, zwischen denen ein Tonplattenboden lag. Da das Gebäude noch auf Situationsplänen des 19. Jahrhunderts erscheint, wurde es wohl erst im Zuge des Neubaus der Kaserne abgerissen.

Die Arbeiten konnten im Berichtsjahr grösstenteils abgeschlossen werden; für das Jahr 2020 sind nur noch einzelne Einsätze geplant.

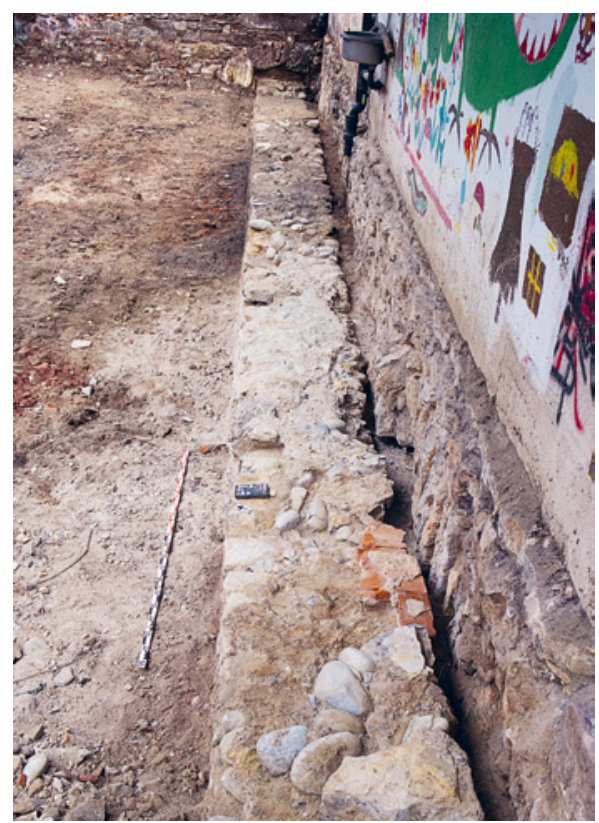

ABB. 11 Der freigelegte Teil der Stadtmauer am Klingentalgraben, links davon die Verfüllung des Stadtgrabens. Foto: Roman Schmidig.

\section{$2018 / 25$}

\section{SPIEGELGASSE 11}

Anlass: Neubau AUE (Amt für Umwelt und Energie)

Zeitstellung: Römische Zeit, Mittelalter, Neuzeit

Untersuchungsdauer: November 2018 bis August 2019

Verantwortlich: Sven Billo, Margit Dauner

Text: Sven Billo

Die archäologischen Untersuchungen im Zusammenhang mit dem Neubau des Amts für Umwelt und Energie (AUE) an der Spiegelgasse 11 waren die grösste geplante Grabung für das Jahr 2019. Bereits im November 2018 mussten dafür im Vorfeld zwei Flächen in Zusammenhang mit der Baugrubensicherung untersucht werden. Dabei kamen Mauerreste, Teile eines Mörtelgussbodens sowie mittelalterliche Kulturschichten zu Tage.

Für einen ausführlicheren Überblick zu den Ergebnissen der Ausgrabung siehe die Coverstory im vorliegenden Jahresbericht.

\section{8/32}

\section{ST. ALBAN-GRABEN (A) 5 / LUFTGÄSSLEIN (A)}

Anlass: Werkleitungsbauten

Zeitstellung: Römische Zeit, Mittelalter, Neuzeit

Untersuchungsdauer: Oktober 2018 bis Dezember 2019

Verantwortlich: Martin Allemann

Text: Martin Allemann

Bereits seit Oktober 2018 ist die Archäologische Bodenforschung am St. Alban-Graben im Einsatz, wo die Bauarbeiten für das grosse Parkhaus unter der Strasse zuerst Leitungsgräben, anschliessend aber auch grössere Bodeneingriffe mit sich brachten. ${ }^{25}$ Das unterirdische Parking kommt mehrheitlich in dem im 19. Jahrhundert aufgefüllten, mittelalterlichen St. Alban-Graben der Inneren Stadtmauer zu liegen und tangiert daher im Verhältnis zu seiner Grösse recht wenig von der archäologischen Substanz (АВв. 12).

Im Bereich St. Alban-Graben / Luftgässlein sind schon oft gut erhaltene Befunde des römischen Vicus, das heisst der römischen Siedlung im offenen Vorfeld des Münsterhügels, ${ }^{26}$ aber auch der mittelalterlichen Stadtbefestigung zum Vorschein gekommen, dazu Gräber aus der Spätantike und dem Frühmittelalter. ${ }^{27}$ Paradoxerweise haben die um 1230 erbaute Innere Stadtmauer und ihr Graben zwar in der heutigen Strassenflucht des St. Alban-Grabens alle älteren Spuren zerstört und eine Schneise durch Vicus und Gräberfelder geschlagen, stadteinwärts aber zu einer ungewöhnlich $\rightarrow$ 

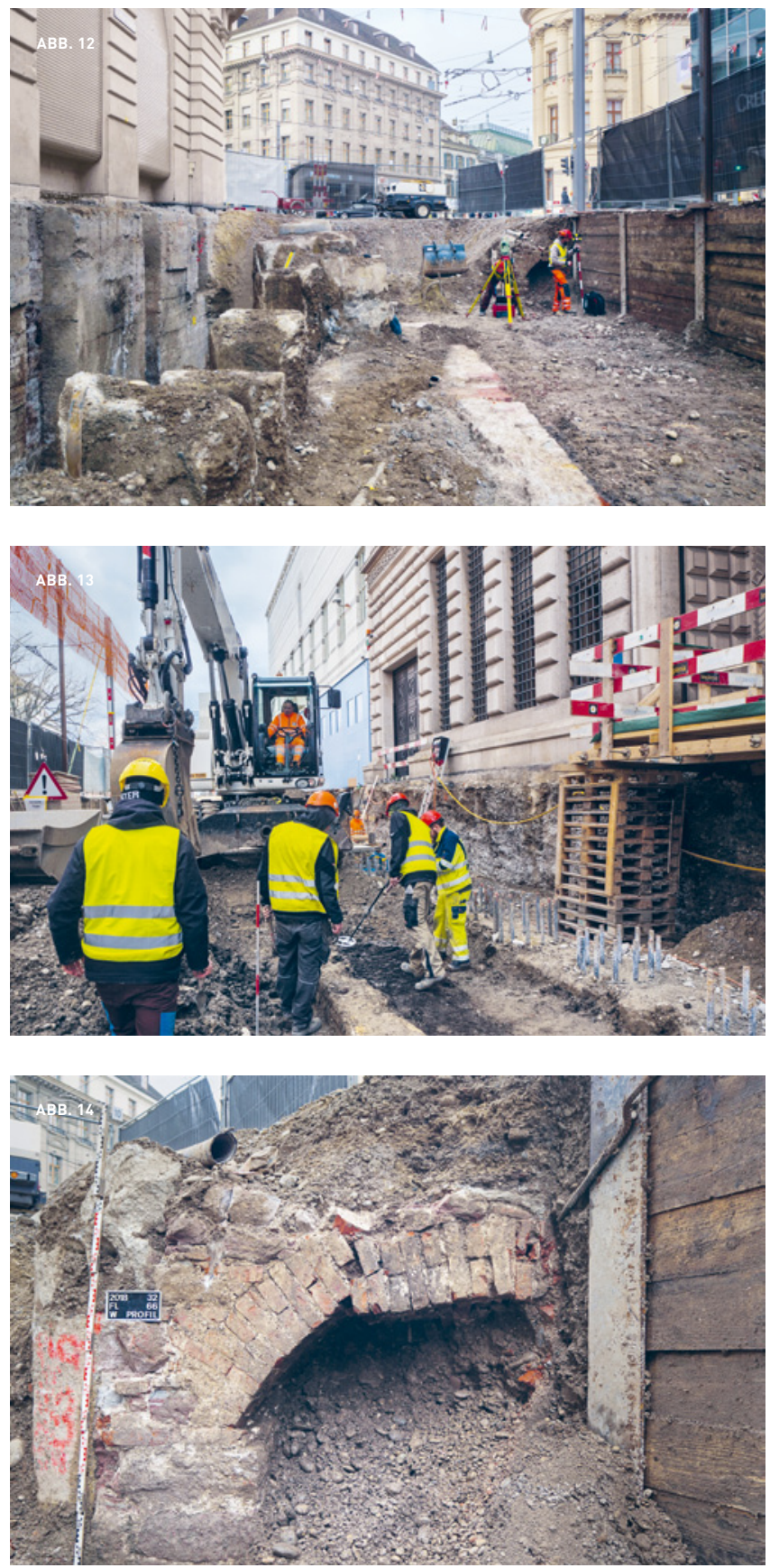

guten Erhaltung älterer Befunde geführt: Hinter der Stadtmauer, nordwestlich des St. Alban-Grabens, schüttete man den Grabenaushub zu mächtigen Planien an. Diese Hinterschüttungen, in den Gärten Rittergasse 20 und St. Alban-Graben 11 in einer Mächtigkeit von mehreren Metern sichtbar, schützen bis heute die darunter liegenden antiken und frühmittelalterlichen Befunde vor Bodeneingriffen.

Das Luftgässlein mündet erst seit dem Bau der heutigen Credit Suisse 1958 in der aktuellen Flucht in den St. Alban-Graben. Zuvor war sein südlicher Abschnitt nicht überbaut gewesen. Der Aushub für einen Leitungsgraben zeigte rasch, dass hier trotz vieler Eingriffe noch substanzielle Reste sowohl der Inneren Stadtmauer als auch schwarze, tonige und nur schwer zu differenzierende antike Schichten erhalten geblieben sind. Die vielen, sehr unterschiedlich grossen und tiefen Bodeneingriffe erbrachten zahlreiche Befunde, von denen hier nur die wichtigsten knapp vorgestellt werden können: Die Schale der Inneren Stadtmauer konnten wir im Berichtsjahr nur punktuell und oberflächennah fassen, tiefere Aufschlüsse sind erst 2020 zu erwarten. Ähnlich verhält es sich mit der Kontermauer - deren Flucht konnten wir zwar fast auf der ganzen Länge des St. Alban-Grabens einmessen (ABB. 13), erst beim untertägigen Parkhausaushub in den nächsten Jahren werden wir aber flächigere und damit aussagekräftigere Aufschlüsse zu ihrer Baugeschichte oder zur Stadtgrabentiefe erhalten.

An der Inneren Stadtmauer konnte gut $70 \mathrm{~cm}$ unter dem heutigen Gehniveau ein überwölbter, niedriger Durchlass dokumentiert werden. Er gehört wohl zu einem spätmittelalterlichen Aquädukt, der als Teil des sogenannten Münsterwerks, über den Stadtgraben hinweg, den Münsterhügel mit Frischwasser versorgte. ${ }^{28}$ Ein besser erhaltener Aquädukt wohl ähnlicher Zeitstellung kam zwischen den Gebäuden der Credit Suisse und der UBS zum Vorschein; hier konnte sogar noch ein eingebrochener Bogen dokumentiert werden (ABB. 14). Diese beiden kleinen Aquädukte über den St. Alban-Graben sind auf dem Merianplan von 1615 verzeichnet (AвB. 15). Ihre Lage ist gut gewählt: Um den Münsterhügel ohne aufwändige Druckleitungen und Hochbauten mit Fliesswasser versorgen zu können, kommt aufgrund der steilen Hangflanken nur eine Zuleitung von Südosten in Frage.

Andere Befunde stammen erst aus der Zeit nach der Aufgabe und Verfüllung des Stadtgrabens 1786 bis 1815: In der schuttreichen Grabenverfüllung lag ein unterirdischer, überwölbter Sickerschacht. Diese «Cÿsterne» gehörte zu einer Kanalisation des frühen 19. Jahrhunderts. ${ }^{29}$ Auch eine etwa gleichzeitig gemauerte, überwölbte Kanalisationsleitung, eine sogenannte Dole, konnten wir über weite Strecken fassen. Um Aufwand zu sparen, hatte man sie direkt an die 
unterirdisch noch vorhandene Kontermauer angesetzt und diese damit als eine der Stützmauern in den Bau einbezogen. Für den Sickerschacht wurden, wie bereits bei einem in den 1980 er-Jahren aufgedeckten Schacht, ${ }^{30}$ jüdische Grabsteine in Drittverwendung verbaut. Die hebräischen Inschriften sind allerdings wesentlich schlechter erhalten als diejenigen auf den 1984 geborgenen Steinen: Das Wenige, das sich entziffern lässt, entspricht den üblichen, weit verbreiteten Segenswünschen und Gebetsformeln - weder Namen noch Jahreszahlen sind überliefert. ${ }^{31}$ Die Grabsteine stammen ursprünglich vom jüdischen Friedhof am Petersplatz, der nach dem Pogrom von 1349 verwüstet worden war. In der Folge wurden sie dann - wie ein Bericht aus dem 17. Jahrhundert nahelegt - mit der Schriftseite nach oben als Mauerdecksteine auf der Kontermauer der Inneren Stadtmauer missbraucht. ${ }^{32} \mathrm{Nach}$ dem Abbruch dieser Mauer wurden die Grabsteine offenbar für den Kanalisationsbau weiterverwendet.

Südlich der Kontermauer hatten sich Reste des römischen Vicus erhalten: In einem schmalen Streifen schwarzen, tonigen Materials zwischen Kunstmuseum und Dolenmauer lagen Kieselwackenböden, Pfostenreihen, mögliche Wandgräbchen und mindestens ein Wasserleitungsgraben mit einem Teuchelring, das heisst der eisernen Dichtung zwischen zwei (nicht erhaltenen) Holzröhren. Diese Leitung lag deutlich zu tief, um - wie der spätmittelalterliche Aquädukt - den Münsterhügel versorgen zu können. Es handelt sich daher wohl eher um eine lokale Leitung für die Feinverteilung des Wassers innerhalb des Vicus. Damit dürften wir den ersten Nachweis einer antiken Fliesswasserversorgung Basels vor uns haben! Im Fundmaterial dominieren Münzen besonders des 3. und 4. Jahrhunderts, die im schwarzen, tonigen Material zwar nur schwer zu erkennen waren, dafür aber hervorragend erhalten sind (АВB. 16). Zwei Säuglingsbestattungen zeugen vom römischen Brauch, Neugeborene in den Wohnhäusern zu begraben. ${ }^{33}$

Die Fortsetzung des Projektes in den nächsten Jahren, insbesondere der eigentliche Aushub für das Parking, versprechen weitere Aufschlüsse und grössere Fundmengen aus der Stadtgrabenverfüllung

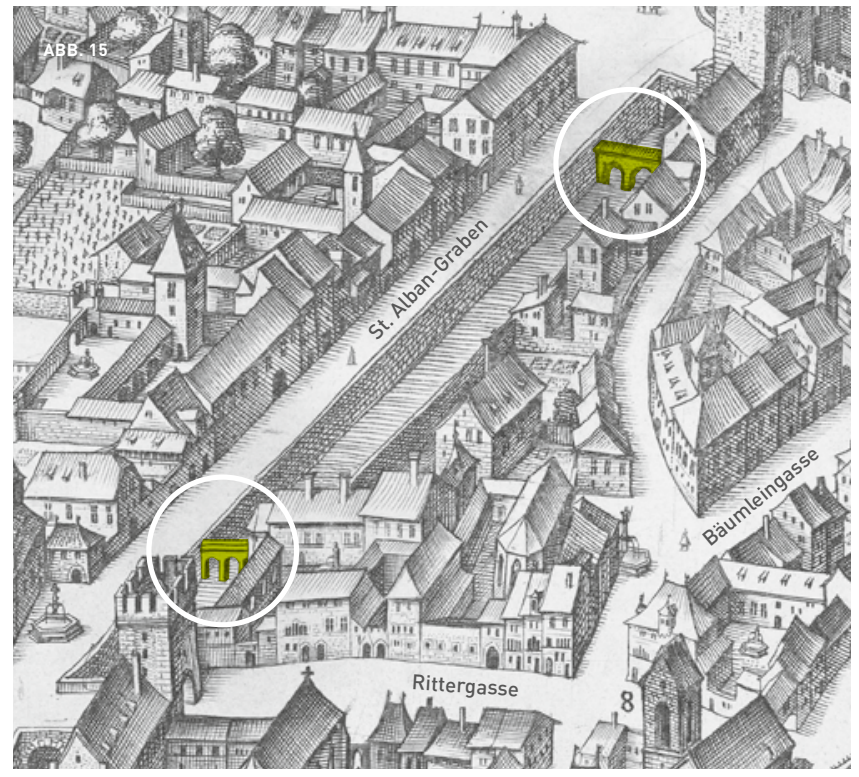

ABB. 16

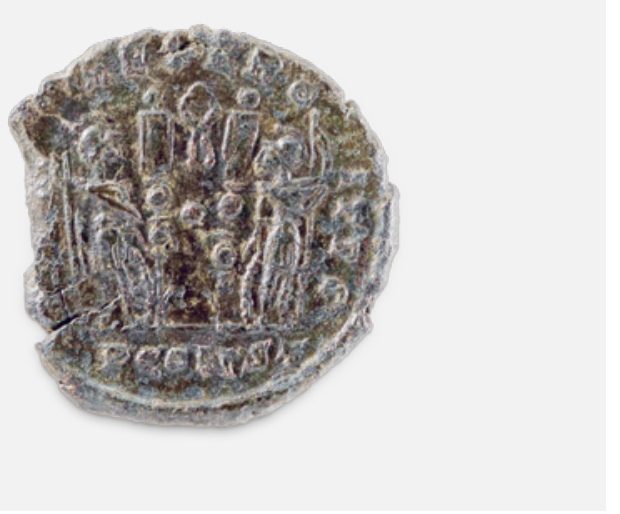

ABB. 12 Die westliche Hälfte der Grabung, zwischen UBS links und Credit Suisse rechts der Strasse, im Vordergrund auf dem Niveau der Baugrube die Kontermauer. Foto: Martin Allemann.

ABB. 13 Südlich (im Foto rechts) der Kontermauer und der Dole hatten sich dunkle römische Schichten erhalten. Foto: Fabian Bubendorf.

ABB. 14 Der Rest eines Aquäduktbogens, der im Stadtgraben entdeckt wurde, stammt vom sogenannten Münsterwerk, der mittelalterlichen Wasserversorgung des Münsterhügels. Foto: Fabian Bubendorf.

ABB. 15 Auch auf dem Merianplan von 1615 sind die beiden Aquädukte eingezeichnet. Der westliche (obere) war noch besser erhalten, für den östlichen (unteren) haben wir bisher nur Indizien. Plan: Peter von Holzen.

ABB. 16 Die Münzen, hier ein Aes 3 des Kaisers Constantin I aus Arelate (Arles, Frankreich) von 333 n. Chr., waren im tonigen Boden teils sehr gut erhalten. Foto: Philippe Saurbeck. 


\section{$2018 / 34$}

\section{THEODORSKIRCHPLATZ 7}

Anlass: Umbaumassnahmen im Waisenhaus

Zeitstellung: Mittelalter, Neuzeit

Untersuchungsdauer: Oktober bis Dezember 2018

Verantwortlich: Norbert Spichtig, Martin Allemann

Text: Martin Allemann, Simon Graber

Während der Umbauarbeiten im Vorfeld des 350-Jahr-Jubiläums des Waisenhauses meldete die Denkmalpflege bei der Archäologischen Bodenforschung mehrere Bodeneingriffe. ${ }^{34}$ Die Eingriffe tangierten den mittleren Waisenhausflügel und den Hofbereich. Im Hausinnern konnten mehrere Bodenniveaus und Mauern dokumentiert werden, im Aussenbereich kam eine weitere Mauer zum Vorschein.

Das Waisenhaus wurde 1669 im ehemaligen Kartäuserkloster eingerichtet, das 1416 - nach acht Jahren Bauzeit als jüngstes der Basler Klöster eingeweiht worden war. Die Kartause lag direkt an der Kleinbasler Stadtmauer bei der Theodorskirche. Die grösste Bedeutung und zahlreiche Zuwendungen erlangte das Kloster in seiner kurzen Bestehenszeit während des Basler Konzils von 1431 bis 1449. Nach der Reformation verweigerten die Mönche den Austritt aus dem Kloster, so dass es erst mit dem Tod des letzten Bruders im Jahr 1564 in städtische Verwaltung überging und gut einhundert Jahre später zum Waisenhaus umfunktioniert wurde. Mit der Umgestaltung und dem Abbruch des grossen Kreuzgangs sowie der letzten Mönchszelle 1776 verlor die Kartause ihr typisches Äusseres, so dass sie im heutigen Stadtbild kaum mehr als solche wahrgenommen wird. ${ }^{35}$

Die Befunde können nicht mit Sicherheit eingeordnet werden, stammen vermutlich aber aus der Nutzungszeit als Waisenhaus. Die Böden und Mauerreste im mittleren Flügel gehören möglicherweise zu einem Treppenhaus mit Abort und der hier eingerichteten Wäscherei. Die Mauer im Aussenbereich lässt sich im Abgleich mit dem Falknerplan von 1862 als rechteckiger Kanalisationsschacht interpretieren.

\section{8/37}

\section{KASERNENSTRASSE 23 (KIRCHENCHOR)}

Anlass: Innensanierung Klingentalkirche, Werkleitungsbauten

Zeitstellung: Mittelalter, Neuzeit

Untersuchungsdauer: November 2018 bis Dezember 2019

Verantwortlich: Roman Schmidig

Text: Roman Schmidig

Ein grosser Teil der Arbeiten auf dem Kasernenareal ${ }^{36}$ betraf den Innenbereich der 1293 geweihten Klosterkirche. Diese diente nach der Reformation unter anderem als Truppenunterkunft, Salzmagazin und Kasernenstall. ${ }^{37}$ Heute befinden sich im Gebäude Künstlerateliers. Im Zuge der Innensanierung musste der Boden des gesamten Kirchenchors abgetragen und um ca. $50 \mathrm{~cm}$ tiefergelegt werden. Rund um die Kirche herum wurden neue Leitungen verlegt.

Der auffällig lange Chor der Klingentalkirche war aus archäologischer Sicht bisher unbekanntes Terrain. Aufgrund der 2017 durchgeführten Sondierung wurden höchstens Grabeinbauten, jedoch kein älteres Bodenniveau erwartet. ${ }^{38}$ Nach dem Entfernen des modernen Betonbodens erschien jedoch zunächst grossflächig ein älterer, hellgrauer Mörtelboden, auf dem Abdrücke von teils in einem orthogonalen, teils in einem diagonalen Raster verlegten Tonplatten zu erkennen waren. Einige wenige dieser Platten hatten sich erfreulicherweise in einer Nische in der Lettnerrückwand noch in originaler Lage erhalten. Eine um 1425 geprägte Münze datiert diesen Boden, der dank des freundlichen Entgegenkommens der Bauleitung erhalten werden kann, ${ }^{39}$ in die Klosterzeit.

Im westlichsten Teil des Chors fanden sich im Mörtel Balkennegative vom Unterbau eines Holzbodens. An der Nord- und Südwand zeigte sich jeweils ein L-förmiger, ca. $75 \mathrm{~cm}$ tiefer und $110 \mathrm{~cm}$ breiter, gemauerter Kanal mit verputzten Seiten und gemörteltem Boden (Авв. 17). Diese beiden Kanäle wurden zusammen mit dem grossflächigen Mörtelboden angelegt und könnten ein Teil des Unterbaus des Chorgestühls gewesen sein, um die Feuchtigkeit des Bodens fernzuhalten. Allerdings fehlen hierfür Vergleichsbeispiele.

Im Ostbereich des Chors lag der Boden etwas höher und war deshalb schon bei früheren Umbauten gekappt worden. Stattdessen fanden sich an der Nordwand zwei gemauerte Grabkammern von $2 \mathrm{~m}$ Tiefe. Darin lagen im unteren Bereich noch insgesamt mindestens zehn Skelette von erwachsenen, sowohl männlichen als auch weiblichen Individuen (Авв. 18). Zahlreiche Einzelknochen, die offenkundig durch Nachbestattungen umgelagert worden waren, konnten keinem Skelett mehr zugeordnet werden. Die tatsächliche Zahl 

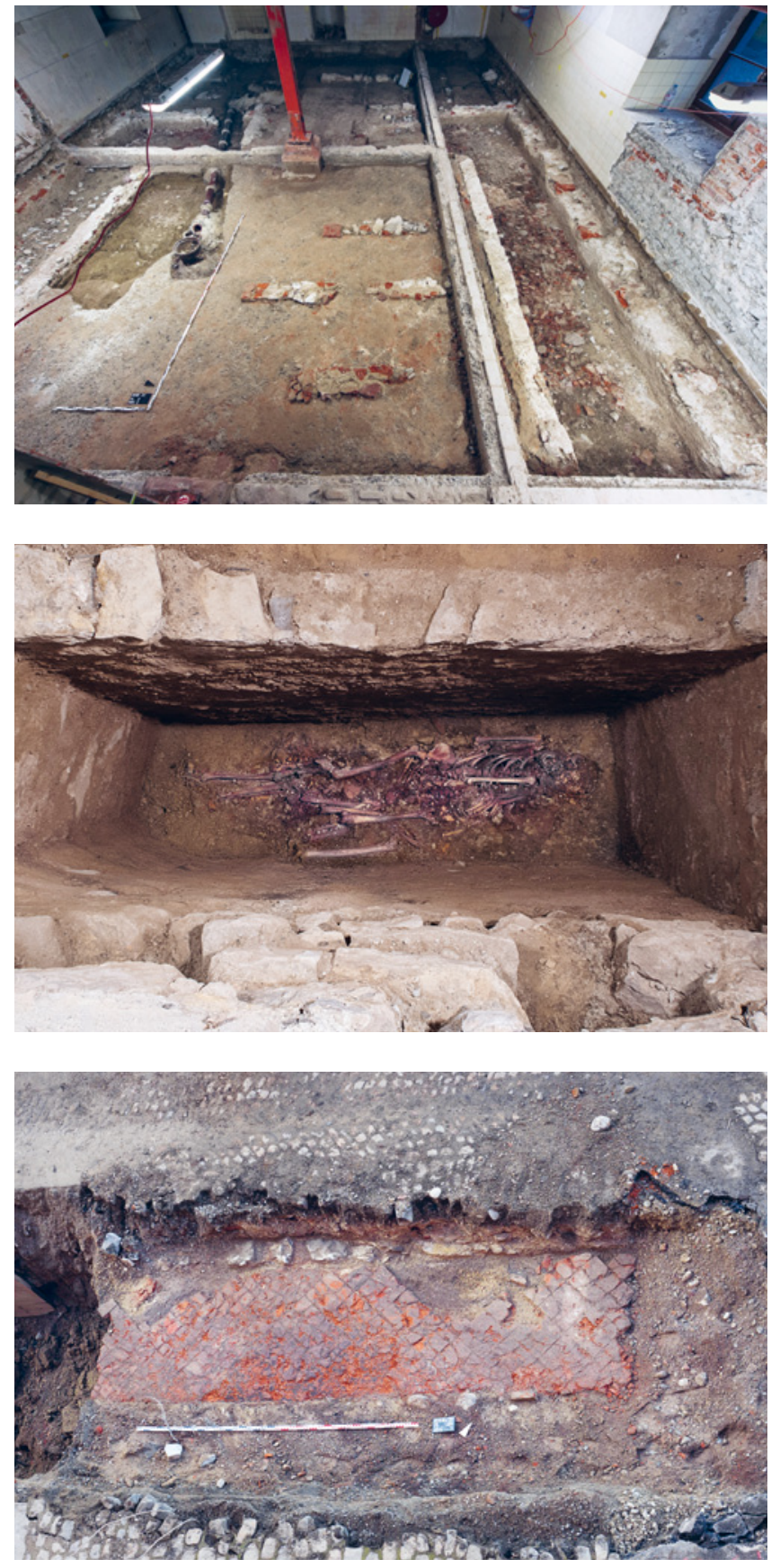

ABB. 17 Westbereich des Chors. In der Bildmitte der Mörtelboden mit den diagonalen Plattenabdrücken, darauf liegen die als Balkenauflager wiederverwendeten Tonplatten. Links und rechts die beiden L-förmigen Kanäle. Foto: Philippe Saurbeck

ABB. 18 Eine der Grabkammern im Ostbereich des Chors mit einem Skelett. Foto: David Roth.

ABB. 19 Ein Tonplattenboden im Kreuzgang nördlich der Klosterkirche. Foto: Fabian Bubendorf. der hier bestatteten Individuen dürfte demnach aber deutlich höher gewesen sein. Eine weitere Grabkammer in der Mittelachse des Chors konnte aus statischen Gründen nicht ausgegraben werden. Es ist bekannt, dass im Klingentalkloster unter anderem die Gründerfamilie von Klingen und die Klosterinsassen bestattet worden waren. ${ }^{40}$ Die Identität der im Berichtsjahr entdeckten Skelette muss jedoch offenbleiben, auch weil sie über keine Beigaben verfügten.

Im späten 17. Jahrhundert wurden sowohl im Bereich der Leutkirche, das heisst dem Bereich der Kirche, in dem sich während des Gottesdienstes die Laien aufhielten, als auch im Chor mehrere Geschosse eingezogen. ${ }^{41}$ Wohl aus dieser Zeit stammen die zahlreichen Balkenauflager, für die man teilweise auch die mittelalterlichen Tonplatten wiederverwendet hatte. Die Auflager durchschlagen den Mörtelboden in regelmässigen Abständen beziehungsweise sind auf inn aufgesetzt. Weitere Befunde wie ein Fassauflager aus Backsteinen stehen wohl mit der nachreformatorischen gewerblichen Nutzung des Kirchenraums in Zusammenhang. Die jüngsten Fundamente aus Bruchsteinen schliesslich entsprechen dem Bauplan der 1860 eingezogenen Zwischenwände.

Schon bei einer Grabung im Jahr 2000 konnten Teile des spätestens 1860 abgebrochenen Lettners dokumentiert werden, allerdings ohne dass damals ein älterer Boden aufgedeckt worden wäre.42 Bei der Verlegung der Kanalisationsanschlüsse für die neuen Toiletten kam nun etwas südlich davon erstmals ein Mörtelboden mit Ton- und Sandsteinplatten zum Vorschein. Er lag auf gleicher Höhe wie die Basis eines Lettnerpfeilers, so dass es sich wohl um den originalen Boden der um 1293 vollendeten Kirche handeln dürfte. Westlich des Lettners konnte ausserdem ein weiteres Stück Mörtelboden möglicherweise der Originalboden der Leutkirche - gefasst werden. Leider war die Stufe von der Leutkirche auf den Lettner, welche etwa $15 \mathrm{~cm}$ hoch gewesen sein müsste, nicht mehr vorhanden. In der Ostwand der Leutkirche fand sich jedoch die Türschwelle des Durchgangs in die im 19. Jahrhundert abgerissene Katharinenkapelle.

Ausserhalb der Kirche wurden rund um das Gebäude Werkleitungen verlegt. Entlang der Nordwand zog der Graben längs durch den Südflügel des Kreuzgangs und die östlich daran anschliessende, 1441/45 errichtete Sakristei. Erwartungsgemäss kamen im Kreuzgang Teile des Bodens zum Vorschein (Aвв. 19). Es zeigte sich, dass dieser mehrphasig war, da stellenweise mindestens zwei Plattenböden übereinander lagen. In der Sakristei konnte hingegen kein Boden nachgewiesen werden, dort wurden lediglich Teile der Mauern freigelegt. $\rightarrow$ 
Südlich der Kirche wurde der nördliche Abschluss des Querbaus zum Brüderhaus hin gefasst (ABB. 20). ${ }^{43}$ Ausserdem hatte sich neben der Kirchenmauer bis 1779 ein Laienfriedhof befunden, auf welchem jedoch nach der Reformation nur noch Pestleichen und Ertrunkene bestattet worden waren. Bereits in früheren Jahren hatte man hier Skelette ausgegraben, ${ }^{44}$ weshalb wir auch bei den diesjährigen Leitungsarbeiten vor Ort waren. Bei mehreren Bodeneingriffen konnten insgesamt 23 Skelette freigelegt werden. Beim Chorhaupt, direkt unter dem modernen Pflaster, lag über einem erwachsenen Individuum ein von weissem Kalkpulver umgebenes Kinderskelett. Holzreste und Sargnägel zeugen davon, dass das verstorbene Kind in einem Holzsarg bestattet worden war. Weiter westlich davon, vor der Südmauer des Kirchenchors, konnten im Bereich des Laienfriedhofs 21 weitere Skelette geborgen werden. Diese lagen bereits 1,5 m unter dem aktuellen Bodenniveau, da das natürliche Gelände gegen den Rhein hin deutlich absinkt und dieser Bereich nach Aufgabe des Friedhofs aufgeschüttet worden ist.

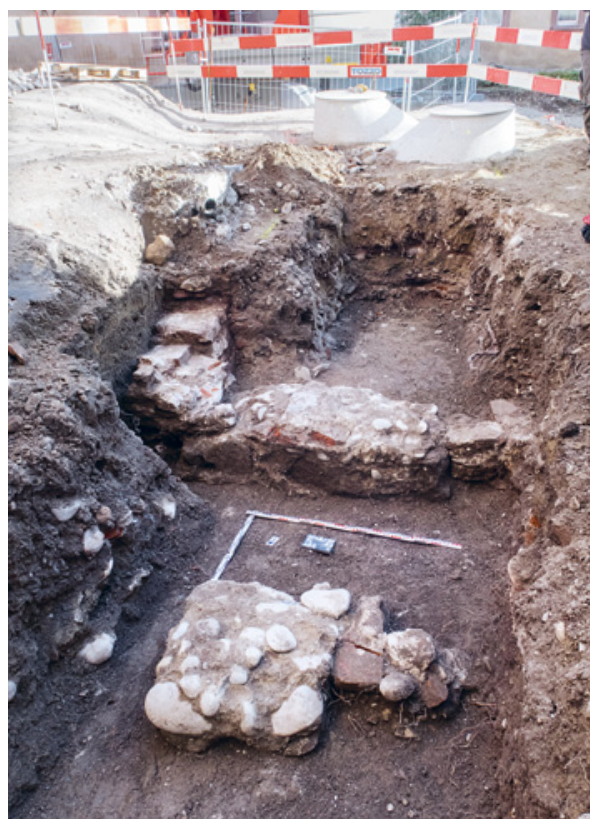

ABB. 20 Der nördliche Abschluss eines Gebäudes am Klingentalweglein. Unten im Bild ein quadratisches Pfeilerfundament. Foto: Roman Schmidig.

\section{9/1}

\section{MARKTPLATZ (A) 2-11}

Anlass: Bau einer Wasser- und Stromleitung, Erneuerung der Pflästerung

Zeitstellung: Mittelalter, Neuzeit

Untersuchungsdauer: Januar bis Oktober 2019

Verantwortlich: Johann Savary, Fabian Bubendorf

Text: Johann Savary

Die Verlegung von neuen Wasser- und Stromleitungen sowie die Erneuerung der Pflästerung auf dem Marktplatz fanden in verschiedenen Etappen statt, um den Marktbetrieb weiterhin zu ermöglichen. Die baubegleitenden Arbeiten der Archäologischen Bodenforschung führten dabei zu einer umfangreichen Dokumentation. An der südöstlichen Ecke des Platzes - dieser machte im Mittelalter unter der Bezeichnung «Kornmarkt» nur ein Sechstel der heutigen Grösse aus - kamen unter anderem Überreste einer mittelalterlichen Häuserzeile zum Vorschein. Die Gebäude waren offensichtlich Opfer eines Brandes geworden, bei dem es sich möglicherweise um den aus den historischen Quellen bekannten Brand von 1377 handelt. Gefasst werden konnte auch eine Häuserzeile, welche die nördlichen zwei Drittel des aktuellen Platzes in Anspruch nimmt, darunter Reste der «alten Schol», das heisst des grossen, über dem Birsig gelegenen Schlachthauses. Besonders erwähnenswert ist zudem ein aus dem mittelalterlichen Bauschutt geborgenes Metallobjekt, bei dem es sich mit grosser Wahrscheinlichkeit um einen Münzstempel handelt.

Einen ausführlichen Überblick zu den Ergebnissen der Ausgrabung am Marktplatz bietet die Coverstory im vorliegenden Jahresbericht. 


\section{$2019 / 3$}

\section{STEINENBERG (A) / ELISABETHENSTRASSE (A)}

Anlass: Verlegung eines Fernwärme-Hausanschlusses

\begin{tabular}{l} 
Zeitstellung: Mittelalter, Neuzeit \\
\hline Untersuchungsdauer: Januar bis September 2019 \\
\hline Verantwortlich: Martin Allemann \\
Text: Simon Graber, Martin Allemann
\end{tabular}

Im Zusammenhang mit der Verlegung einer neuen Fernwärmeleitung kam beim Kassieren alter Leitungen im Bereich der Kreuzung beim Bankverein (АВB. 21) an zwei Stellen die Kontermauer der inneren Stadtbefestigung zum Vorschein. ${ }^{45}$ Die Mauer war hier von der alten Leitung durchschlagen worden, doch konnten beide Abbruchstümpfe auf bis zu 1,5 m Höhe beobachtet und dokumentiert werden. Grabenseitig besitzen sie eine sauber gesetzte Schale aus grösseren Sand- und Kalksteinquadern, landseitig eine Schale aus Bruchsteinen. Der Mauerkern aus Sand- und Kalksteinbruch sowie vereinzelten Geröllen ist mit viel Mörtel vergossen und lässt keine Lagen erkennen. Die insgesamt eher fundarme Verfüllung des Stadtgrabens bestand aus Schuttschichten im Wechsel mit recht homogenem, lehmigem Kies.

Die heute stark befahrene Kreuzung war auch in früheren Zeiten ein zentraler Verkehrsknotenpunkt: Durch den Aeschenschwibbogen gelangte man in die Stadt und erreichte über die Freie Strasse auf direktem Weg den Marktplatz. Entsprechend war dieser Bogen eines der wichtigsten und am häufigsten genutzten Stadttore.

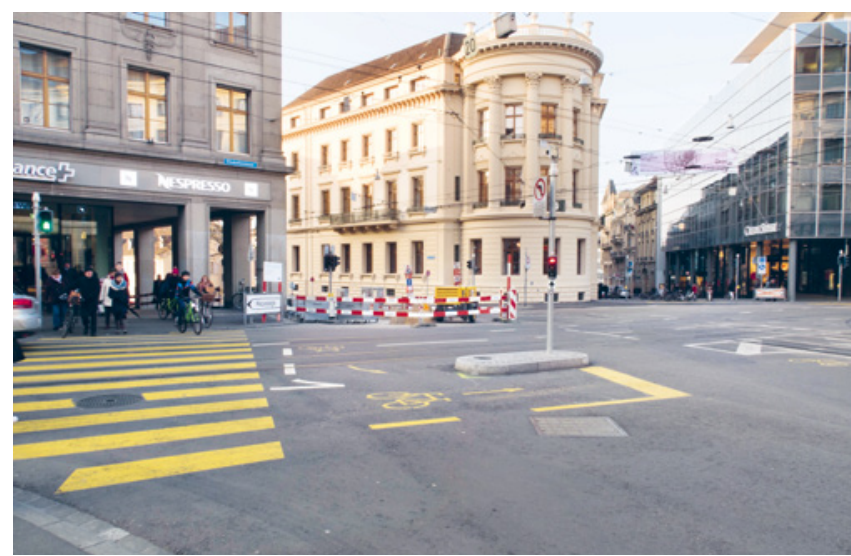

ABB. 21 Übersicht über die Kreuzung beim Bankverein, rechts am Eingang in die Freie Strasse stand einst der Aeschenschwibbogen. Die Kontermauer kam links hinter der Abschrankung zum Vorschein. Foto: Martin Allemann.

\section{9/10}

\section{STEINENGRABEN 30-36}

Anlass: Abbruch und Neubau Wohnhäuser

\section{Zeitstellung: Mittelalter}

Untersuchungsdauer: April bis September 2019

Verantwortlich: Martin Allemann, Benedikt Wyss

Text: Simon Graber

Der im Vorfeld umstrittene Abbruch der Wohnhäuser am Steinengraben und der Neubau durch die Helvetia Versicherung führten für die Archäologische Bodenforschung zu diversen baubegleitenden Einsätzen. Direkt unter der Fassade der Häuserreihe stand die spätmittelalterliche Kontermauer, die der Äusseren Stadtmauer gegenüberlag und den Stadtgraben befestigte. Die zwischen 1361 und 1398 errichtete äussere Stadtbefestigung ersetzte die durch das Erdbeben von 1356 in Mitleidenschaft gezogene Innere Stadtmauer und ging mit einer massgeblichen Erweiterung des Stadtgebietes einher. Der Mauerverlauf ist bekannt; und bereits in früheren Untersuchungen - auch in unmittelbarer Nachbarschaft zur Liegenschaft am Steinengraben - konnten Charakter und -aufbau der Kontermauer erforscht werden. ${ }^{46}$ Beim Bau von Werkleitungen in mehreren kleinen Abschnitten am Steinengraben war es zudem im Rahmen einer weiteren Massnahme im Berichtsjahr möglich, die Äussere Stadtmauer mitsamt der Kontermauer zu dokumentieren. ${ }^{47}$

Der neu untersuchte Mauerabschnitt stellt mit insgesamt 35,5 m Länge und 5,5 m Höhe bezüglich seiner Ausdehnung einen der grössten Aufschlüsse zur Kontermauer dar. Freigelegt wurde die Landseite der Mauer, das heisst nicht die ehemals sichtbare grabenseitige Wand, sondern die gegen das Erdreich gesetzte Rückseite (ABB. 23). Diese erscheint zwar weniger spektakulär, ist jedoch für die Rekonstruktion der Bauabläufe deutlich aussagekräftiger.

Zwischen den Abbruch-, Aushub- und Sicherungsarbeiten der Erne $A G^{48}$ wurde in 14 einzelnen Dokumentationsschritten eine Gesamtansicht der Mauer erstellt. Diese verfügt - trotz der hier verwendeten grob zugerichteten $\rightarrow$ 


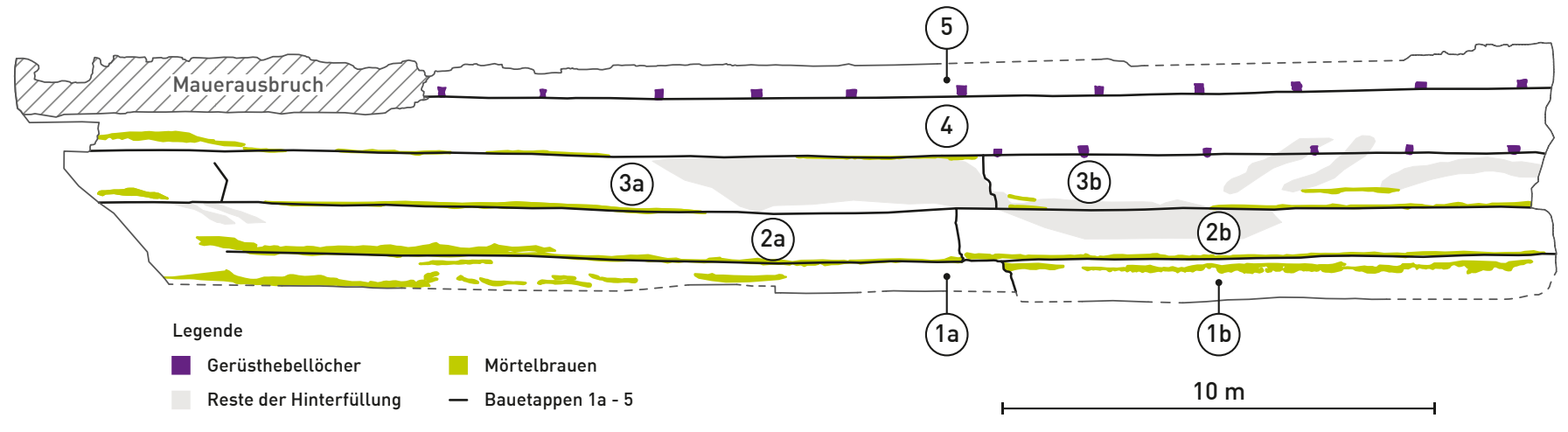

ABB. 22 Vereinfachte Profilansicht (Ostprofil) des ca. 35 m langen Ausschnitts der Kontermauer. Es zeigt die früher nicht sichtbare Rückseite, an der sich Anhaltspunkte zum Bauvorgang ablesen lassen. Massstab 1:200. Umzeichnung: Peter von Holzen.

Bruchsteine - über ein äusserst regelmässiges Erscheinungsbild. Dies ist den sauber versetzten Mauerlagen geschuldet, bestehend aus einer Schicht grob behauener Quader im Wechsel mit einer Ausgleichslage aus Geröllen. Die Etappen 1a/b zeigen eine grosse Menge an hervorquellendem Mörtel und wurden direkt gegen die Baugrubenwand gesetzt. Die darauf aufliegenden Etappen wurden in der Baugrube frei aufgemauert. Die ersten drei Etappen sind durch vertikale Baufugen unterteilt. In regelmässigen Abständen erscheinen deutliche Mörtelbrauen, die mit den horizontalen Baufugen beziehungsweise Etappengrenzen zusammenfallen und anzeigen, dass nach dem Fertigstellen einer Etappe das Mauerstück hinterfüllt wurde. Dort, wo den Etappenfugen die Mörtelbrauen fehlen, wurden Gerüsthebellöcher ausgespart. Die Hinterfüllung besteht aus sauberem Kies, wie er vor Ort

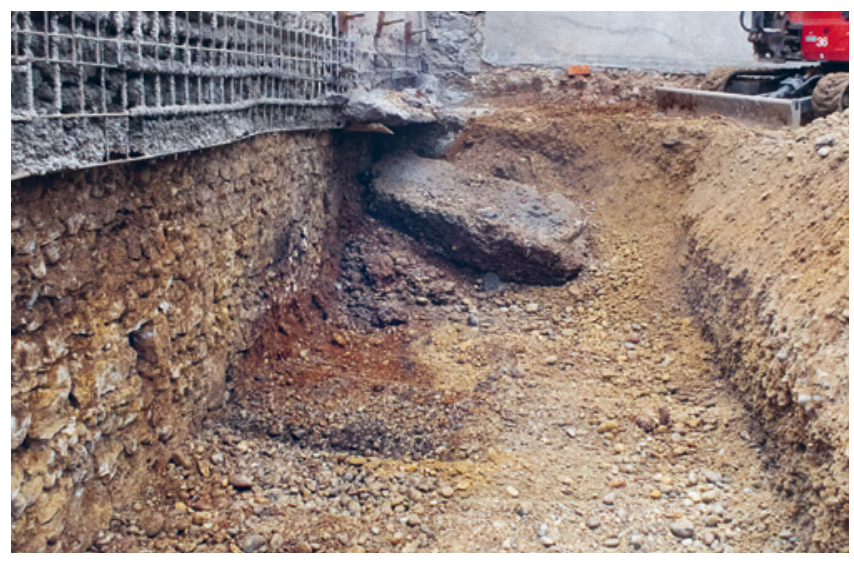

ABB. 23 Aushubarbeiten an der Kontermauer. Im oberen Bereich ist die Mauer mit Ankern und Spritzbeton gesichert, unten ist das regelmässige Mauerwerk sichtbar. Foto: Benedikt Wyss. ansteht. In wenigen Bereichen wurde aber auch dunkles, erdiges Füllmaterial verwendet, das als Schichtrest am Mauerwerk zurückgeblieben ist und dadurch Hinweise auf den Vorgang der Hinterfüllung gibt.

Anhand dieser Beobachtungen lässt sich der Bauvorgang rekonstruieren: Erst wurde die Etappe 1a gemauert und hinterfüllt, danach die Etappen 1b und 2a sowie 2b und 3a, schliesslich die Etappe 3b. Dieses sukzessive Vorgehen lässt sich unter anderem an den Resten der Hinterfüllung ablesen. Die Etappe 3b wurde nicht unmittelbar hinterfüllt, sondern es wurde ein Gerüst als Arbeitsplattform für die Etappe 4 errichtet. Die Etappe 5 schliesslich wurde auf ganzer Länge von einem Gerüst aus gemauert. Bei diesen letzten beiden Etappen lassen sich keine vertikalen Baufugen mehr erkennen, demzufolge umfassen sie nun längere Abschnitte (АВB. 22).

Anhand des Befundes ergeben sich weiterführende Überlegungen und Fragen: Lassen sich an den Etappengrenzen Jahreswechsel ablesen? Falls dies zuträfe - was sehr plausibel erscheint -, wäre am beobachteten Teilstück mindestens sechs Jahre lang gebaut worden. Zeigt das Einsetzen der Gerüsthebellöcher über der Etappe 3b, dass das Füllmaterial zeitweise knapp wurde oder dass es auf der Grossbaustelle andernorts dringender benötigt wurde? Oder sind die Etappen 3b, 4 und 5 nicht in einer Baugrube, sondern als frei aufgehendes Mauerwerk entstanden, wodurch das Gelände hinter der Kontermauer nach dem Errichten dieser Etappen um mehrere Meter angehoben worden wäre? Können mit den vertikalen Etappengrenzen eventuell einzelne Baulose gefasst werden? Um diese Fragen beantworten zu können, wären in einem grösseren Rahmen alle bisherigen Aufschlüsse zur äusseren Stadtbefestigung und insbesondere auch die Schriftquellen einzubeziehen. 


\section{9/12}

\section{STEINENGRABEN (A) IWB}

Anlass: Werkleitungen

\begin{tabular}{l} 
Zeitstellung: Mittelalter \\
\hline Untersuchungsdauer: Mai 2019 \\
Verantwortlich: Martin Allemann, Benedikt Wyss \\
Text: Simon Graber
\end{tabular}

Bei umfassenden Werkleitungssanierungen am Steinengraben konnte die Archäologische Bodenforschung die spätmittelalterliche Stadtbefestigung untersuchen (ABB. 24). Die neuen Leitungen liegen im Bereich des Stadtgrabens, der im 19. Jahrhundert verfüllt wurde; die Hausanschlüsse queren jeweils die Äussere Stadtmauer oder deren Kontermauer.

Zu klären waren Verlauf und Erhaltung der Mauerwerke. Im Abschnitt am Steinengraben liess sich die Stadtbefestigung in der Vergangenheit bereits mehrfach untersuchen, wobei Teile der Äusseren Stadtmauer ${ }^{49}$ beziehungsweise der Kontermauer ${ }^{50}$ beobachtet wurden (ABB. 25). Die in dieser Fundchronik ebenfalls besprochene Grabung 2019/10 zeigt, dass sich die Erforschung dieses Bauwerks durchaus lohnt und zu neuen Fragen führt, deren Klärung allerdings nicht nur eine Gesamtschau aller bekannten Befunde, sondern auch die Aufnahme der noch nicht erforschten Abschnitte erfordern würde.

An der Errichtung der Äusseren Stadtmauer wurde mit Unterbrüchen von 1361 bis 1398 gearbeitet. Sie umfasste die Vorstädte und weiterhin landwirtschaftlich genutzte Grünflächen, die grosszügige Reserven für das weitere Wachstum der Stadt bildeten. ${ }^{51}$ Der äussere Befestigungsring ersetzte wehrtechnisch die um 1230 erbaute Innere Stadtmauer, die jedoch bestehen blieb und allmählich in neu entstehende Gebäude integriert wurde. Ein Zusammenhang zwischen dem Bau der neuen Stadtmauer ab 1361 und dem Erdbeben von 1356 scheint naheliegend. Da es sich nicht um eine Sanierung beziehungsweise um die Wiederherstellung des status quo ante, sondern um die zusätzliche Fortifikation der bis dahin von der Ringmauer nicht umschlossenen Vorstädte handelt, ist der direkte Zusammenhang im Detail jedoch unklar und quellenmässig nicht belegt.
Zur Äusseren Stadtmauer gibt es historisches Bild- und Planmaterial: einerseits den Merianplan von 1615 und andererseits vier nicht realisierte Entwürfe des elsässischen Festungsbaumeisters und Kartographen Daniel Specklin (15361589) für eine zeitgemässe Stadtbefestigung von $1588 .{ }^{52}$ Letztere zeigen jene Teile der spätmittelalterlichen Befestigung, welche in die geplante Anlage hätten integriert werden sollen. Im Abschnitt am Steinengraben ragten demnach einst drei Türme empor. Während der mittlere Turm archäologisch belegt ist, ${ }^{53}$ liessen sich der nördliche und der südliche Turm bisher nicht lokalisieren.

In den Leitungsgräben konnte über eine grosse Distanz hinweg insgesamt fünfmal die Stadtmauer und ebenso oft die Kontermauer beobachtet und dokumentiert werden. ${ }^{54}$ Turmfundamente kamen keine zu Tage, obschon zwei Hausanschlüsse in einem Bereich lagen, wo bislang der Standort des nördlichen Turms am Steinengraben angenommen wird. Einige wenige Funde aus der Grabenverfüllung stammen aus dem 19. Jahrhundert.
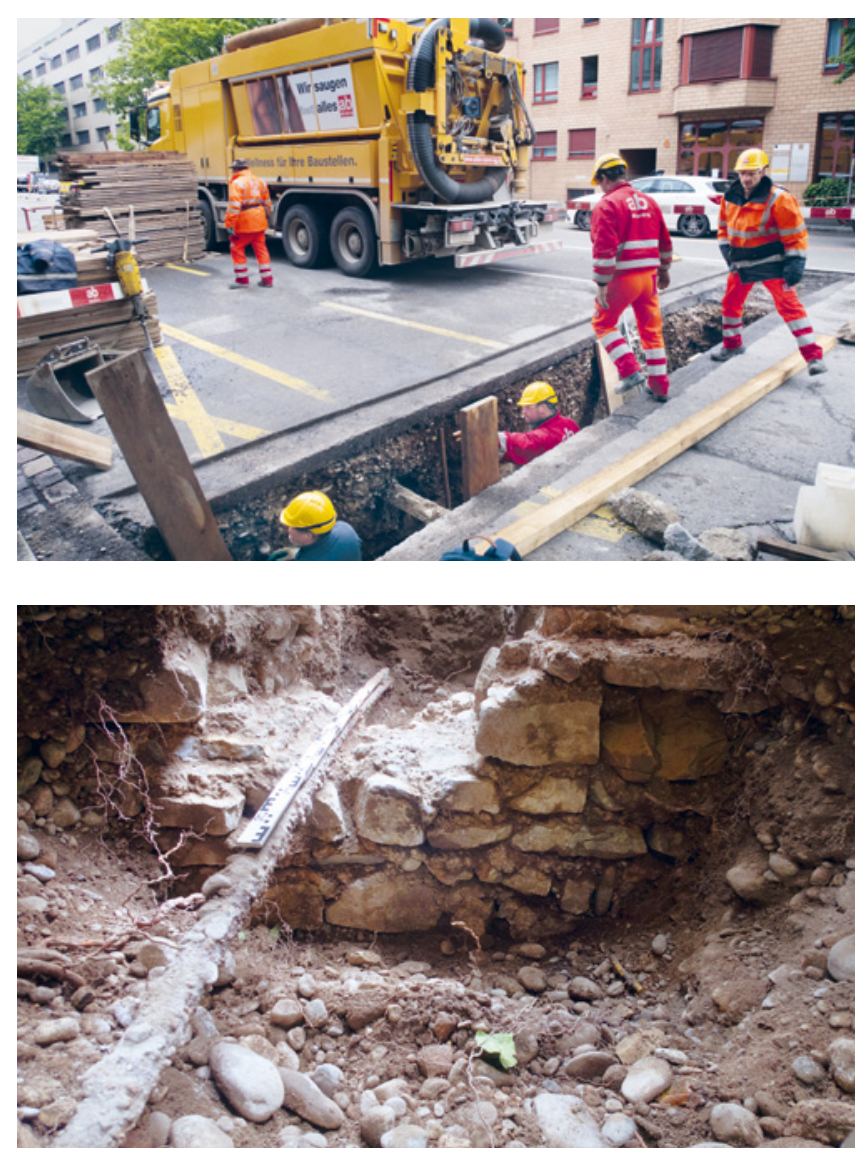

ABB. 24 Übersicht über die Baustelle: Das Trassee der Werkleitung quert den Steinengraben, an dessen Stelle sich ursprünglich der im 19. Jahrhundert aufgefüllte Stadtgraben befand. Foto: Martin Allemann.

ABB. 25 Ansicht der Äusseren Stadtmauer, die von einem alten Hausanschluss durchbrochen wird. Sichtbar ist die stadtseitige Mauerschale. Foto: Martin Allemann. 


\section{9/20}

\section{SÄGERGÄSSLEIN 2, 4 / UNTERE RHEINGASSE 12}

Anlass: Umbau und Sanierung

Zeitstellung: Mittelalter, Neuzeit

Untersuchungsdauer: August 2019

Verantwortlich: Sven Billo, Roman Schmidig

Text: Sven Billo

Bereits seit mehreren Jahren wird im bekannten Kleinbasler Lokal «Zer Alte Schmitti» mit unterschiedlicher Intensität umgebaut und saniert. ${ }^{55}$ Das Projekt wird von der Denkmalpflege eng begleitet. ${ }^{56}$ Da mehrere Bodenniveaus im Keller und im Erdgeschoss abgesenkt werden sollten, wurde im August 2019 eine baubegleitende Untersuchung der Archäologischen Bodenforschung nötig. ${ }^{57}$

Bereits auf Basis kleinerer Untersuchungen der Denkmalpflege um die Jahrtausendwende vermutete man im Bereich des Hauses Sägergässlein 4 einen Kernbau aus dem 13. Jahrhundert. ${ }^{58}$ Dieser konnte nun während der aktuellen Untersuchungen der Denkmalpflege und der Archäologischen Bodenforschung eindeutig gefasst und dokumentiert werden. Dabei handelt es sich um einen annähernd quadratischen Steinbau mit einer Seitenlänge von ca. 8,5 m. Das Gebäude gehört zu den ersten Häusern, die nach dem Bau der Rheinbrücke um 1225 im Zentrum des heutigen Kleinbasel entstanden sind. Schriftlich fassbar wird es erstmals 1323 als Haus «Ze Waltzhut». ${ }^{59}$

Bei der aktuellen Untersuchung wurde der Abbruch eines modernen Betonbodens und eines neuzeitlichen Tonplattenbodens innerhalb des Kernbaus begleitet. Unter den beiden Böden kam eine Rollierung aus Rheinwacken zum Vorschein, die aufgrund der angestrebten Bodenhöhe ebenfalls abgetragen werden musste. Die Rollierung lag auf einem Mörtelestrich auf, der sich über den gesamten Kernbau er-

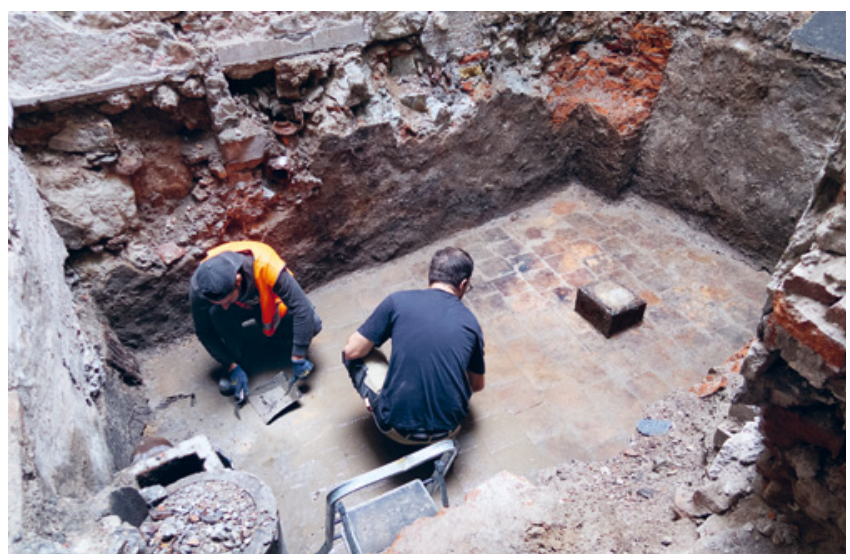

ABB. 26 Mitarbeiter der Bodenforschung legen einen neuzeitlichen Tonplattenboden im Hof unter den ehemaligen Toiletten frei. Foto: Benedikt Wyss. streckte. Dies ist insofern bemerkenswert, als dass das Haus 1413 längs geteilt worden war: Der nördliche Teil des Gebäudes hiess ab diesem Zeitpunkt «Zum Unteren Waldshut», der südliche «Zum Oberen Waldshut». Diese Zweiteilung lässt sich an der noch bestehenden Kellermauer ablesen, die quer durch den Kernbau verläuft. Da der Mörtelestrich unter der Mauer hindurchzieht, muss er vor der Teilung - vermutlich im 14. Jahrhundert - angelegt worden sein. Ob ein Brandfleck auf dem Mörtelboden mit dem Stadtbrand von 1354 oder dem Erdbeben von 1356 in Verbindung gebracht werden kann, lässt sich nicht eindeutig entscheiden. Auffällig ist jedenfalls, dass er sich in derselben Hausecke befindet, in der die Denkmalpflege aufgrund von Verfärbungen im Mauerwerk ebendiese Ereignisse fassen konnte. ${ }^{60}$ Dank einer Anpassung der ursprünglich geplanten Raumhöhe bleibt dieser alte Boden aus der Frühzeit Kleinbasels unter der neuen Betonbodenplatte erhalten.

Das Bauprojekt machte ausserdem zusätzliche Eingriffe in zwei an den Kernbau angrenzenden Bereichen notwendig: Der Kellerboden wurde nicht nur innerhalb des Kernbaus abgesenkt, sondern auch vor dem Kernbau in Richtung Untere Rheingasse. Dort kann ein mittelalterliches Holzgebäude angenommen werden, welches in diesem Fall einem gängigen Bautypus der Wohnhäuser des 12./13. Jahrhunderts entspräche; zudem lässt eine Kellertür mit Spitzbogen in diesem Bereich einen Abgang vermuten. ${ }^{61}$ Leider konnte keines von beidem archäologisch nachgewiesen werden, vermutlich war das Bodenniveau an dieser Stelle bereits zu stark abgetragen. Aufgeschlossen wurden lediglich der typische gelbe Hochflutsand sowie moderne Kanalisationsleitungen.

Die letzte Untersuchung fand im östlichen Hof in Richtung Sägergässlein 6 statt. Nachdem die modernen Toilettenkabinen - auf dem Hof befand sich wohl spätestens ab dem 19. Jahrhundert eine Latrine - abgebrochen und der Bauschutt abgetragen worden war, kam ein Tonplattenboden zu Tage (AвB. 26). Der Boden aus Platten in der Grösse von $20 \times$ $20 \mathrm{~cm}$ dürfte zwischen dem 16. und 19. Jahrhundert entstanden sein und musste dem neuen Liftschacht weichen, welcher bis in den Hochflutsand hinunterreicht. 


\section{9/22}

\section{PETERSGRABEN (A) 1 / BLUMENRAIN (A) 25}

Anlass: Leitungserneuerung

\begin{tabular}{l} 
Zeitstellung: Neuzeit \\
\hline Untersuchungsdauer: August 2019 \\
\hline Verantwortlich: Susan Steiner \\
\hline Text: Susan Steiner
\end{tabular}

Auch ein unscheinbarer Mauerrest kann stadthistorisch von Interesse sein - dies zeigte der Einblick in einen kleinen Leitungsgraben am unteren Ende des Petersgrabens. Zwischen zahlreichen Leitungen war nur wenige Meter nördlich der Hausnummer Petersgraben 1 unter dem Trottoir ein 1,4 m langes Mauerstück erhalten geblieben. Um einen Teil der Stadtbefestigung handelt es sich nicht, da die Mauer mit $50 \mathrm{~cm}$ Breite dafür zu schmal war und zudem im Grabenbereich zwischen der Inneren Stadtmauer und ihrer Kontermauer lag. ${ }^{62}$ Nachdem der Stadtgraben in diesem Bereich des Petersgrabens 1806 aufgefüllt worden war, wurde hier ein Garten angelegt, der von der Strasse durch eine niedrige Mauer getrennt war. Die Gartenanlage - und damit das Mauerstück - gehörte zur Einfriedung des Gebäudekomplexes an der Ecke Petersgraben/Blumenrain, dem ehemaligen Erimanshof (ABB. 27). ${ }^{63}$

Für eine Gartenmauer zeigt dieses Mauerstück bis weit hinunter einen erstaunlich einheitlichen Aufbau aus relativ regelmässigen und qualitativ guten Kalksteinquadern. Möglicherweise wurden hier Steine der Stadtmauer wiederver-

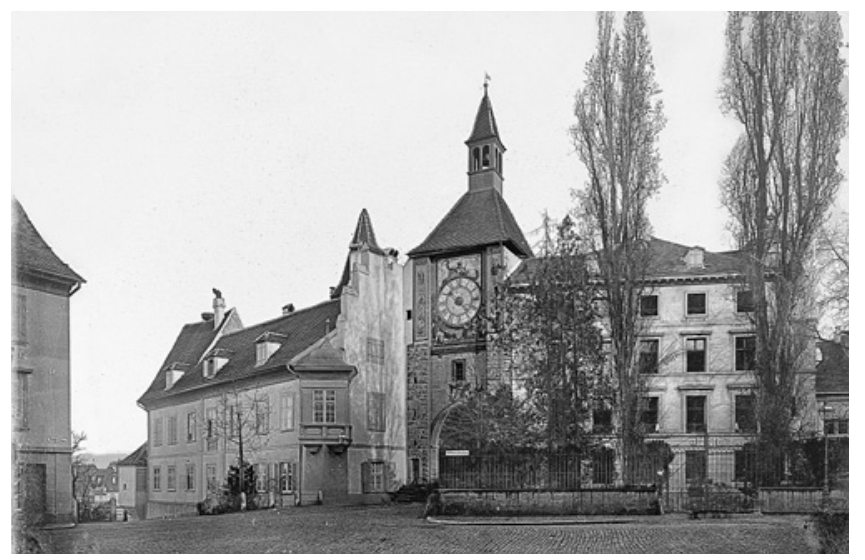

ABB. 27 Ansicht um 1870 mit dem St. Johannschwibbogen, dem heute noch bestehenden Seidenhof links und rechts dem Erimanshof mit der Umfassungsmauer, von der ein Stück aufgedeckt wurde. Foto: StABS NEG 01389 wendet. An der grundstückseitigen Mauerseite ist ein Versatz zu sehen, der rund $50 \mathrm{~cm}$ unterhalb des heutigen Strassenniveaus liegt. Es handelt sich um eine minime Neuausrichtung des Mauerverlaufs nach einigen bereits vermauerten Steinlagen. Falls diese kleine Korrektur nach der Fertigstellung des Fundaments erfolgt sein sollte, könnte daraus zu schliessen sein, dass das Gehniveau in diesem Bereich des Petersgrabens in der ersten Hälfte des 19. Jahrhunderts bis zu 0,5 m unter dem heutigen Niveau des Trottoirs lag.

\section{9/23}

\section{PETERSPLATZ (A) 1}

Anlass: Leitungserneuerung

\section{Zeitstellung: Neuzeit}

Untersuchungsdauer: August 2019

Verantwortlich: Susan Steiner

Text: Susan Steiner

Im Gegensatz zu anderen Parkanlagen in Basel hat der Petersplatz nie als Friedhof gedient. Historisch ist über den Platz kaum etwas bekannt, so dass auch ein kleiner Ausschnitt eines Leitungsgrabens am südlichen Rand des Petersplatzes für die Archäologie von Bedeutung war (ABB. 28).

Die Geschichte des benachbarten Areals, auf dem heute das Kollegienhaus der Universität steht, lässt sich dagegen bis ins Mittelalter zurückverfolgen. Unter dem Nordflügel des Universitätsgebäudes befand sich - möglicherweise bereits im 11. Jahrhundert - der Friedhof der ersten Jüdischen Gemeinde. Nach der Vernichtung und Vertreibung der in Basel ansässigen Jüdinnen und Juden im Jahr 1349 wurde auch der Friedhof zerstört. Anschliessend nutzte man das Gelände als Werkhof. Das 1438 errichtete Korn- und Zeughaus musste dann 1937 dem heutigen Kollegiengebäude weichen. ${ }^{64}$

Der kleine Leitungsgraben lag nur $2 \mathrm{~m}$ vom Kollegienhaus entfernt und zeigte bis zur 1,1 m tiefen Sohle Profilaufschlüsse, die trotz der Leitungseinbauten im Süden und teilweise im Osten noch ungestört vorlagen. Es konnten dunkle, graubraune Lehmschichten mit Kies, Ziegelresten sowie einzelnen Knochenstücken und zwei neuzeitlichen Keramikfragmenten beobachtet werden. In den Profilschichten zeigte sich ein mörtelhaltiges Kiesband, das in einer Mächtigkeit von bis zu $6 \mathrm{~cm}$ erhalten war und gegen Westen auslief. Dieses Mörtelband stellt möglichweise den Rest eines ehemaligen Laufhorizonts dar, vielleicht in Zusammenhang mit einem Bauplatz. Oberhalb der mörtelhaltigen Kieselschicht waren rötlich verbrannte Lehmstücke zu sehen, entweder Reste $\rightarrow$ 
eines Feuerplatzes oder von verbranntem Abbruchmaterial möglicherweise Relikte der Sprengung des alten Zeughauses. ${ }^{65}$

Insgesamt handelt es sich vermutlich um neuzeitlichen Abbruchschutt. Er stammt am ehesten vom alten Korn- und Zeughaus, das im Viertel zwischen Petersgraben, Petersplatz, Spalengraben und sogenanntem Vesalianum an der Vesalgasse stand (АВв. 29). Das mörtelhaltige Kiesband spricht dafür, dass sich der untersuchte Leitungsgraben innerhalb der ehemaligen Baustelle für das Kollegiengebäude der Universität Basel befand.
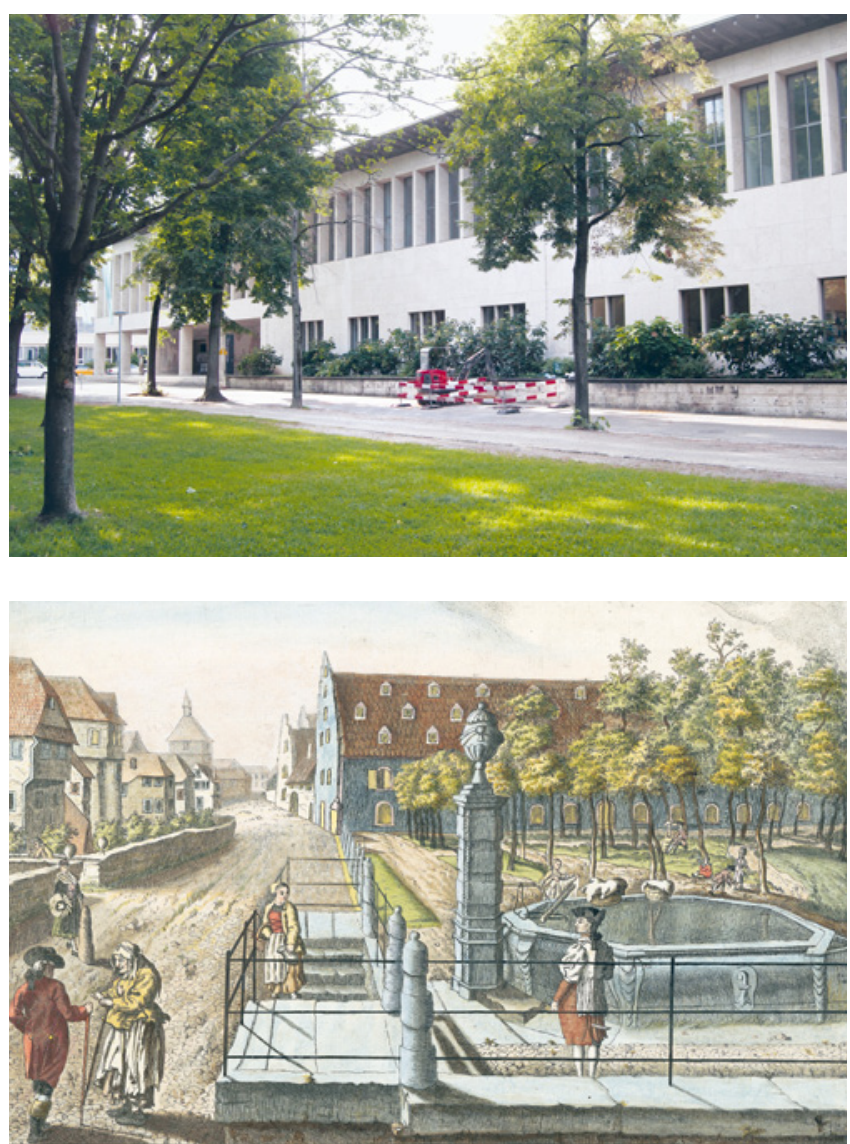

ABB. 28 Der Leitungsgraben war knapp $2,5 \mathrm{~m}^{2}$ gross und befand sich im Süden des Petersplatzes, unmittelbar vor der Rabatte, die das Kollegiengebäude umgibt. Im Profil kam direkt unter der Pflästerung brandgeröteter Lehm zum Vorschein. Foto: Susan Steiner.

ABB. 29 Petersgraben und Petersplatz, im Hintergrund das grosse, blau gestrichene Zeughausgebäude. Kolorierte Radierung von Reinhardt Keller, 1788. Bild: StABS, BILD Falk. A 155

\section{9/25}

\section{RHEIN (A), HÖHE BLUMENRAIN (SEIDENHOF)}

Anlass: Flussfund

Zeitstellung: Neuzeit

Untersuchungsdauer: August 2019

Verantwortlich: Martin Allemann

Text: Martin Allemann

Bei Flussfunden ist der Übergang von Zivilisationsmüll über moderne Wertsachen zu archäologisch bedeutsamen Objekten eher fliessend. Bisweilen finden sich auch bei Putzaktionen ältere oder unbekannte Objekte, die in die Zuständigkeit der Archäologischen Bodenforschung fallen. In vorbildlicher Weise informierten Joshua und Jonathan Steck, die zusammen mit ihrer Schwester oft schwimmend den Rhein von Müll befreien, die Archäologische Bodenforschung, als sie immer wieder an ein und derselben Stelle - einer Spalte neben einer grossen Steinplatte unterhalb des Seidenhofes beim Blumenrain - insgesamt sieben gleichartige Keramikschälchen fanden (АВB. ${ }^{301}{ }^{66}$ Der Fund ist insofern speziell, als dass damit eine Konzentration identischer Objekte an einem einzigen Ort belegt ist, so dass quasi von einer «Fundstelle» und nicht nur von einem «Einzelfund» gesprochen werden kann. Bei den Keramikschalen handelt es sich vermutlich um neuzeitliche Gefässe, möglicherweise aus dem Bereich der Pharmazie. ${ }^{67}$ Unklar ist, wie die Schalen an diese Stelle am Rheinbord gelangten.

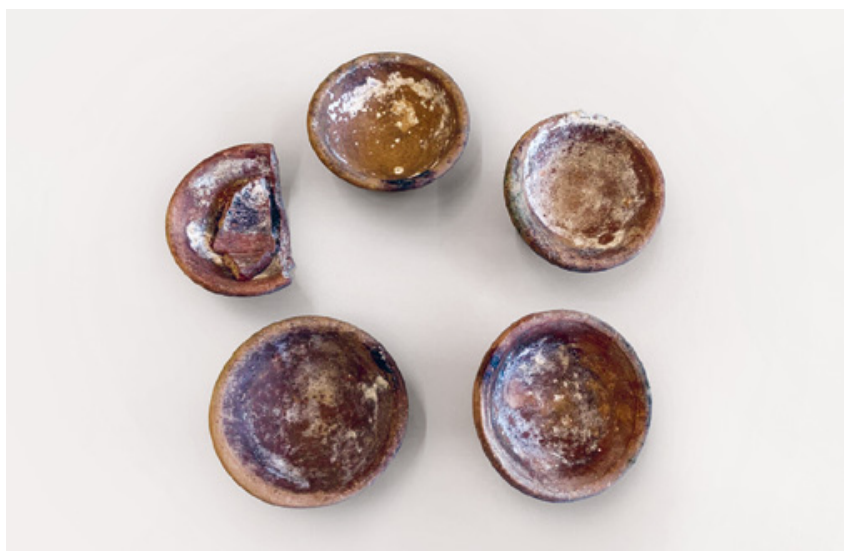

ABB. 30 Fünf der sieben Keramikschälchen. Für metallurgische Laborkeramik weisen sie zu schwache Hitzespuren auf, zeigen aber gleichzeitig weisse, schwammig-wachsartige Rückstände, die für Lämpchen unüblich sind. Ihre Form weicht von derjenigen der meisten anderen Lämpchen ab. Foto: Frank Fässler 


\section{9/31}

\section{KLINGENTALWEGLEIN (A)}

Anlass: Neugestaltung Klingentalweglein, Werkleitungsbauten

Zeitstellung: Mittelalter, Neuzeit

Untersuchungsdauer: September bis Oktober 2019

Verantwortlich: Roman Schmidig, Sven Billo

Text: Roman Schmidig

Im Rahmen der Neugestaltung des Kasernenareals ${ }^{68}$ wurden das Kopfsteinpflaster des Klingentalwegleins sowie die Treppe zum Unteren Rheinweg entfernt, um einen stufenlosen Durchgang zu schaffen. Dabei musste ein Teil des Klingentalwegleins leicht abgesenkt werden. Da auf alten Plänen an dieser Stelle einige heute nicht mehr vorhandene Gebäude eingezeichnet sind, ${ }^{69}$ wurden die Bauarbeiten von der Archäologischen Bodenforschung begleitet. ${ }^{70}$

Gleich zu Beginn kamen die Reste eines Anbaus am Brüderhaus des Kleinen Klingentals, welches die Gebäude südlich der Klingentalkirche umfasst, zum Vorschein. Es handelt sich um einen Befund, der schon bei einer Grabung im Jahr 2008 freigelegt wurde, damals jedoch nicht vollständig sichtbar war. ${ }^{71}$ Da die Zerstörung des gesamten noch vorhandenen Befundes drohte, dokumentierten wir inn nochmals als Ganzes. Es stellte sich heraus, dass die bereits bekannten Mauern und der Plattenboden, in dessen nordöstlichem Bereich nebst quadratischen Tonplatten auch rechteckige Backsteine liegen, noch bis zu 2 m nach Norden weiterziehen und dann durch einen modernen Eingriff gestört werden. Die nördliche Abschlussmauer war jedoch gerade noch im Ansatz vorhanden, so dass der Grundriss rekonstruiert werden kann. Eine quadratische, in den Plattenboden eingelassene und mit Buntsandsteinen eingefasste Vertiefung war komplett mit Bauschutt verfüllt. Nach deren Freilegung zeigte sich, dass eine Stufe auf eine tiefere Ebene mit Mörtelboden hinabführt. Das kleine Gebäude könnte eines der Querbauten auf dem Merianplan von 1615 sein. Es erscheint noch auf dem Falknerplan und wurde demnach erst in der zweiten Hälfte des 19. Jahrhunderts abgebrochen.

Ein Wasser-Hausanschluss weiter östlich, der vom Klingentalweglein zum Kirchenchor hin verlegt wurde, durchschnitt ein parallel zur Klingentalkirche verlaufendes Fundament. Dieses gehört wohl zu der im 19. Jahrhundert abgebrochenen Katharinenkapelle. Das 1,2 m breite Mauerwerk konnte nur noch im Profil dokumentiert werden.

\section{$2019 / 32$}

\section{SPALENVORSTADT (A) 37}

Anlass: Erneuerung eines Wasser-Hausanschlusses

Zeitstellung: Mittelalter, Neuzeit

Untersuchungsdauer: September 2019

Verantwortlich: Martin Allemann

Text: Martin Allemann

Im Gegensatz zu grösseren Bauvorhaben erhält die Archäologische Bodenforschung nicht für jeden Hausanschluss automatisch ein Baugesuch. Eine solche nicht gemeldete Baustelle entdeckte ein Mitarbeiter der Archäologischen Bodenforschung zufällig vor dem Haus Spalenvorstadt 37, das heisst an einer archäologisch sensiblen Stelle. Die Geschichte der Spalenvorstadt ist ab dem Zeitpunkt des Baus der Äusseren Stadtmauer in der zweiten Hälfte des 14. Jahrhunderts, in deren Zusammenhang auch das Spalentor entstand, gut bekannt. ${ }^{72}$ Weniger weiss man hingegen über die Frühzeit der Vorstadt. Sicher ist jedoch, dass sie bereits über eine eigene Befestigung inklusive Toranlage verfügte.

Bei der am Folgetag durchgeführten Dokumentation, die ohne Behinderung der Arbeiten noch am selben Tag abgeschlossen werden konnte, ${ }^{73}$ liessen sich bis auf den kleinen Mauerrest einer abweichend verlaufenden Vorgängerfassade aber nur Leitungsstörungen beobachten. Da die heutige Fassadenflucht mit derjenigen des Falknerplans aus den 1860erJahren identisch ist, muss die angetroffene Mauer aus Kalkbruchstein, Backstein und Sandstein älter sein. Allerdings fällt es schwer, deren Abbruch anlässlich der Begradigung der Fassadenflucht zu datieren, da Strassen sehr häufig verbreitert und Fassadenfluchten immer wieder an geradere Baulinien angepasst wurden. 


\section{$2019 / 36$}

\section{SPALENGRABEN 8C (BOTANISCHER GARTEN)}

Anlass: Abbruch und Neubau des Tropenhauses

\section{Zeitstellung: Mittelalter}

Untersuchungsdauer: November bis Dezember 2019

Verantwortlich: Birgit Lißner, Benedikt Wyss

Text: Simon Graber, Martin Allemann

Der Neubau des Tropenhauses im Botanischen Garten führte zu grösseren Eingriffen ins Erdreich. In diesem Bereich waren die Kontermauer zur zwischen 1361 und 1398 errichteten Äusseren Stadtmauer ${ }^{74}$ und Gräber des zwischen 1825 und 1868 belegten Spalengottesackers zu erwarten.

Der Aushub tangierte glücklicherweise keine Gräber. Es konnte jedoch an mehreren Stellen die Stadtgrabenverfüllung beobachtet und ein knapp $6 \mathrm{~m}$ langes Teilstück der Kontermauer (АВв. 31) aufgenommen werden. ${ }^{75}$ Sie ist zweischalig, wobei grabenseitig Sandsteine und rückwärtig Gerölle und Kalkbruchsteine verbaut wurden, während der Mauerkern aus Geröllen und Kalksteinbruch besteht. Damit zeigt sie das bekannte, andernorts gesicherte Bild. Erstaunlich ist, wie gleichmässig das Bauwerk der Äusseren Stadtmauer angesichts einer Bauzeit von über 40 Jahren und einer Länge von 4,1 km erscheint. Mit dem Einsatz im Botanischen Garten konnten Verlauf und Machart der Kontermauer verifiziert werden. ${ }^{76}$

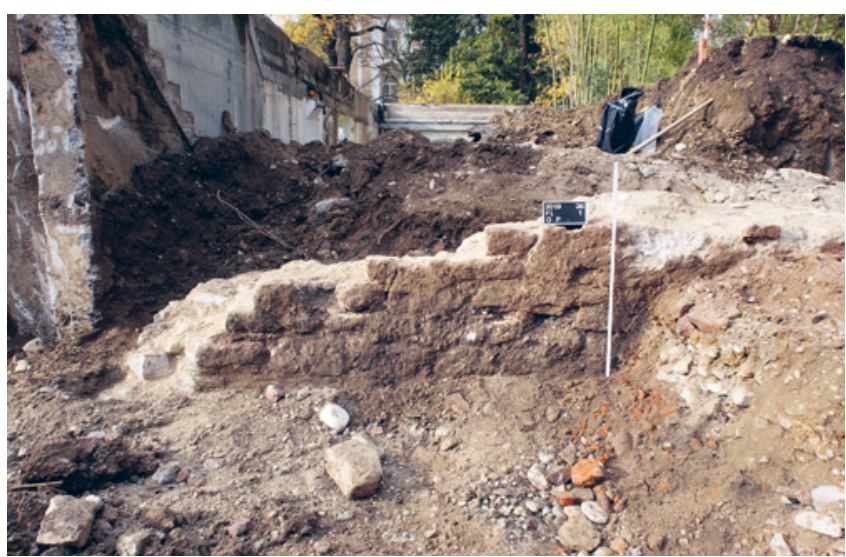

ABB. 31 Im Bereich des heutigen botanischen Gartens konnte ein ca. 6 m langes Teilstück der Kontermauer aufgedeckt werden. Foto: Birgit Lißner

\section{9/39}

\section{LEONHARDSSTRASSE 6}

Anlass: Umbau des kleinen Musiksaals der Musikakademie

\begin{tabular}{l} 
Zeitstellung: Neuzeit \\
\hline Untersuchungsdauer: Dezember 2019 \\
\hline Verantwortlich: Martin Allemann, Birgit Lißner \\
\hline Text: Martin Allemann
\end{tabular}

Kurz vor Weihnachten wurde uns telefonisch mitgeteilt, dass bei einem Umbau in der Musikakademie ein altes Mauerstück aufgedeckt worden war. Innert weniger Stunden dokumentierten wir neben den weiter laufenden Bauarbeiten eine Mauer aus grossen Bruchquadern aus körnigem, gelblichem Kalkstein, die den kleinen Musiksaal der Länge nach schräg durchquerte. ${ }^{77}$ Ihre westliche Flanke, an die betonierte Becken neueren Datums stiessen, war verputzt, während die östliche Flanke gegen das Erdreich gemauert worden war. Es handelt sich also um die Kellermauer eines westlich anschliessenden Gebäudes: Der Bau stand - soweit ohne aufwendigere Nachforschungen zu eruieren war - ursprünglich im Garten des Hauses Leonhardsstrasse 4, gehörte als Hinterhaus vermutlich aber zu einem Haus am Leonhardsgraben. ${ }^{78}$ All diese ehemaligen Gartenparzellen zwischen der Inneren und der Äusseren Stadtmauer wurden im Verlauf des 18. und 19. Jahrhunderts mehrfach umorganisiert, geteilt und zusammengelegt. Häufige Nachbarschaftsstreitigkeiten taten ein Übriges, um zahlreiche Akten und sehr unübersichtliche historische Besitzverhältnisse zu hinterlassen. 


\section{AUSSENBEZIRKE/ BETTINGEN/RIEHEN}

\section{$2018 / 22$}

\section{HILTALINGERSTRASSE 68, 76}

Anlass: Rückbau Tanklager und Bodensanierung

Zeitstellung: Neuzeit
Untersuchungsdauer: August 2018 bis Juni 2019
Verantwortlich: Norbert Spichtig, Birgit Lißner
Text: Norbert Spichtig

Gegen Ende des 19. Jahrhunderts war der Kirchfriedhof von Kleinhüningen stark überbelegt, was vermutlich mit dem rasanten Bevölkerungszuwachs der damals noch eigenständigen Gemeinde zusammenhing. Deshalb musste 1882 ein neuer Friedhof auf freiem Feld an der Landesgrenze zu Deutschland angelegt werden. Er umfasste zunächst eine Fläche von weniger als $900 \mathrm{~m}^{2}$ mit der Sektion A für Erwachsene sowie den Sektionen a und b für grosse beziehungsweise kleine Kinder. Insgesamt waren fast 300 Grabplätze vorhanden. Nur zehn Jahre nach der Eröffnung dieses neuen Friedhofs musste er 1892 bereits deutlich erweitert werden: Es wurden die Sektionen B, C und D für Erwachsene, die Sektion c für Kinder unter einem Jahr und die Sektion d für Kinder bis zu 15 Jahren angelegt. Auf dem nun fast $2500 \mathrm{~m}^{2}$ grossen Areal wurde Raum für insgesamt 718 Grabplätze geschaffen, davon 368 für Kinder und 350 für Erwachsene. ${ }^{79}$ Anders als auf dem Kirchfriedhof wurden die Gräber streng in Reihen angeordnet (ABB. 32) , mit Normmassen der Grabplätze für Erwachsene, grosse beziehungsweise kleine Kinder ${ }^{80}$ Die Belegung folgte mit nur wenigen Ausnahmen - strikt der reihigen Anordnung. Im ältesten Teil des Friedhofs wurde nach mindestens 20-jähriger Liegezeit ein zweiter Turnus begonnen, das heisst, die bestehenden Gräber wurden aufgehoben und neue Bestattungen an den vorherigen Graborten vorgenommen. Die im Basler Staatsarchiv überlieferten Grabregister ${ }^{81}$ und Unterlagen lassen die lückenlose Identifikation der Verstorbenen für die Erstbelegung der Grabplätze für den Zeitraum von 1886 bis 1932 und teilweise auch für den zweiten Turnus im ältesten Friedhofareal zu. Neben der Grabnummer sind Name, Heimatort, Alter, Beerdigungsdatum, Wohngemeinde und teilweise -adresse, manchmal auch Konfession und andere Angaben verzeichnet. Infolge der Inbetriebnahme des zentralen Friedhofs Hörnli wurde in Kleinhüningen die letzte Bestattung am 20. Januar 1932 vorgenommen. Bis dahin dürften dort gegen 1000 Personen ihre letzte Ruhestätte gefunden haben.

Bereits in den 1950er-Jahren wurde das Gelände durch ein Tanklager überbaut, ${ }^{82}$ das 2018 im Hinblick auf eine geplante Neuüberbauung rückgebaut wurde. Im Vorfeld der anschliessenden Bodensanierung wurden Teile der Erwachsenen- und Kinderbezirke im Erweiterungsteil des Friedhofs in einer Rettungsgrabung untersucht (АВB. 33). ${ }^{83}$ In anderen $\rightarrow$
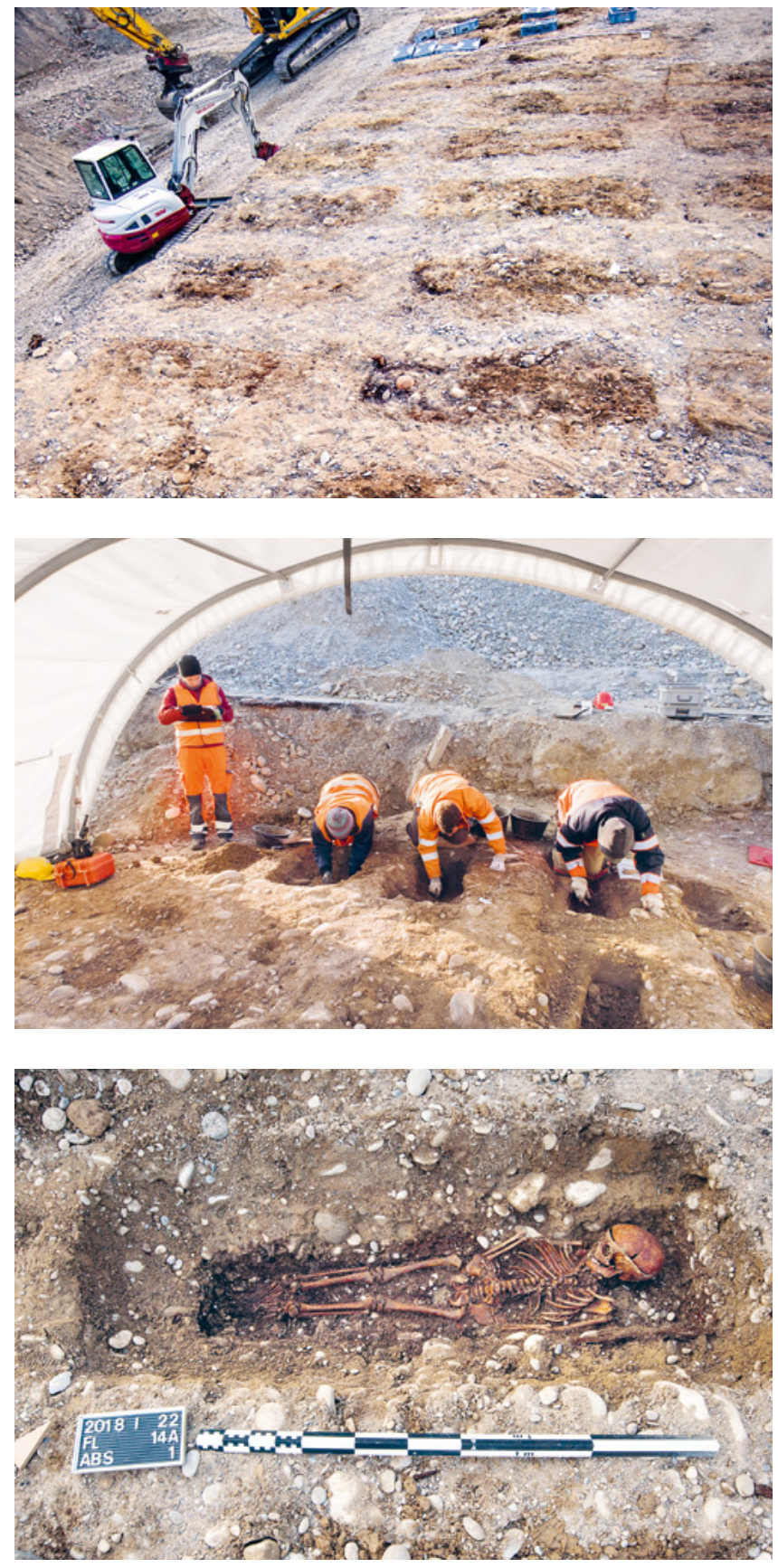

ABB. 32 Nach dem maschinellen Abtrag der modernen Überdeckung zeichnen sich die regelmässig angelegten Grabgrubenreihen ab. Foto: Birgit Lißner.

ABB. 33 Die in Reihen angeordneten Gräber werden sorgfältig ausgegraben und dokumentiert. Foto: Birgit Lißner.

ABB. 34 Die Toten wurden in Rückenlage oft mit den Händen auf dem Becken bestattet. Der aufgeschnittene Schädel lässt eine anatomische Sektion erkennen. Foto: Semira Ryser. 
Zonen wurden die Skelettreste zur Wiederbestattung auf dem Friedhof Hörnli freigegeben. ${ }^{84}$ Einzig ganz im Westen des Friedhofs könnten noch Bestattungen im Boden verblieben sein, falls sie nicht früheren Bodeneingriffen zum Opfer gefallen sind ${ }^{85}$

Insgesamt wurden 84 Gräber von Erwachsenen und Jugendlichen, 27 Kinderbestattungen und 25 Gräber von Kleinkindern (unter 1 Jahr) archäologisch erfasst (АВB. 35). Während in der Sektion D ein Grossteil der Bestattungen unterhalb der modernen Industrieeinbauten ganz oder zumindest teilweise erhalten geblieben war, erwies sich die Sektion $\mathrm{C}$ ebenfalls mit Erwachsenengräbern als massiv gestört. Auch in der Sektion d mit Kindern beziehungsweise Jugendlichen zwischen einem und 15 Jahren hatten zahlreiche jüngere Bodeneingriffe dazu geführt, dass viele Gräber ganz oder teilweise zerstört worden waren. Im ergrabenen Südostteil von Sektion c mit Kleinkindern unter einem Jahr beziehungsweise mit Totgeburten waren dagegen viele der Gräber zumindest in Teilen vorhanden, auch wenn die Skeletterhaltung sich oftmals als schlecht erwies.

In den nördlichen Sektionen des Gottesackers wurden die Toten mit dem Kopf im Norden bestattet, südlich davon gegengleich, so dass alle jeweils in Richtung des mittig durch den Friedhof führenden Zugangswegs blickten. Fast alle Verstorbenen sämtlicher Altersgruppen wurden in Rückenlage zur Ruhe gebettet; seitliche Lagerungen sind die Ausnahme. Die Hände wurden oftmals auf dem Becken zusammengelegt. Zahlreiche Holzreste, Nägel und Beschlagteile stammen von den Särgen. Manchmal zeugen Knöpfe oder Gewandhaken, gelegentlich auch Textilreste, von der ehemaligen Bekleidung.

Beigaben und Mitfunde sind eher selten: Zwölf Personen sicher oder wahrscheinlich katholischen Glaubens - darunter ein mit wenigen Monaten verstorbener Knabe - wurden Rosenkränze mitgegeben. Ansonsten fanden sich aber sowohl bei den Kleinstkindern als auch den älteren kaum bewusst beigegebene Objekte. Bei den Jugendlichen und Erwachsenen zeigt sich ein ähnliches Bild: Im Grab eines 1910 im Alter von 59 Jahren verstorbenen Mannes fand sich neben dem linken Unterschenkel ein Einräppler, der 1829 im Kanton Bern geprägt worden war. ${ }^{86}$ Beim rechten Ellbogen einer älteren Frau lag ein Fingerhut, der allgemein mit Hausarbeit oder einer beruflichen Tätigkeit in Verbindung gebracht werden könnte. Daneben fanden sich vereinzelt auch Fingerringe, zum Beispiel ein goldener Ehering mit den eingravierten Initialen des Ehemanns. ${ }^{87}$ In vier Gräbern zumeist älterer Frauen, die zwischen 1908 und 1911 verstorben waren, wurden künstliche Gebisse vermutlich aus Kautschuk ${ }^{88}$ gefunden, wobei dieser Zahnersatz in einem Fall bei den Füssen deponiert war.
Bei zwei Individuen wurde eine sichere beziehungsweise wahrscheinliche Amputation festgestellt: Bei einem 57-jährigen Seidenfärber war der linke Unterschenkel abgetrennt worden, wobei die Operationsstelle verwachsen war. Unklarer ist der Befund bei einer mit fast 50 Jahren verstorbenen Frau, deren linker Arm amputiert worden sein könnte. Bei 22 Individuen wurden postmortale Eingriffe in Form von Schädelöffnungen (Авв. 34) beziehungsweise bei fünf Toten zusätzlich aufgeschnittene Oberschenkelknochen festgestellt, die auf medizinische Obduktionen hinweisen. ${ }^{89}$

Bereits im Feld wurde eine erste anthropologische Aufnahme ohne Kenntnis der individuellen Daten aus den Sterberegistern durchgeführt. Allerdings wurde die Analyse, neben dem Zeitdruck, manchmal durch schlechte Knochenerhaltung und durch Einsickerungen von Brennstoffresten erschwert. Dennoch zeigt sich bei den Jugendlichen bis Erwachsenen durch den Abgleich mit den Sterberegistern, dass diese provisorischen Geschlechtsbestimmungen grossmehrheitlich zutreffen. Für wenige Individuen ab 16 Jahren konnten zudem etwas genauere Schätzungen der Spanne des erreichten Alters durchgeführt werden. Das tatsächliche Sterbealter, wie es quellenkundlich überliefert ist, liegt hier meist ebenfalls zwischen dem unteren und oberen Schätzwert. Weiter wurden bereits vereinzelt auch pathologische Veränderungen am Skelett erfasst.

Da die bestatteten Personen dank ihrer Anordnung in regelmässigen Reihen mittels Grabplänen und -registern identifiziert werden können, bilden die geborgenen Individuen eine herausragende Grundlage für anthropologische Methodenüberprüfungen beziehungsweise -weiterentwicklungen. Es geht also nicht darum, mittels anthropologischer Kriterien Alter, Geschlecht etc. eines unbekannten Individuums zu bestimmen, sondern umgekehrt zu überprüfen, wie gut anthropologische Analysen sind beziehungsweise auszuloten, wo und wie Verbesserungen erzielt werden können. Mittlerweile liegen im Kanton Basel-Stadt aus dem Spitalfriedhof St. Johann, ${ }^{90}$ aus dem Rosental-Gottesacker ${ }^{91}$ und nun aus Kleinhüningen archäologisch geborgene Bestattungen neuzeitlicher Datierung vor, die aufgrund von Schriftquellen identifiziert werden können. Dadurch wird es möglich, sie mit weiteren historischen Quellen zu verbinden. Dies eröffnet nicht nur das Feld für anthropologische beziehungsweise medizinische und medizinhistorische Fragestellungen, sondern beispielsweise auch für die Abklärungen der Lebensumstände anhand von Merkmalen am Skelett oder sozialhistorische Analysen. ${ }^{92}$ 


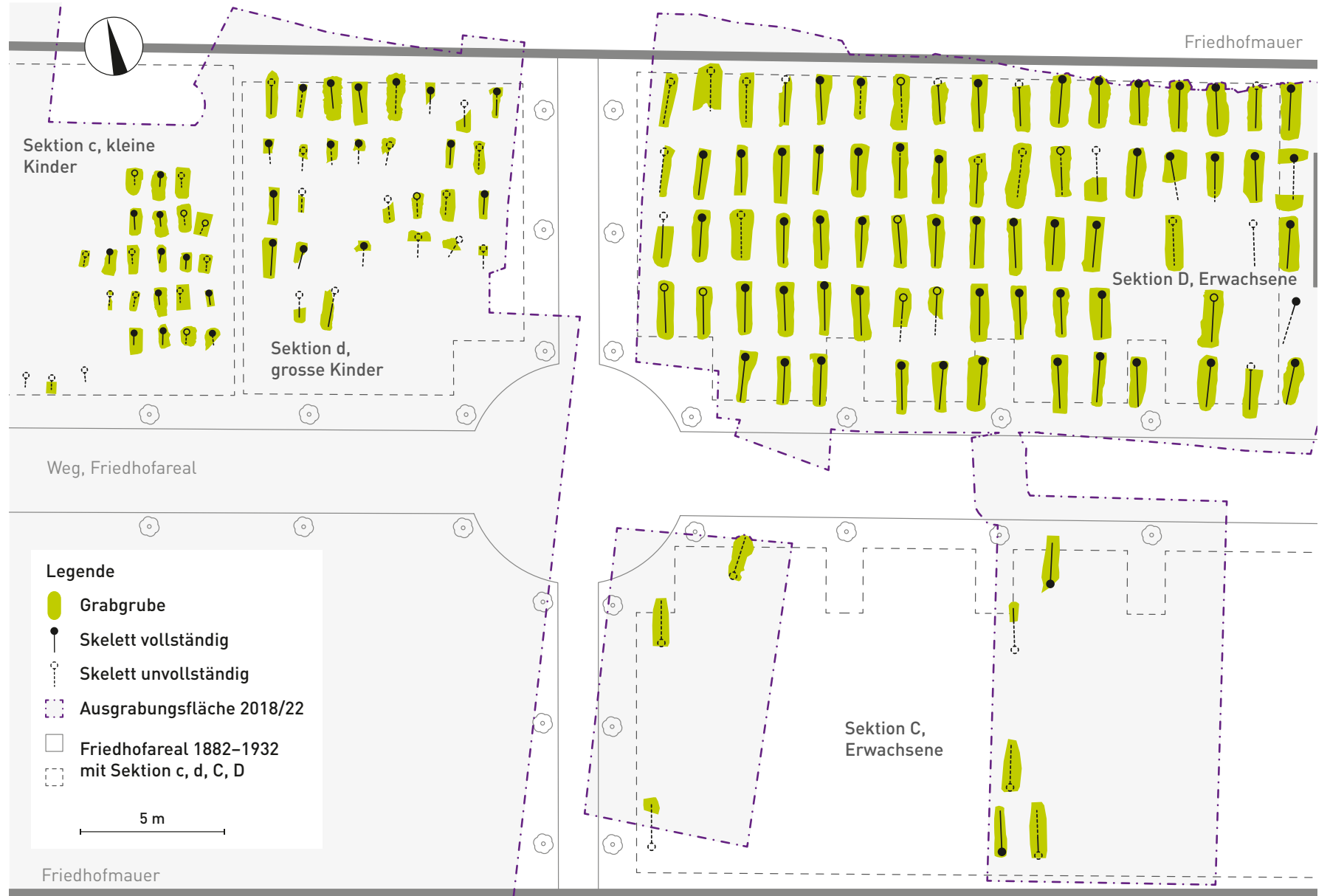

ABB. 35 Östlicher Teil des Friedhofs, der flächig ergraben

wurde. Die restlichen Bereiche sind modern gestört.

Planbearbeitung: Peter von Holzen. 


\section{9/4}

\section{MISSIONSSTRASSE 21B}

Anlass: Abbruch und Neubau im Gartenbereich

Zeitstellung: Geologie, Neuzeit

Untersuchungsdauer: Januar bis April 2019

Verantwortlich: Martin Allemann, Susan Steiner

Text: Martin Allemann, Susan Steiner

Ein geplanter Neubau im bisher nicht überbauten Gartenbereich der Basler Mission löste archäologische Kontrollgänge aus. Die grosse Baugrube lag zwar ausserhalb der spätmittelalterlichen Kernstadt, aber in einer sehr siedlungs- und verkehrsgünstigen Lage, so dass es nicht ausgeschlossen war, hier noch bisher unbekannte prähistorische, römische oder auch frühmittelalterliche Siedlungsrelikte zu finden.

Das Basler Missionshaus wurde in der Mitte des 19. Jahrhunderts an der «Strasse nach Burgfelden» erbaut, die im Mittelalter für den Handel mit dem Sundgau - die Kornkammer Basels - von grosser Bedeutung war. Das Areal befand sich ausserhalb der zu dieser Zeit noch weitgehend bestehenden mittelalterlichen Stadtmauern auf freiem Feld und war das erste grosse Gebäude vor dem Spalentor. Etwa ab 1860, nach der Fertigstellung des Gebäudes, wurde die Strasse nach der Mission benannt. ${ }^{93}$ Der grösste Teil des Hinterhofes war bereits zu Beginn als Garten angelegt und genutzt worden.

Bei unseren Kontrollgängen kamen in der Baugrube ausschliesslich neuzeitliche und moderne Funde zum Vorschein, darunter aber auch mögliche Ackerbauhorizonte, die durchaus älter sein könnten als der Gartenbau der Zeit, als hier Missionare ausgebildet wurden. Daher entnahmen wir mikromorphologische Proben für spätere Analysen dieser alten Pflughorizonte. In diesem Bereich waren keine Siedlungstätigkeiten fassbar - vermutlich waren hier die Spuren des Ackerbaus deshalb so gut erhalten. Im Zuge der späteren Baugrubenerweiterungen kamen dagegen Mauerfundamente und ein Schacht zu Tage. ${ }^{94}$ Bei einem Abgleich mit alten Plänen erwiesen sich die Mauern als Überreste der Missionsturnhalle, die in den 1890 er-Jahren erbaut worden war und

wegen des Schulhausneubaus der 1920er-Jahre abgebrochen wurde. Der angeschnittene Schacht hingegen datiert in eine etwas ältere Zeit: Er ist Teil eines aus regelmässigen, $30 \mathrm{~cm}$ mächtigen, roten Sandsteinquadern gebauten Sodbrunnens, der einen Innendurchmesser von 1,1 m hat. Der Brunnen ist laut Dokumenten aus dem Missionsarchiv älter als das Missionsgebäude und wurde bald nach 1896 obsolet, nachdem vertraglich ein Wasseranschluss mit der IWB vereinbart worden war. ${ }^{95}$

Der Brunnenschacht war mit einer recht homogenen Mischung aus Kies mit reichlich Kohle und Schlacken verfüllt. Die Funde daraus stammen aus der Zeit um 1900 und umfassen gestempeltes Geschirr, Jugendstilglas, eine Glühbirne der Marke Radium, die ab 1904 produziert wurde, und eine beschriftete Pfeife aus Porzellan des Herstellers Imhoff, Cassel. Diese Porzellanpfeifen waren damals vor allem bei Kundschaft in Deutschland populär, von wo viele der Basler Missionare stammten. Einige Elektroarmaturen und viele technische Bestandteile aus Metall, darunter unter anderem Elektroden zum Galvanisieren, gehören vermutlich zu einer Metallwerkstatt. Eine solche stand hier laut Auskunft eines Mitarbeiters der Mission einst nebst einer Wagenremise und diente möglicherweise, wie auch der Gartenbau, zur handwerklichen Ausbildung der Missionare. 


\section{$2019 / 5$}

\section{RIEHENRING 63-75 (CLARATURM)}

Anlass: Neubau

\begin{tabular}{l} 
Zeitstellung: Mittelalter, Neuzeit \\
\hline Untersuchungsdauer: Januar bis Juli 2019 \\
\hline Verantwortlich: Norbert Spichtig, Martin Allemann \\
Text: Norbert Spichtig
\end{tabular}

Bereits im Dezember 2018 waren durch die Baufirma Implenia anlässlich des Rückbaus der bestehenden Gebäude für den Neubau des Claraturms zwei parallel verlaufende Mauern freigelegt worden. ${ }^{96}$ Da die Bauleitung zunächst von Kellermauern der abgerissenen Häuser ausging, wurden für geologische Abklärungen Teile des Mauerwerks und der Boden rückgebaut. Die Archäologische Bodenforschung wurde erst hinzugezogen, als die entsprechende Zone für ihre Nutzung als Baustellenzufahrt wieder aufgefüllt worden war. Auf Fotos des Bauleiters liess sich jedoch nachträglich zweifelsfrei ein Abschnitt eines Gewerbekanals mit Resten des Deckengewölbes identifizieren. Als einige Wochen später die Zone unter Begleitung durch die Archäologische Bodenforschung vom überdeckenden Bauschutt wieder freigeräumt werden konnte, zeigte sich, dass sich im Boden keinerlei intakte Überreste des zuvor erfassten Kanalabschnitts mehr erhalten hatten. Dafür konnte etwas weiter östlich immerhin ein weiteres kurzes Stück der südlichen Kanalwange aus Kalkbruchsteinen und einigen roten Sandsteinen mit dem Ansatz des Gewölbes aus sauber zugerichteten roten Sandsteinquadern freigelegt und dokumentiert werden. Südlich an die Gewerbekanalmauer schlossen weitere Mauerteile aus Kalkbruchsteinen an, die einem angrenzenden Gebäude aus der Neuzeit zuzuordnen sind.

Die kurzen, archäologisch erfassten Abschnitte des Gewerbekanals können dem sogenannten Krummen Teich zu-

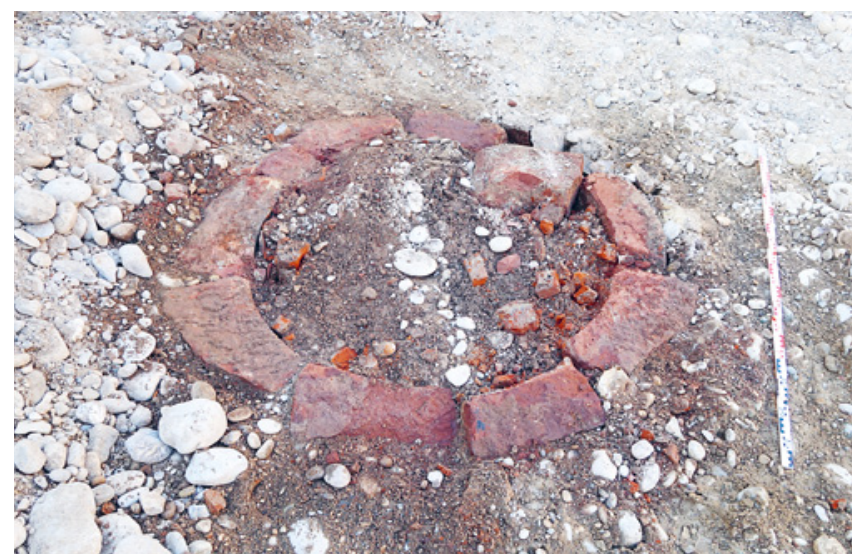

ABB. 36 In der Baugrube konnte der Kranz eines neuzeitlichen Brunnens aus rotem Sandstein freigelegt werden. Foto: Norbert Spichtig. geordnet werden. Der Kanal war 1262 vom bischöflichen Brotmeister Heinrich von Ravensburg als Abzweigung des älteren Riehenteichs erbaut worden, mit dem er sich kurz vor der Stadtmauer Kleinbasels wieder vereinte. Nach dem Erbauer wird er deshalb auch «Brotmeisterteich» genannt. ${ }^{97}$ Die Wasserentnahme aus dem Hauptteich führte in der Folge immer wieder zu Streitigkeiten, die auch nach der Regelung von 1304, wonach nur ein Drittel der Gesamtwassermenge dem Krummen Teich zugeführt werden dürfe, nicht gänzlich versiegten. ${ }^{98}$ Das so herangeführte, kalkarme Wasser der Wiese wurde auf vielfältige Weise genutzt, insbesondere für handwerkliche Zwecke und auch als Grundlage für die Kraftversorgung des Gewerbes. Der ursprünglich offene Brotmeisterteich wurde in der Neuzeit streckenweise mit einem Gewölbe überdeckt. Der technologische Wandel im Zuge der Industrialisierung führte allmählich zu einem Bedeutungsverlust der jahrhundertelang das Umland und das Stadtbild Kleinbasels prägenden Teiche. Die Verlegung des Badischen Bahnhofs vom Riehenring an den heutigen Standort führte 1907 schliesslich zur Stilllegung des Krummen Teichs. 1917 wurden dann die letzten beiden Teiche Kleinbasels aufgehoben. ${ }^{99}$

Auch der zweite Befund in der Baugrube für den Claraturm steht in Zusammenhang mit der Wasserversorgung: Knapp 20 m nordwestlich des Gewerbekanals kam unterhalb der Bodenplatte des Untergeschosses des einstigen Gebäudes Riehenring 75 der Kranz eines Brunnenschachtes zum Vorschein (ABB. 36). Es handelt sich auf dem erfassten Niveau um einen kreisrunden Schacht von gut $1 \mathrm{~m}$ lichter Weite aus trocken gesetzten, nur im Innenbereich sauber zugeschlagenen, roten Sandsteinen. Dieses Baumaterial lässt für die Errichtung der Anlage eine zeitliche Einordnung ins 19. Jahrhundert vermuten. Aus der Verfüllung über der Sohle barg das Baugeschäft unter anderem eine dickwandige, komplett erhaltene Weinflasche, die nahelegt, dass der ungefähr $10 \mathrm{~m}$ in den kiesigen Untergrund hinein gegrabene Brunnen Ende des 19. oder Anfang des 20. Jahrhunderts aufgegeben und anschliessend verfüllt worden sein dürfte. 


\section{9/7}

\section{PARKWEG (A), NAUENSTRASSE - AESCHENGRABEN}

Anlass: Koordinierter Werkleitungs- und Strassenbau

\section{Zeitstellung: Neuzeit}

Untersuchungsdauer: Februar 2019

Verantwortlich: Susan Steiner

Text: Susan Steiner

Im Februar wurde der Archäologischen Bodenforschung eine Mauer in einem Leitungsgraben im Parkweg gemeldet. ${ }^{100}$ Es handelte sich um ein solides Mauerstück aus Kalk- und Buntsandsteinen, das mindestens noch 1,15 m tief unter dem Trottoir in jenem Bereich der Strasse erhalten war, in dem diese eine $90^{\circ}$-Kurve macht (ABB. 37). Auf dem Gelände, das der Parkweg heute einschliesst, befand sich bis 2015 das Hilton-Hotel.

Auf dem von 1857 bis 1859 aufgenommenen und 1862 publizierten Löffelplan ist zu erkennen, dass es sich bei den Mauerresten um das Fundament der Umfassungsmauer eines grossen Areals handelt, das zum Aeschengraben 25 gehörte. Dort stand spätestens seit Ende der 1850er-Jahre eine Villa in einer parkähnlichen Anlage. Der grosszügige Garten grenzte an den Botanischen Garten von Basel an oder war sogar ein Teil davon, als dieser zwischen 1838 und 1896 vor dem Aeschentor lag, bevor er an seinen heutigen Standort beim Spalentor verlegt wurde. Das grosse Haus war der Firmensitz der Seidenbandfabrik Frey-Thurneysen und Christ. Erst 1896 wurde der Parkweg angelegt, ${ }^{101}$ der zu grossen Teilen über das ehemalige Areal des Aeschengrabens 25 führt.

Der Mauerrest unter dem Trottoir des Parkwegs bleibt weitgehend erhalten. Auf dem Gelände, das die Umfassungsmauer einst umgab, entsteht heute der Baloise Park.

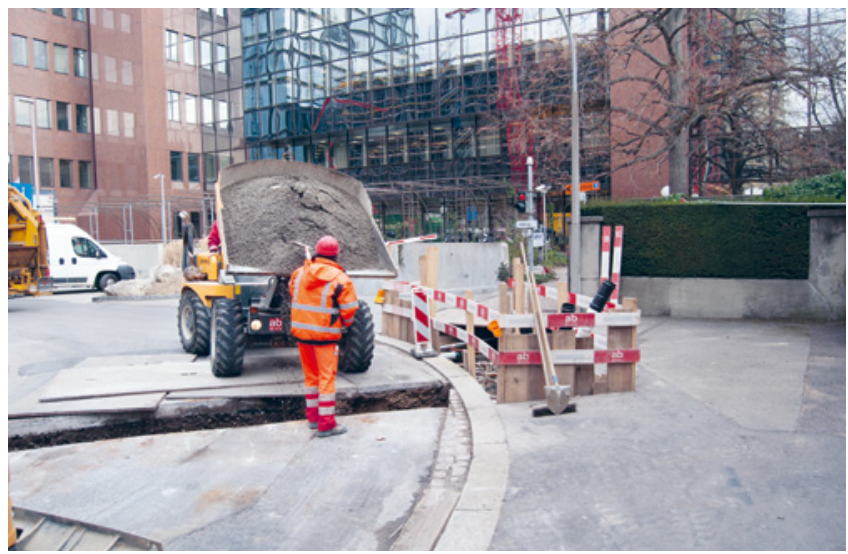

ABB. 37 Der Mauerrest wurde im abgesperrten Bereich des Trottoirs, gleich in der Kurve des Parkwegs, gefunden. Foto: Susan Steiner.

\section{$2019 / 8$}

\section{NONNENWEG 56}

Anlass: Abbruch und Neubau Wohnhaus

Zeitstellung: Neuzeit

Untersuchungsdauer: März 2019

Verantwortlich: Martin Allemann, Benedikt Wyss

Text: Martin Allemann, Simon Graber

Anfang März ging durch die Bauleitung eine Fundmeldung in der Archäologischen Bodenforschung ein, es sei bei Aushubarbeiten im Nonnenweg ein Schacht - vermutlich ein Brunnen - gefunden worden. ${ }^{102}$ Der Schacht aus sauber gesetztem Mauerwerk war rund $8 \mathrm{~m}$ tief und mit einer grossen Sandsteinplatte abgedeckt (АВв. 38). Eine Zuleitung in Form einer Steinzeugröhre führte in sein Inneres. Der Schacht gehört wohl zur Bebauung des späten 19. Jahrhunderts.

Eine direkte Versorgung mit Fliesswasser gab es damals lediglich für eine Anzahl von Häusern in der Innenstadt, ansonsten fand diese durch die Brunnwerke statt. In den Aussenquartieren erfolgte die Wasserversorgung über mässig ergiebige Sodbrunnen, die entsprechend häufig anzutreffen sind. ${ }^{103}$ Mit dem enormen Bevölkerungswachstum ab der Mitte des 19. Jahrhunderts und den in diesem Zusammenhang neu angelegten Aussenquartieren wurde die Wasserversorgung allerdings zunehmend prekär.

Ein Abgleich der Höhen zeigte jedoch, dass der Schacht etwa $9 \mathrm{~m}$ über dem Grundwasserpegel endet - die Interpretation als Brunnen kann daher nicht zutreffen. Der Deckstein und die Zuleitung sind ein Indiz dafür, dass der Schacht wohl als Sickerschacht diente, der Abwässer in den Grund leitete.

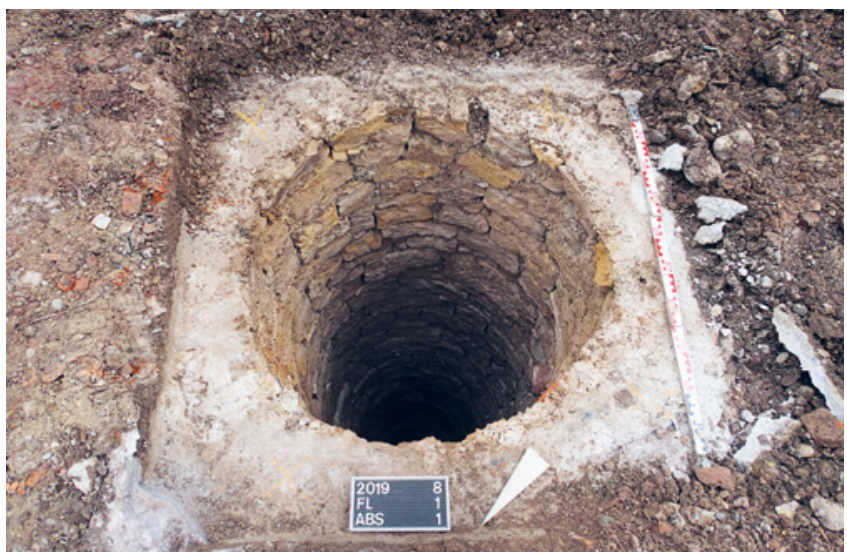

ABB. 38 Der Brunnenkranz nach dem Entfernen des quadratischen Decksteins. Foto: Benedikt Wyss. 


\section{$2019 / 13$}

\section{RIEHEN - INZLINGERSTRASSE 270}

Anlass: Abbruch des Gebäudes und Neubauten

\begin{tabular}{l} 
Zeitstellung: Geologie, Neuzeit \\
\hline Untersuchungsdauer: April bis Mai 2019 \\
Verantwortlich: Susan Steiner \\
\hline Text: Susan Steiner
\end{tabular}

Der Aushub für den Neubau mehrerer Einfamilienhäuser an der Inzlingerstrasse 270 in Riehen wurde wegen der Nähe zur römischen Fundstelle Hinterengeli und aufgrund einzelner prähistorischer Funde in der Umgebung archäologisch begleitet (ABB. 39). Es kamen jedoch weder aus der römischen Epoche noch aus der Urgeschichte Hinterlassenschaften zu Tage. Unser Interesse weckten aber ein geologischer Wechsel im Untergrund und ein besonderer Grabstein.

Der Blick in die Baugruben zeigte zunächst grossflächige Auffüllungen. Zur Erweiterung des stark gegen Süden abfallenden Geländes war hier früher Aushubmaterial im grossen Stil aufgebracht worden, um einen ebenen Garten zu erhalten. ${ }^{104}$ Laut geologischem Atlas der Schweiz befindet sich genau unter dieser Parzelle ein geologischer Gesteinswechsel. Dieser war stellenweise auch auf der Baustelle zu beobachten: Während auf der Riehen zugewandten Seite auch in $3 \mathrm{~m}$ Tiefe noch ein gelblicher Lehm vorkommt, steht auf der anderen Seite der Parzelle auf derselben Höhe ein Sandstein an, der vorwiegend rot, stellenweise auch hellgrau aussieht (ABB. 40). Dieser Buntsandstein lässt sich bis zur deutschen Grenze (Inzlingen) und darüber hinaus feststellen. Auf dem Niveau der Baugrubensohlen war dieser Sandstein aufgeweicht, lose und etwas umgelagert. ${ }^{105}$ In tieferen Lagen steht er dagegen intakt an und eignet sich durchaus als Baumaterial für Gebäude oder andere Konstruktionen wie etwa Mauern oder Brunnen. ${ }^{106}$ Bei unseren Begehungen konnten wir jedoch keine Hinweise auf einen Abbau dieses Buntsandsteins finden.

Am Rand des grosszügigen Gartens stand eine aufwändig und sorgfältig gestaltete eiserne Grabstele aus der Mitte des 19. Jahrhunderts. Die Grabinschrift verrät, dass der Verstorbene Ignaz Gmür hiess, zwischen 1775 und 1848 gelebt hatte, aus Schänis (SG) stammte und «Kantonsrath» sowie «Bezirksamman» gewesen war. Doch wie kam sein Grabstein nach Riehen?

Nachforschungen ergaben, dass die Inzlingerstrasse 270 im 19. Jahrhundert zusammen mit den Nachbarparzellen einen Rebhang bildete. Erst in den 1960er-Jahren entstand das grosse Einfamilienhaus, während an diesem Hang in der näheren Umgebung bereits einige Häuser standen. In der Riehener Dokumentationsstelle - dem Gemeindearchiv - ist der Name Gmür weder in den Verzeichnissen aller im
19. Jahrhundert in Riehen wohnhaften Personen noch in denjenigen der Liegenschaftsbesitzer aus dieser Zeit gelistet. Lediglich im Historischen Grundbuch ist vermerkt, dass die Parzelle im Jahre 2003 von einer Frau Gmür an ihre Tochter vererbt wurde. Es ist daher anzunehmen, dass erst im Laufe des 20. Jahrhunderts eine Person oder Familie mit diesem Namen nach Riehen kam. Offensichtlich war der verstorbene Vorfahre für die Familie so wichtig, dass dessen Grabstele mit nach Riehen genommen wurde - Recherchen im St. Galler Staatsarchiv zeigen, dass Ignaz Gmür in Schänis (SG) begraben worden war. ${ }^{107}$ Die eiserne Grabmarkierung befindet sich heute im Historischen Museum Basel.
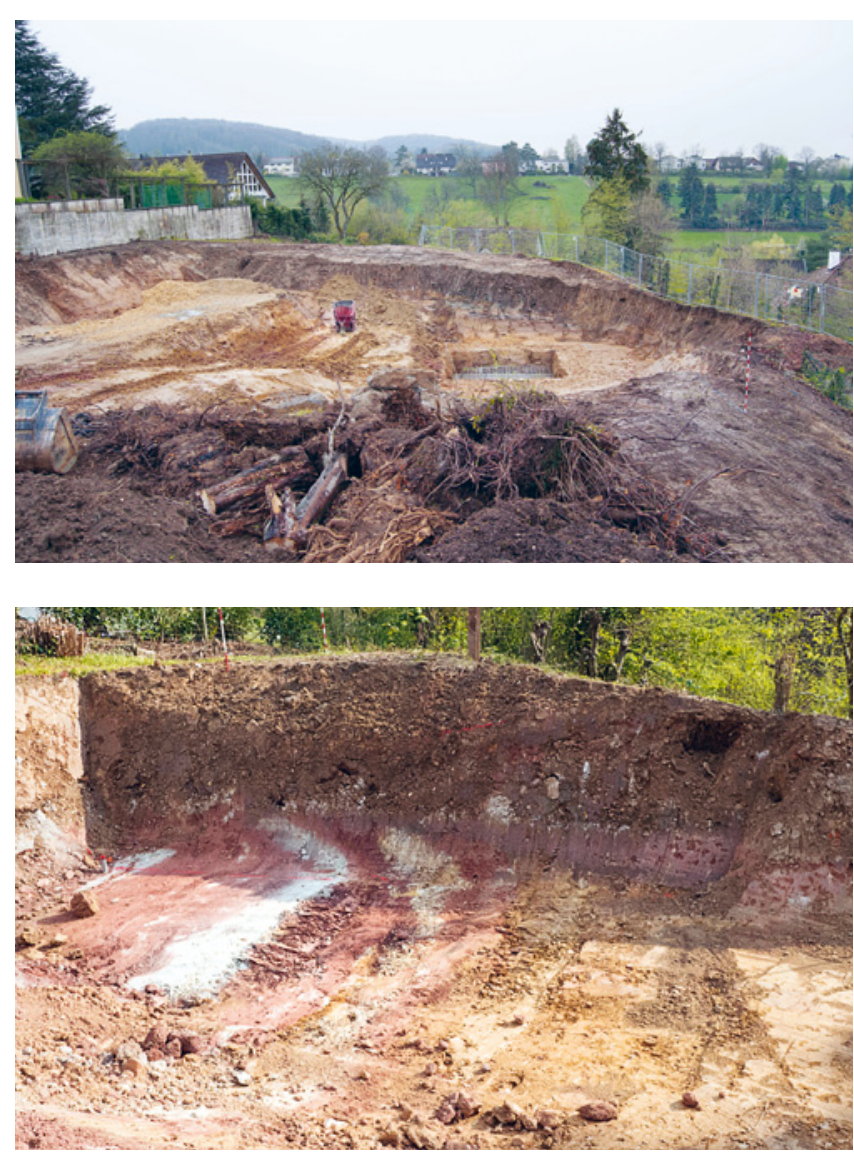

ABB. 39 Der mit Hilfe von Abbruchmaterial erweiterte, terrassenartige Garten an der Inzlingerstrasse gibt einen herrlichen Blick nach Süden frei. Foto: Susan Steiner.

ABB. 40 Neben den gelben Lehmen kam an der Baugrubensohle roter Buntsandstein zum Vorschein, der stellenweise eine hellgraue Farbe zeigt. Foto: Susan Steiner. 


\section{9/15}

\section{RIEHEN - AM BETTINGERBACH}

Anlass: Oberflächenfund

Zeitstellung: Mittelalter

Untersuchungsdauer: Mai 2019

Verantwortlich: Martin Allemann

Text: Martin Allemann

Am Ufer des Bettingerbachs zwischen Riehen und Bettingen fand Hannes Thern ein Keramikfragment. Sein Vater meldete den Fund bei der Archäologischen Bodenforschung. ${ }^{108}$ Bei diesem Fragment handelt es sich um den Fuss eines spätmittelalterlichen, innen glasierten Dreibeintopfs. Möglicherweise stammt dieser Keramikfuss aus Bettingen und wurde durch den Bach verlagert; vielleicht kommt er aber auch vom naheliegenden Wenkenhof, an dessen Stelle bereits frühmittelalterliche Gehöfte standen.

\section{9/17 \\ RIEHEN - RUDOLF-WACKERNAGEL- \\ STRASSE 116}

Anlass: Aushub für einen Swimmingpool

Zeitstellung: Mittelalter, Neuzeit

Untersuchungsdauer: Mai 2019

Verantwortlich: Susan Steiner, Martin Allemann

Text: Martin Allemann

Neue Entdeckungen und die deutlich gesteigerte Bautätigkeit haben Riehen in den letzten Jahren stärker in unser Blickfeld gerückt. Für frühere Epochen, aber auch noch für das Mittelalter, sind in dieser landwirtschaftsgünstigen Siedlungskammer zahlreiche kleine Siedlungen zu erwarten, die wegen der bislang nur dünnen Bebauung auch besser erhalten sein dürften als in der Innenstadt. Daher begleiteten wir im Berichtsjahr viele kleine Projekte. An den Hängen erhofften wir uns Erkenntnisse zu geologischen Vorgängen wie Hangfliessen, um Lage und Erhaltung von Fundstellen verlässlicher voraussagen zu können. Viele Siedlungen lagen nahe der Schwemmkegel von Bächen und wurden von Lösslehm überdeckt, den die Erosion von den Hängen hinuntergetragen hatte.

In steiler Lage an der Rudolf-Wackernagel-Strasse erbrachte der begleitete Aushub ${ }^{109}$ eine Scherbe im Lösslehm, die zu einer unglasierten Schüssel aus dem 15. oder 16. Jahrhundert gehört. ${ }^{110}$ Die weitere Baubegleitung ergab aber weder Funde noch Befunde, so dass die Scherbe vermutlich entweder durch Hangfliessen von weiter oben oder zusammen mit Mist aus dem Dorf auf die Landwirtschaftsflächen gelangte. 


\section{9/21}

\section{RIEHEN - INZLINGERSTRASSE 319}

Anlass: Sondierungen vor einem tief greifenden Aushub

\begin{tabular}{l} 
Zeitstellung: Römische Zeit, Neuzeit \\
\hline Untersuchungsdauer: August bis September 2019 \\
\hline Verantwortlich: Martin Allemann, Johann Savary, Birgit Lißner \\
Text: Johann Savary
\end{tabular}

Der Neubau einer parzellenfüllenden Autoeinstellhalle mit fünf Doppel-Einfamilienhäusern an der Inzlingerstrasse 319 hatte den Abbruch einer alten Villa zur Folge. Da sich die Parzelle in direkter Nähe des römischen Gutshofs von Hinterengeli befindet, führte die Archäologische Bodenforschung vor Projektbeginn diverse Sondierungen durch. Dabei konnte leider nur festgestellt werden, dass die Baugrube der alten Villa alle älteren Schichten zerstört hatte. Im Gartenteil war eine mächtige Schicht Lösslehm künstlich aufgebracht worden, während der Teil in der Nähe des Hauses stark mit modernem Material, unter anderem einem Eisenrad, Isolationswolle und modernen Nägeln, verunreinigt war. Die Analyse eines breiten Profils an der Strassenseite, das durch einen grossen Teil der Parzelle verlief, konnte dieses Resultat bestätigen.

Positiv hingegen war das zufällige Zusammentreffen mit Bruno Wieland, dem Besitzer der Nachbarparzelle. Er war in seinem Garten immer wieder auf römische Funde gestossen, die er über die Jahre hinweg gesammelt hatte. Für die Abgabe der Funde danken wir ihm sehr!

\section{9/27}

\section{RHEIN (A), NÄHE WETTSTEINBRÜCKE}

Anlass: Oberflächenfund

\section{Zeitstellung: Neuzeit}

Untersuchungsdauer: August 2019

Verantwortlich: Martin Allemann

Text: Martin Allemann

Stephan Bruyaka aus Lörrach fand beim Baden am Kleinbasler Rheinbord unweit der Wettsteinbrücke unter anderem zwei Münzen (ABB. 41), die seine Mutter umgehend der Archäologischen Bodenforschung meldete. ${ }^{111}$ Erst kurz zuvor war dort Aushub von der Vertiefung der Schifffahrtsrinne abgelagert worden, so dass die Funde möglicherweise aus dem Flussbett stammen. Dem Zehn-Rappen-Stück von 1899 sieht man die lange Zeit im Fluss gut an, die 50-Centesimi-Münze mit dem Bild des italienischen Königs Vittorio Emanuele II. (1820-1878) ist hingegen aus Silber und deshalb besser erhalten. ${ }^{112}$ Mit dieser italienischen Prägung aus dem Jahr 1863 konnte man damals dank der Lateinischen Münzunion auch in Basel bezahlen - vielleicht hatte sie also kein italienischer Tourist oder Arbeiter im Rhein verloren, sondern ein Basler, der sich wie der Finder an einem heissen Sommertag im Rhein erfrischte.

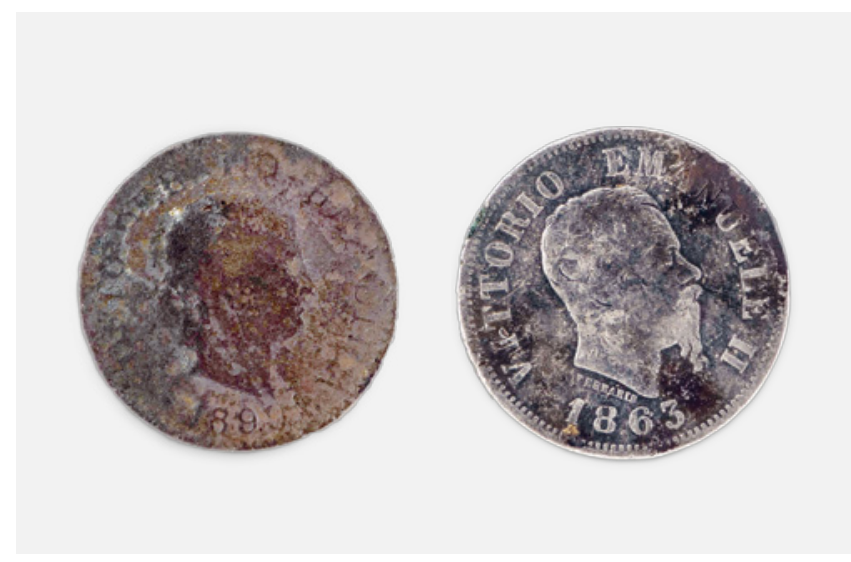

ABB. 41 Links das stark verwitterte Zehn-Rappen-Stück von 1899, rechts die besser erhaltenen 50 Centesimi mit dem Porträt von Vittorio Emanuele II. von Italien. Foto: Philippe Saurbeck. 


\section{9/28}

\section{GIESSLIWEG (A) 64}

Anlass: Leitungsbauten

Zeitstellung: Neuzeit

Untersuchungsdauer: August 2019

Verantwortlich: Martin Allemann

Text: Martin Allemann

Nach einem Anruf des Baugeschäfts konnten wir am Giessliweg in Kleinhüningen neuzeitliche Kellermauern dokumentieren, die beim Leitungsbau aufgedeckt worden waren. ${ }^{113}$ Die Mauern waren aus Bruchstein errichtet, aber mit modernem Verputz und Leitungsanschlüssen versehen. Das Gebäude, zu dem sie einst gehörten, ragte früher weit in die heutige Strasse vor und wurde nach deren Begradigung in den 1960er-Jahren abgebrochen.

\section{9/30}

\section{BETTINGEN - AUF DEM BUECHHOLZ}

Anlass: Auflesen von Streufunden bei Spaziergängen

Zeitstellung: Geologie

Untersuchungsdauer: Januar bis Dezember 2016

Verantwortlich: Johann Savary, Birgit Lißner

Text: Johann Savary

Bei der Sondierungsaktion im Zusammenhang mit einem Bauprojekt an der Inzlingerstrasse 319 (2019/21) traf unser Team den Nachbarn Bruno Wieland an. Dieser hatte bei diversen Spaziergängen in Bettingen Silexknollen aufgelesen, die er uns freundlicherweise übergab. Die Bestimmung der Stücke durch den Geoarchäologen Philippe Rentzel (IPNA Basel) lässt auf ein lokales Vorkommen des Rohmaterials (Hornstein des Trigonodus-Dolomits) schliessen, das durchaus zur Werkzeugherstellung genutzt wurde. Da die Bruchflächen aber gerade beziehungsweise rechtwinklig zueinander laufen und Schlagmarken, Bulbi und Wallnerlinien fehlen, kann man daraus schliessen, dass es sich hier um frostgesprengte Stücke handelt. Die Fundobjekte könnten also durchaus ausgewittert oder ausgepflügt sein. Trotzdem werden sie aufgrund der in diesem Areal zahlreich gefundenen urgeschichtlichen Artefakte aufbewahrt.

\section{9/40}

\section{BETTINGEN - IM JUNKHOLZ}

Anlass: Prospektion (Feldbegehung)

Zeitstellung: Paläolithikum, Neolithikum

Funddatum: Herbst 2019

Verantwortlich: Ingmar M. Braun

Text: Ingmar M. Braun

Seit der Verfasser im Mai 1990 die wohl bisher grösste neolithische Siedlung des Kantons Basel-Stadt mit zahlreichen unterschiedlichen Silex- und Felsgesteinartefakten entdeckt hat, werden an dieser Stelle immer wieder Funde gemacht. Ausser den zahlreichen neolithischen Artefakten sind von hier auch ein mittelpaläolithischer Levalloiskern aus Radiolarit und das Proximalteil einer konvexen Rückenspitze, die typologisch ins Spätpaläolithikum datiert, ${ }^{114}$ bekannt.

Anlässlich von Feldbegehungen im Herbst 2019 fand der Autor weitere steinzeitliche Funde (АВB. 42). Das Silexensemble umfasst zwei retuschierte Abschläge, einen Kernstein, sieben unretuschierte Abschläge und einen Klopfstein. Bei dem Rohmaterial handelt es sich hauptsächlich um den lokal anstehenden Chalcedon und Trigonodus-DolomitHornstein. Vereinzelte Objekte sind aus ortsfremdem Silex hergestellt. Zu nennen ist auch ein möglicher Abschlag aus feinkörnigem Quarzit. Wie bereits bei früheren Begehungen, wurden ebenfalls Felsgesteinartefakte gefunden: ein Mühlsteinfragment mit Arbeitsspuren auf einer Seite, vier Fragmente von möglichen Mühlsteinen aus grobkörnigem Sandstein und ein Fragment eines möglichen Schleifsteins aus feinkörnigem Sandstein.

Die Artefakte stehen im Zusammenhang mit den von dort bereits bekannten neolithischen Funden. Der mögliche Abschlag aus Quarzit könnte wegen des Rohmaterials eventuell auch ins (Mittel-)Paläolithikum datieren, wie der bereits früher an dieser Stelle gefundene Levalloiskern aus Radiolarit.

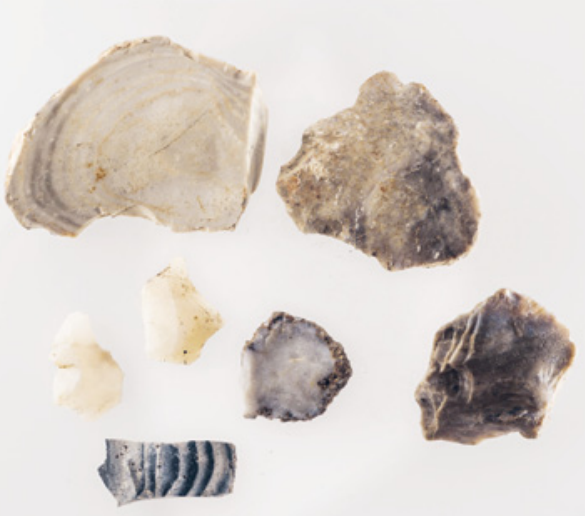

ABB. 42 Abschläge aus lokalem Chalcedon und Trigondus-Dolomit-Hornstein sowie ortsfremdem Silex. Foto: Philippe Saurbeck. 


\section{9/41}

\section{BETTINGEN - AUF DEM BUECHHOLZ}

Anlass: Prospektion (Feldbegehung)

Zeitstellung: Paläolithikum, Neolithikum

Funddatum: Herbst 2019

Verantwortlich: Ingmar M. Braun

Text: Ingmar M. Braun

Anlässlich von Feldbegehungen auf einem Acker im Bereich der Flur «Auf dem Buechholz» fand der Verfasser im Herbst 2019 - wie bereits bei früheren Begehungen ${ }^{115}$ - steinzeitliche Artefakte (АВв. 43). ${ }^{116}$ Zu den früheren Funden gehört unter anderem ein aus Quarzit hergestellter Faustkeil. ${ }^{117}$ Das im Herbst aufgelesene Fundmaterial umfasst drei Abschläge, zwei davon aus dem lokal anstehenden Chalcedon und einen Restkern, ebenfalls aus Chalcedon. Diese Funde datieren wohl am ehesten ins Neolithikum.

Von besonderem Interesse ist weiter ein polyedrischer Kernstein. Da es sich beim verwendeten Rohmaterial um einen ähnlichen Quarzit wie beim bereits gefundenen Faustkeil handelt und er von derselben Fundstelle stammt, könnte dieser polyedrische Kernstein eventuell auch ins Altoder Mittelpaläolithikum einzuordnen sein. Ebenfalls von dieser Fundstelle stammt ein retuschierter Quarzitabschlag, der möglicherweise desgleichen ins Paläolithikum gehört. ${ }^{118}$

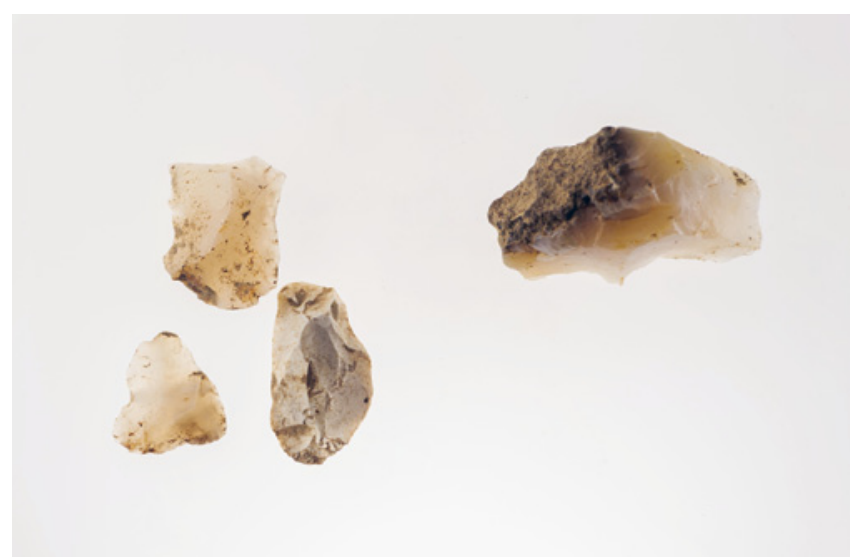

ABB. 43 Drei Abschläge (links) und ein Restkern aus lokalem Chalcedon (rechts). Foto: Philippe Saurbeck. 


\section{ANMERKUNGEN}

1 Für die erneut sehr angenehme und konstruktive Zusammenarbeit danken wir herzlich Manuel Eggenberger (TBA), Patric Thalmann (Aegerter \& Bosshardt AG) sowie Peter Leuenberger und Franco de Marco mit seiner Equipe (Pensa $A G$ ).

2 Grabung 1975/26 Schlüsselberg 5-17 / Münsterplatz (A) 19, 20. Vgl. Rudolf Fellmann: Schlüsselberg 9-17, in: BZ 76 (1976), 187-190.

3 Sven Billo, Martin Allemann: 2017/5 Schlüsselberg (A), in: JbAB 2018, Basel 2019, 44.

4 Vgl. Inv. 1963/20.1.1-4 (Antistitium); Inv. 2008/3.16210 (Rollerhof); Inv. 1978/13.5477 (Andlauerhof). Mit den Neufunden zusammen sind auf dem Münsterhügel insgesamt mindestens neun rhombische Steinplatten bzw. -fragmente geborgen worden.

5 Unter anderem in Zusammenhang mit einer Reparatur der Fussböden der Barbarathermen aus constantinischer Zeit (1. Hälfte 4. Jh.). Vgl. Michael Dodt: Barbarathermen, in: Trierer Zeitschrift 73/74 (2010/11), 286-292; Michael Dodt: Marmorluxus in den grossen römischen Thermen der Stadt Trier, in: Funde und Ausgrabungen im Bezirk Trier 46 (2014), 52-67. Für die Hinweise und die Gastfreundschaft danke ich herzlich Franziska Doevener und Andreas Schaflitzl, beide Trier.

6 Ausstellung im Museum CLASSIS Ravenna Museo della Città e del Territorio.

7 Die Steinplatten aus Trier und Xanten wurden aus Kohlekalk hergestellt. Vgl. Vilma Ruppiene: Natursteinverkleidungen in den Bauten der Colonia Ulpia Traiana. Gesteinskundliche Analysen, Herkunftsbestimmung und Rekonstruktion, Xantener Berichte 28, Mainz 2015, 183-190. Für den Hinweis danke ich herzlich Christine Pümpin.

8 Für die kurze Begutachtung der Steinplatte (Inv. 2008/3.16210) danke ich herzlich Philippe Rentzel.

9 Vgl. Eckhard Deschler-Erb, Kaspar Richner: Ausgrabungen am Basler Murus Gallicus 1990-1993, Materialhefte zur Archäologie in Basel 12, Basel 2013.

10 Yolanda Hecht: Die Ausgrabungen auf dem Basler Münsterhügel an der Rittergasse 4, Materialhefte zur Archäologie in Basel 16, Basel 1998.

11 Für die in diesem Zuge entstandenen Dokumentationen wurden rückwirkend folgende Laufnummern vergeben: 1837/1 (Franz Dorotheus Gerlach), 1854/4, 1861/2 und 1866/3 lalle Wilhelm Vischer-Bilfinger) sowie schliesslich 1885/1, 1884/4 und 1887/2 im Rahmen des Schulhausbaus lalle Karl Stehlin, Theophil Burckhardt-Biedermann, Ernst Stückelberg).
12 Vgl. Deschler-Erb, Richner 2013, 14-16.

13 Die keltischen und frührömischen Befunde hat Yolanda Hecht ausgewertet, vgl. Hecht 1998. Die spätantiken und frühmittelalterlichen Befunde wurden zwar teils erkannt und dokumentiert, sind aber bislang unbearbeitet.

14 Sven Billo: 2017/1 Münsterplatz 10-12, in: JbAB 2017, Basel 2018, 43-44.

15 Für den frühen Einbezug der Archäologie, die grosse Rücksichtnahme und die angenehme sowie konstruktive Zusammenarbeit danken wir herzlich Karine Grand und Steffen Keck (Grand Paysage), André Buess (Weberbuess Architekten), José Barreiro und seiner Equipe (Straumann-Hipp AG) sowie Samuel Töfferl und Jerôme Rigert mit seiner Equipe (Jos. Schneider AG).

16 Grabung 1944/1 unter der Leitung von Rudolf Laur-Belart.

17 Für die angenehme und konstruktive Zusammenarbeit danken wir herzlich Dominique Jeanneret (Stadtgärtnerei), Xaver Stranner (Tilia Baumpflege AG) sowie Tobias Aebi und Enrico Zweifel (PNP Geologie \& Geotechnik $A G)$.

18 Für die angenehme Zusammenarbeit bedanken wir uns bei den Polieren Mario Wülser (Erne AG) und Walter Gass (Tozzo AG) sowie ihren Equipen.

19 Françoise Maurer: Die Kunstdenkmäler des Kantons Basel-Stadt, Bd. IV. Die Kirchen, Klöster und Kapellen, Teil 2. St. Katharina bis St. Niklaus, Basel 1961, 22-28.

20 So etwa in Langenthal (BE). Vgl. Andreas Heege: Langenthal, St. Urbanstrasse 40-44. Die Hafnerei Staub und ihre Werkstatt, in: Archäologie Bern. Jahrbuch des Archäologischen Dienstes des Kantons Bern, Bern 2011, 209-287.

21 Maurer 1961, 23.

22 Christoph Ph. Matt: 2001/31 Klybeckstrasse 1B (ehemalige Reithalle), in: JbAB 2001, Basel 2003, 75-76.

23 Daniel Burckhardt-Werthemann: Häuser und Gestalten aus Basels Vergangenheit, Basel 1925, 31.

24 Vgl. auch Fundbericht 2019/31 im vorliegenden Jahresbericht (S. 61).

25 Für die rechtzeitige Einbindung sowie die konstruktive und angenehme Zusammenarbeit danken wir herzlich Sven Walther (Credit Suisse), Claudio Stern (Dietziker Partner), Pascal Frei (Rapp AG), Beat Hofmann, Daniel Illerhaus, Severin Brosy, Sandro Comi, Pius Forster, Sandro Leuenberger und ihren Equipen (Implenia AG), Susanne Pfenninger sowie Denis Guske (Geotechnisches Institut) und Andreas Kettner (GVA).
26 Sandra Ammann: Basel, Rittergasse 16. Ein Beitrag zur Siedlungsgeschichte im römischen vicus, Materialhefte zur Archäologie in Basel 17, Basel 2002; Petra Ohnsorg: Aufgetischt und abgeräumt. Basel, Rittergasse 29A - Auswertung einer Fundstelle im römischen Vicus, Materialhefte zur Archäologie in Basel 18, Basel 2004

27 Zur mittelalterlichen Stadtmauer und Überbauung in diesem Abschnitt vgl. unter anderem Guido Helmig: Ein Aufschluss der Inneren Stadtmauer am St. Alban-Graben. St. AlbanGraben (A) / Rittergasse 20, 1990/25, in: JbAB 1990, Basel 1992, 27-34. Zu den spätrömischen und frühmittelalterlichen Gräbern vgl. Regine Fellmann Brogli, Sylvia Fünfschilling, Reto Marti, Beat Rütti, Debora Schmid: Das römisch-frühmittelalterliche Gräberfeld von Basel/Aeschenvorstadt, Basler Beiträge zur Ur- und Frühgeschichte 10, Basel 1992; Guido Helmig, Christian Stegmüller: 1999/6 St. Alban-Graben 5-7, in: JbAB 2000, Basel 2001, 54-57.

28 Die sogenannten Brunnwerke wurden in der zweiten Hälfte des 13. Jahrhunderts angelegt und durch die Stadtmauer hindurchgeführt. Vgl. Andreas Fischer: Mauern, Schanzen, Tore. Basels Befestigungen im Wandel der Zeit, Basel 2007, 37.

29 StABS Planarchiv D 6,82: Schnittzeichnung der Dole und dreier (!) Schächte, leider ohne Lokalisierung.

30 Katia Guth-Dreyfus: Neue Grabsteinfunde vom mittelalterlichen Judenfriedhof in Basel, in: BZ 85 (1985), 330-336.

31 Vorausinventarnummern 2018/32.133 und 2018/21.135. Für ihre Bemühungen um die Entzifferung der Inschriften und den spannenden Austausch zum Thema danken wir herzlich Roger Harmon (Universität Basel) und Simon Erlanger (Universität Luzern).

32 Cornelia Alder, Christoph Ph. Matt: Der mittelalterliche Friedhof der ersten jüdischen Gemeinde in Basel, Materialheft zur Archäologie in Basel 21, Basel 2010, 21-23 (mit weiterführender Literatur). Auch bei den Neufunden belegen die im Bereich der Inschrift eingebrachten Klammerlöcher, dass die Steine mit der Schriftseite nach oben auf der Kontermauer lagen. 
33 Für weitere Beispiele für diesen Brauch vgl. Martin Allemann: 2018/3 Münsterplatz (A) 7-8, in: JbAB 2018, Basel 2019, 45. Zum Phänomen allgemein vgl. Simon Kramis, Viera Trancik: Extra locos sepulturae - Literaturreview zu römerzeitlichen Perinatenfunden auf dem Gebiet der heutigen Schweiz, in: Bulletin der Schweizerischen Gesellschaft für Anthropologie 20/2 (2014), 5-26.

34 Für Meldung und Unterstützung danken wir Frank Löbbecke (Kantonale Denkmalpflege Basel-Stadt) herzlich. Bei Stephan Weisskopf (Vischer Architekten) und dem Team von Staumann-Hipp möchten wir uns für die gute Zusammenarbeit vor Ort bedanken.

35 Felix Ackermann, Therese Wollmann: Klöster in Basel. Spaziergänge durch fünf Jahrhunderte, Basel 2009, 186-203; Casimir Hermann Baer: Die Kunstdenkmäler des Kantons BaselStadt, Bd. III. Die Kirchen, Klöster und Kapellen, Teil 1. St. Alban bis Kartause, Basel 1941, 451-454.

36 Vgl. den Bericht zur Grabung 2018/19 im vorliegenden Band (S. 47-49).

37 François Maurer: Die Kunstdenkmäler des Kantons Basel-Stadt, Bd. IV. Die Kirchen, Klöster und Kapellen, Teil 2. St. Katharina bis St. Niklaus, Basel 1961, 22.

38 Marco Bernasconi: 2017/25 Kasernenstrasse 23, in: JbAB 2017, Basel 2018, 58-59.

39 Für die angenehme Zusammenarbeit bedanken wir uns beim Bauleiter Gian Fistarol und den beteiligten Baufirmen Egeler Lutz AG, Straumann Hipp AG und Tozzo AG.

40 Maurer 1961, 56-57.

41 Maurer 1961, 53.

42 Christoph Ph. Matt: 2000/45 Kasernenstrasse 23 (Klingentalkirche), in: JbAB 2000, Basel 2001, 76-78.

43 Vgl. den Bericht zur Grabung 2018/19 im vorliegenden Band (S. 47-49).

44 Kaspar Richner, Viera Trancik: Der ehemalige Klingentalfriedhof Kasernenstrasse 23 (A), 1991/13, in: JbAB 1991, Basel 1994, 208-212.

45 Für die Absprache und gute Zusammenarbeit danken wir Daniel Rinderknecht (IWB), Beat Oehen (Aegerter \& Bosshardt), Remo Fluri, Domenico Avati, Michelangelo Schillaci und Stéphane (Bertschmann AG) herzlich.

46 Christoph Ph. Matt: Steinengraben 22 / Leonhardsstrasse 22/24. Zum Neufund der spätmittelalterlichen Kontermauer, in: JbAB 1989, Basel 1991, 46-53.

47 Vgl. den Bericht zur Grabung 2019/12 im vorliegenden Band (S. 57).
48 Wir danken Oliver Hamacher und Armend Ajvazi (Hrs Real Estate AG) sowie Thomas Troll (Erne AG) herzlich für die angenehme und konstruktive Zusammenarbeit.

49 Vgl. Rudolf Moosbrugger-Leu: 1971/30 Steinengraben 41, in: BZ 72 (1972), 369; Rolf d'Aujourd'hui: Steinengraben 47 (A), 1986/28, in: BZ 86/2 (1986), 212-213; Christoph Ph. Matt: 2010/17 Steinengraben (A) 41, in: JbAB 2010, Basel 2011, 57.

50 Vgl. Christoph Ph. Matt: Steinengraben 22 / Leonhardstrasse 22/24, in: JbAB 1989, Basel 1991, 46-53 (Grabung 1988/43); Rolf d'Aujourd'hui: 1992/26 Kanonengasse (A), in: JbAB 1992, Basel 1995, 12; Rolf d'Aujourd'hui: 1993/7: Steinengraben 18, Kontermauer, in: JbAB 1993, Basel 1996, 14; Christoph Ph. Matt: 2011/6 Steinengraben 16, in: JbAB 2011, Basel 2012, 50.

51 Andreas Fischer: Mauern, Schanzen, Tore. Basels Befestigungen im Wandel der Zeit, Basel 2007, 47

52 Visierungen von Daniel Specklin über die Fortification der Stadt, 1588. No. I-IV, StABS Planarchiv $T 4$.

53 Vgl. Moosbrugger-Leu 1972.

54 Herzlich danken wir Anna Petry Elias (IWB) und Reto Hügi (Gruner $A G$ ) für die angenehme und konstruktive Zusammenarbeit.

55 Martin Stich: Das ehemalige Rotlicht-Lokal «zer alte Schmitti» wird zu einem OldtimerPub, in: Vogel Gryff, 26. September 2019, Nr. 17, 3.

56 Frank Löbbecke (Bauforschung, Denkmalpflege Basel-Stadt) sei herzlich für die effiziente und angenehme Zusammenarbeit sowie die freundlichen Hinweise gedankt.

57 Für die gute Kooperation danken wir Yasar Sahin (Sahin $\mathrm{GmbH}$ ) und Birgit Körner (GA Ingenieure $\mathrm{GmbH}$ ).

58 Stephan Tramèr: Untere Rheingasse 12, «Zer Alte Schmitti» (D 2000/11), in: JbAB 2001, Basel 2003, 203-208.

59 Thomas Lutz: Die Kunstdenkmäler des Kantons Basel-Stadt, Bd. VI. Die Altstadt von Kleinbasel - Profanbauten, Bern 2004, 218-220 (Untere Rheingasse 12 mit Sägergässlein 2).

60 Stephan Tramèr: Acht Jahrhunderte Bauen, Wohnen und Arbeiten im Kleinbasel. Das Haus zum Waldshut an der Unteren Rheingasse 12 / Sägergässlein 2, in: Kantonale Denkmalpflege Basel-Stadt, Jahresbericht 2017, Basel 2017. 70-72.

61 Tramèr 2017, 70.
62 Zu den Mauern der Burkhardschen und der Inneren Stadtmauer und deren Verlauf im Bereich des Petersgrabens vgl. Christoph Ph. Matt: Die mittelalterliche Stadtbefestigung am Petersgraben und die Quartiere hinter der Stadtmauer, in: JbAB 1988, Basel 1990, 60-97.

63 Martin Möhle: Die Kunstdenkmäler des Kantons Basel-Stadt, Bd. VIII. Die Altstadt von Grossbasel, Teil 2. Profanbauten, Bern 2016. 129-130 (Exkurs - ehemals Petersgraben 1, Erimanshof).

64 Cornelia Alder, Christoph Ph. Matt: Der mittelalterliche Friedhof der ersten jüdischen Gemeinde in Basel, Materialheft zur Archäologie in Basel 21, Basel 2010.

65 «Sprengung der Grundmauern des alten Zeughauses», in: Basler Nachrichten Nr. 183, Mittwoch, 7. Juli 1937, Titelblatt der zweiten Beilage.

66 Für die Fundmeldung, Abgabe und den spannenden Austausch danken wir herzlich Frank Fässler sowie Joshua und Jonathan Steck.

67 Für Informationen zur möglichen pharmazeutischen Verwendung solcher Gefässe danken wir Corinne Eichenberger (Pharmaziemuseum).

68 Vgl. den Bericht zu den Grabungen 2018/19 und 2018/37 im vorliegenden Band (S. 47-49 und 52-54).

69 Francois Maurer: Die Kunstdenkmäler des Kantons Basel-Stadt, Bd. IV. Die Kirchen, Klöster und Kapellen, Teil 2. St. Katharina bis St. Niklaus, Basel 1961, Abb. 25 und 26.

70 Für die angenehme Zusammenarbeit bedanken wir uns bei Cyrill Gallo (Tozzo AG) und seinem Team.

71 Dagmar Bargetzi: 2008/23 Klingentalweglein (A), in: JbAB 2008, Basel 2010, 50-51.

72 Vgl. Peter Habicht, Christoph Ph. Matt: Das Spalentor und die Vorstadt. Die Geschichte eines Basler Wahrzeichens, Basel 2015.

73 Für die angenehme und konstruktive Zusammenarbeit danken wir herzlich den Equipen von IWB und Birrer + Seiler vor Ort.

74 Vgl. den Bericht zu den Grabungen 2019/10 und 2019/12 im vorliegenden Band (S. 55-56 und 57).

75 Für die gute Zusammenarbeit danken wir Gian Fistarol (Fistarol Sintzel Jakobs Architekten) und Maschinist Thomas Wassmer (Sutter AG). 
76 Zu Aufschlüssen in Zusammenhang mit der äusseren Stadtbefestigung in der näheren Umgebung vgl. Christoph Ph. Matt: 1999/51 Petersplatz 10 (Stachelschützenhaus), in: JbAB 1999, Basel 2000, 80; Martin Allemann: 2015/16 Spalengraben 8, in: JbAB 2015, Basel 2016, 57-58.

77 Für die Fundmeldung und die angenehme und konstruktive Zusammenarbeit danken wir Thomas Osolin und Lea Gnöpff (Osolin \& Plüss Architekten) sowie der Equipe der Firma Marti AG vor Ort.

78 StABS HGB (Historisches Grundbuch), u. a zu den Adressen Leonhardsgraben 42, 44, 46 und Leonhardsstrasse 4,6 und 8 .

791902 war in Diskussion, dass auch der moderne Jüdische Friedhof beim bestehenden Klein hüninger Gottesacker angelegt werden könnte (Der Israelit, 17. April 1902).

80 Vgl. Paul Hugger: Kleinhüningen. Von der «Dorfidylle» zum Alltag eines Basler Industriequartiers, Basel 1984, 88. Zu den mit dem Bestattungswesen des 19. Jahrhunderts verbundenen neuen Vorstellungen s. Andreas Niederhäuser: Tod und Totenbrauchtum in Basel, in: JbAB 2015, Basel 2016, 81-118, bes. 97.

81 Im Staatsarchiv Basel-Stadt wird das Grabregister der Periode 1886 bis 1905 unter der Signatur «Bau 00 15», dasjenige der Jahre 1906 bis 1932 unter der Signatur «SD-REG 8a 0-4-82» geführt.

82 Hugger $1984,88-89$

83 Wir danken dem Bauleiter Heinz Bosshardt und seinem Stellvertreter Bernd Knoll lbeide Aegerter \& Bosshardt AG), dem Bauführer Christian Muri bzw. dem Polier Daniel Bieri der Firma Aregger und ihrem Team sowie Susanne Pfenninger vom Geotechnischen Institut Basel sehr für vielfältige Unterstützung und gute Zusammenarbeit. Stephan Villiger und Marcel Girard (Satram Cica SA) haben wir für ihr Verständnis und Informationen zu danken.

84 Zum Umgang mit Friedhöfen und Bestattungen des 18. bis 20. Jahrhunderts vgl. zuletzt Sandra Lösch, Guido Lassau, Thomas Reitmaier Nur 100 Jahre alt? Historische Friedhöfe zwischen Ignoranz, Akzeptanz und Relevanz, in: as 42 (2019), 4-15.

851993 barg die Kriminalpolizei Skelettreste, die anlässlich des Baus einer Tankstelle an der Hiltalingerstrasse zum Vorschein kamen. Die Archäologische Bodenforschung dokumentierte die Bergung unter der Laufnummer 1993/21.
86 Die Bestimmung verdanke ich Rahel C. Ackermann (Inventar der Fundmünzen der Schweiz).

87 Diese Angaben erbrachten eine weitere Bestätigung bei der Identifizierung der Verstorbenen mittels des Grabregisters.

88 Gebisse aus Kautschuk als Trägermaterial waren in den 1850 er-Jahren entwickelt worden. Vgl. Heinrich Schnettelker: Die Geschichte der Kautschukprothese. Inaugural-Dissertation zur Erlangung des Zahnmedizinischen Doktorgrades der Medizinischen Fakultät der AlbertLudwigs-Universität Freiburg im Breisgau, Freiburg i. B. 2001

89 Inwieweit diese medizinischen bzw. anatomischen Eingriffe in die Spitalakten Eingang fanden, ist zu überprüfen.

90 Zur bislang letzten Grabung im Spitalfriedhof vgl. Susan Steiner: 2015/1, Elsässerstrasse 2, HT-Leitung, in: JbAB 2015, Basel 2016, 48-50.

91 Norbert Spichtig: 2016/19, Rosentalstrasse 17 , in: JbAB 2016, Basel 2017, 55-56.

92 Zu einigen Möglichkeiten vgl. Gerhard Hotz unter Mitarbeit von Marina Zulauf-Semmler und Verena Fiebig-Ebneter: Der Spitalfriedhof und das Bürgerspital zu Basel, in: JbAB 2015, Basel 2016, 120-131; Sandra Pichler: Lesen in einem besonderen Archiv - der Mensch als Geschichtsquelle, in: JbAB 2015, Basel 2016, 132-139.

93 Jürgen Mischke, Inga Siegfried: Die Ortsnamengebung im Kanton Basel-Stadt, Basel 2016, 508-509.

94 Für die Meldung der Entdeckung des Schachtes danken wir herzlich Thomas Hartmann (Burckhardt + Partner Architekten), für das Überlassen von Vermessungspunkten Kestenholz Geomatik, für die angenehme Zusammenarbeit vor Ort Jean-Pierre (MTR) und Sergio Barbosa (Erne AG).

95 Für ihre wertvollen Hinweise und den spannenden Austausch nach der Grabung danken wir herzlich Andrea Rhyn vom Missionsarchiv.

96 Für die Meldung und die Unterstützung vor Ort danke ich Andreas Zieger und seinem Team.

97 Thomas Lutz: Die Altstadt von Kleinbasel Profanbauten. Die Kunstdenkmäler des Kantons Basel-Stadt, Bd. VI, Bern 2004, 30.

98 Lutz 2004, 52-53

99 Lutz 2004, 34.
100 Wir danken René Wenger (gsi Bau- und Wirtschaftsingenieure AG) für die Mitteilung und die gute Zusammenarbeit.

101 In der Liste der Strassennamen von Basel ist auch das Jahr der Benennung jeder Strasse vermerkt. Vgl. https://de.wikipedia.org/wiki/ Liste_der_Strassennamen_von_Basel (24.12.2019).

102 Wir danken Matthias Grunder (BauPro Grunder $A G$ ) und Martin Lutz mit seiner Equipe (Spaini $A G)$ herzlich.

103 Werner Aschwanden: Die Wasserversorgung der Stadt Basel von 1866 bis 2016, Basel 2016, $15-16$.

104 Dem Bauleiter Jan Stricker (Staehelin, Gisin + Partner $A G$ ) danken wir für diese Information und die gute Zusammenarbeit.

105 Im Untergrund dieser Parzelle liegt ein von Nord nach Süd verlaufender Gesteinswechsel vor, der mit der sogenannten Rheintalflexur zusammenhängt. Es handelt sich dabei um eine geologische Verwerfung entlang des Rheingrabens, bei der sich Schichtpakete abgesenkt haben und daher gegenüber den Nachbarstrukturen verschoben sind.

106 Für diesen Hinweis und die Durchsicht der Gesteine aus dieser Baustelle danken wir dem Geoarchäologen Philippe Rentzel (IPNA, Uni Basel).

107 Im Nekrolog von Ignaz Gmür heisst es dazu: «[...] und wurde von einer ungewöhnlichen Menge Volkes aus Gaster und Seebezirk am 4. d.M. zur Grabstätte in Schänis begleitet.» Vgl. Johann Seitz: Geschichte der Familie Gmür von Schänis, in: Schulpolitische Miszellen 19 (1935), 41-44. Für seine wertvollen Recherchen danken wir Jared Hevi vom Staatsarchiv St. Gallen.

108 Für die wertvolle Fundmeldung, die guten Fotos und Angaben zur Fundstelle danken wir herzlich Hannes und Bernd Thern, Riehen.

109 Für die Meldung des Baubeginns und die angenehme und konstruktive Zusammenarbeit danken wir herzlich dem Bauherrn Stephan Künzi, Riehen, und Yves Gygi mit seiner Equipe (Neuschwander Gartenbau, Büsserach).

110 Es handelt sich um eine Schüssel vom Typ 7 oder 11 nach der Typologie von Christine Keller: Gefässkeramik aus Basel, Materialhefte zur Archäologie in Basel 15, Basel 1999, 83-87. 


\section{MÜNZBESTIMMUNGEN}

111 Für die Fundmeldung und Übergabe der Funde danken wir herzlich Tatjana und Stephan Bruyaka, Lörrach, und für die Weiterleitung der Fundmeldung Andreas Fischer, Archäologie Baselland

112 Rahel Ackermann vom Inventar der Fundmünzen der Schweiz sei für ihre spontane Münzbestimmung und die spannenden Erläuterungen für den Finder ganz herzlich gedankt.

113 Für die Fundmeldung und die angenehme Zusammenarbeit danken wir herzlich Marcel Thüring (Gruner AG) und Matthias Hell sowie Ruben Vidal und seiner Equipe (Bertschmann $A G)$.

114 Ingmar M. Braun: «Bettingen BS», in: JbAS 95, Basel 2012, 157.

115 Urs Leuzinger: 1991/46, Bettingen, Rainweg (Auf dem Buechholz 3), in: JbAB 1991, Basel 1994, 19; Ingmar Braun: 1991/47 Bettingen, Auf dem Buechholz (A), in: JbAB 1998, Basel 1999, 41.

116 Die Koordinaten sind der Archäologischen Bodenforschung Basel-Stadt bekannt.

117 Ingmar M. Braun, mit einem Beitrag von Reto Jagher: Zur Entdeckung eines Faustkeiles und anderen paläolithischen Funden aus Bettingen, in: JbAB 1998, Basel 1999, 75-81.

118 Braun, mit einem Beitrag von Jagher 1999 75-81.
S. 46 ABB. 4, Markus Peter (IFS).

S. 51 ABB. 16, Markus Peter (IFS). 